Library, N. W. Widg
APR 87965 Roference book not to be NBS iskon from ine livary.

Eechnical Note

\title{
A FORTRAN PROGRAM FOR DETERMINING AN EMPIRICAL EXPRESSION FOR A QUANTITY MEASURED AT COMBINATIONS OF SEVERAL LEVELS OF EACH OF TWO VARIABLES
}

MARY NAN STEEL, FRANK L. MCCRACKIN, AND JOHN MANDEL

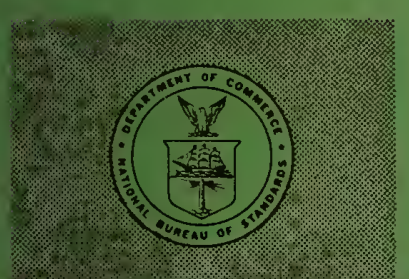

U. S. DEPARTMENT OF COMMERCE NATIONAL BUREAU OF STANDARDS 


\section{THE NATIONAL BUREAU OF STANDARDS}

The National Bureau of Standards is a principal focal point in the Federal Government for assuring maximum application of the physical and engineering sciences to the advancement of technology in industry and commerce. Its responsibilities include development and maintenance of the national stand. ards of measurement, and the provisions of means for making measurements consistent with those standards; determination of physical constants and properties of materials; development of methods for testing materials, mechanisms, and structures, and making such tests as may be necessary, particularly for government agencies; cooperation in the establishment of standard practices for incorporation in codes and specifications; advisory service to government agencies on scientific and technical problems; invention and development of devices to serve special needs of the Government; assistance to industry, business, and consumers in the development and acceptance of commercial standards and simplified trade practice recommendations; administration of programs in cooperation with United States business groups and standards organizations for the development of international standards of practice; and maintenance of a clearinghouse for the collection and dissemination of scientific, tech. nical, and engineering information. The scope of the Bureau's activities is suggested in the following listing of its four Institutes and their organizational units.

Institute for Basic Standards. Electricity. Metrology. Heat. Radiation Physics. Mechanics. Applied Mathematics. Atomic Physics. Physical Chemistry. Laboratory Astrophysics." Radio Standards Laboratory: Radio Standards Physics; Radio Standards Engineering.** Office of Standard Reference Data.

Institute for Materials Research. Analytical Chemistry. Polymers. Metallurgy. Inorganic Materials. Reactor Radiations. Cryogenics. ** Office of Standard Reference Materials.

Central Radio Propagation Laboratory. * Ionosphere Research and Propagation. Troposphere and Space Telecommunications. Radio Systems. Upper Atmosphere and Space Physics.

Institute for Applied Technology. Textiles and Apparel Technology Center. Building Research. Industrial Equipment. Information Technology. Performance Test Development. Instrumentation. Transport Systems. Office of Technical Services. Office of Weights and Measures. Office of Engineer. ing Standards. Office of Industrial Services.

* NBS Group, Joint Institute for Laboratory Astrophysics at the University of Colorado.

** Located at Boulder, Colorado. 


\section{NATIONAL BUREAU OF STANDARDS Technical Note 259}

ISSUED APRIL 12, 1965

\section{A FORTRAN PROGRAM FOR DETERMINING AN EMPIRICAL EXPRESSION FOR A QUANTITY MEASURED AT COMBINATIONS OF SEVERAL LEVELS OF EACH OF TWO VARIABLES}

Mary Nan Steel, Frank L. McCrackin, and John Mandel

NBS Technical Notes are designed to supplement the Bureau's regular publications program. They provide a means for making available scientific data that are of transient or limited interest. Technical Notes may be listed or referred to in the open literature.

For sale by the Superintendent of Documents, Government Printing Office Washington, D.C., 20402 - Price 40 cents 
Contents

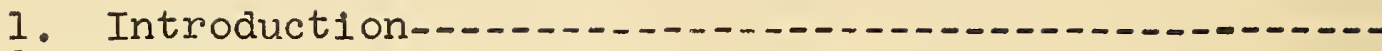

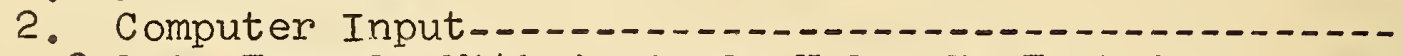

2.I An Example With A single Value In Each Cell-...-

2.2 An Example With Replicate Values In Each Cell-..-

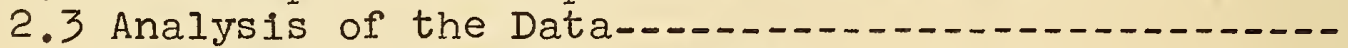

2.31 The Linear Model- LMODEL_....................

2.32 The Weighted Linear Model- LMWCOL_..........

2.33 The Quadratic Model- QMODEL_.............

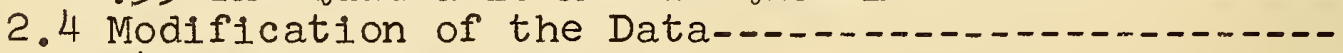

2.41 Omit Data- ONIT-_.....

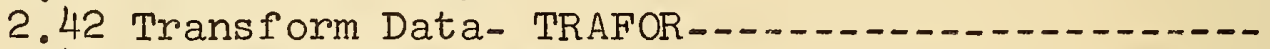

2.43 Correct Data- CORECT-.....

2.44 Reverse Data- REVERS..................... 10

2.45 Combine Data- COMBIN_.................. 10

2.46 New Data- NEWDAT_...................... II

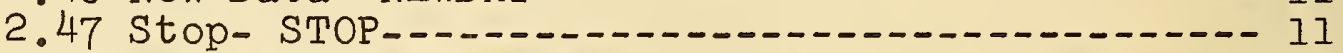

3. Interpretation of Computer Output_............. 11

3.1 The Table With A single Value In Each Cell.....- 11

3.2 The Table with Replicate Values In Each Cell-...- 14

4. References......... 18

Appendix A. Tables of Computer Input and Output ...... 19

Appendix B. Listing of Fortran Program ........... 32

Appendix C. Functions and Subroutines

Used by the Program _.......... 50

Appendix D. Variables Used in Program ............. 51

Appendix E. Flow Diagrams of Program and Subprograms--- 53 
A FORTRAN Program for Determining an Empirical Expression for a Quantity Measured at Combinations of Several Levels of Each of Two Variables

Mary Nan Steel, Frank L. McCrackin, and John Mandel

This note relates to a general procedure, reported elsewhere, for finding an empirical expression for the functional dependence of a measured quantity on two variables. The procedure is applicable when measurements of the dependent variable are available at m.n combinations of $\mathrm{m}$ levels of one variable and $n$ levels of the other; it leads to an algebraic expression relating the three variables.

A Fortran program to perform the various steps of the general procedure is presented along with detalled instructions for its use. The program also includes the calculation of an analysis of variance, of components of variance, of significance tests, tables of residuals, and a number of other quantities.

\section{Introduction}

In many scientific studies, a quantity is measured at several levels for each of two variables. The data are often presented in a table with the rows of the table representing one variable and the columns representing the other variable.

When both variables are continuous, the data can be considered as representing either a surface in three-dimensional space or a family of plane curves [1]1. In the latter representation each curve represents the relation between the measured quantity and one of the variables, for a selected fixed value of the second variable. For different fixed values of this second variable, different curves are obtained. In this fashion a family of curves is generated. An example of this type is the relationship between the volume, the pressure and the temperature of a gas. The objective is to find a mathematical representation of such a relationship.

One or both of the variables may represent categories rather than continuous variables. For example, in interlaboratory studies of test methods [2], the data are often classified in accordance with laboratories (rows) and

materials (columns). In such cases, the main objective is to

${ }^{1}$ Figures in brackets indicate the literature references at the end of this paper. 
determine the effect of the variables (laboratories and materials) on the variability of the data. Methods to determine the relationship between the measured quantity and the variables have been developed by Mandel, et al $[1,2,3,4,5]$.

These methods, which have been referred to as the linear model and the quadratic model, constitute essentially a general procedure for the empirical fitting of the data by means of algebraic expressions. The fitting procedure comprises several steps:

1) the selection of a particular algebraic expression from among a class of such expressions for the most appropriate representation of the data;

2) the calculations of numerical values for the parameters and coefficients occurring in the chosen expression;

3) the estimation of the precision of the calculated parameters and coefficients, tests of significance related to them, and the calculation of confidence intervals for their true values;

4) the derivation of components of variance related to the variability of some of the parameters and coefficients;

5) further statistical interpretations of the parameters, coefficients, and components of variance in terms of the general objectives of the study.

A computer program was developed to perform these analyses and this note presents the program. Section 2 describes how the data are organized to be read into the computer and the instructions required to perform the calculations. Possible modifications to be made to the data by the computer are also described. Section 3 presents two examples with interpretations of the computer output. The tables of computer output examined in Section 3 are given in Appendix A. Appendixes B through $D$ give the FORTRAN program and information required for understanding the program. Appendix E consists of Figures I through 9, the flow diagrams for the computer program and the principal subprograms.

\section{Computer Input}

Two examples are presented as a guide for the practical use of the program. Section 2.1 describes a setup in which each cell contains a single measurement. Section 2.2 presents the case in which replicate measurements in each cell are to be analyzed. It will be noted that the data are set up in a different way in each case (Examples 1 and 2). Each line of data in the lower portion of both examples represents a single card of computer input and the first card is the title card in both cases. The nominal number of replicates of a particular test is put in columns 1 and 2 of this card, followed by any descriptive title. 
Example 1. A Single Value In Each Cell

Round Robin $\frac{\text { The Data }}{\text { on Dielectric Strength }}$

Material

\begin{tabular}{lllllllll}
\hline Lab & 1 & 2 & 3 & 4 & 5 & 6 & 7 & 8 \\
\hline LOH & .80 & 1.13 & .34 & .47 & .22 & .34 & .17 & .20 \\
LMG & .96 & 1.26 & .32 & .61 & .23 & .32 & .17 & .23 \\
LST & .98 & 1.24 & .34 & .52 & .31 & .45 & .20 & .24 \\
LUM & .88 & 1.33 & .32 & .51 & .22 & .31 & .15 & .18 \\
\hline
\end{tabular}

Setup for Computer Input

Column Number

\begin{tabular}{llllllll}
1 & 7 & 15 & 25 & 35 & 45 & 55 & 65 \\
\hline
\end{tabular}

01

ROUND ROBIN ON DIELECTRIC STRENGTH

$\begin{array}{ll} & \text { MATI } \\ \text { LOH } & .80 \\ \text { LMG } & .96 \\ \text { LST } & .98 \\ \text { LUM } & .88 \\ \text { MOREDA } & \\ & \text { MAT8 } \\ \text { LOH } & .20 \\ \text { LMG } & .23 \\ \text { IST } & .24 \\ \text { LUM } & .18 \\ \text { ENDATA } & \\ \text { LMWCOLCAI } & \\ \text { STOP } & \end{array}$

2.I An Example with A Single Value In Each Cell

Example 1 gives experimental data with a single value in each cell. The top table gives the original data. The lower table gives the setup for computer input. In the latter, the first card has $O I$ in columns 1 and 2 and the title that identifies the data follows. The second card contains the column headings from the table and may have as many as seven per card, beginning in card columns $7,15,25,35,45,55,65$ as shown in the example. Next follow the data cards, each of" which has a row heading in columns $1-6$ followed by data corresponding in number and order to the column headings, i.e. the data are placed in card columns 7 through 14, 15 through 24, 25 through 34, 35 through 44, 45 through 54, 55 through 64 
Example 2. Replicate Values In Each Cell Adhesion of Plastic Patches, Method A Condition

\begin{tabular}{|c|c|c|c|}
\hline Material & 1385 & 1415 & 2385 \\
\hline $\mathrm{AA}$ & $\begin{array}{l}18.2 \\
18.6 \\
17.9\end{array}$ & $\begin{array}{l}20.0 \\
19.7 \\
20.0\end{array}$ & $\begin{array}{l}22.1 \\
22.0 \\
20.8\end{array}$ \\
\hline$A B$ & $\begin{array}{l}16.8 \\
15.2 \\
15.6\end{array}$ & $\begin{array}{l}24.5 \\
25.1 \\
23.4\end{array}$ & $\begin{array}{l}17.3 \\
17.7 \\
17.7\end{array}$ \\
\hline $\mathrm{AC}$ & $\begin{array}{l}14.6 \\
13.1 \\
14.2\end{array}$ & $\begin{array}{l}14.7 \\
14.7 \\
14.7\end{array}$ & $\begin{array}{l}14.6 \\
14.2 \\
14.9\end{array}$ \\
\hline$A D$ & $\begin{array}{l}19.5 \\
18.7 \\
16.5\end{array}$ & $\begin{array}{l}15.9 \\
16.5 \\
17 \cdot 7 \\
16.7\end{array}$ & $\begin{array}{l}18.0 \\
20.1 \\
20.3\end{array}$ \\
\hline
\end{tabular}

\section{Setup for Computer Input}

Column Number

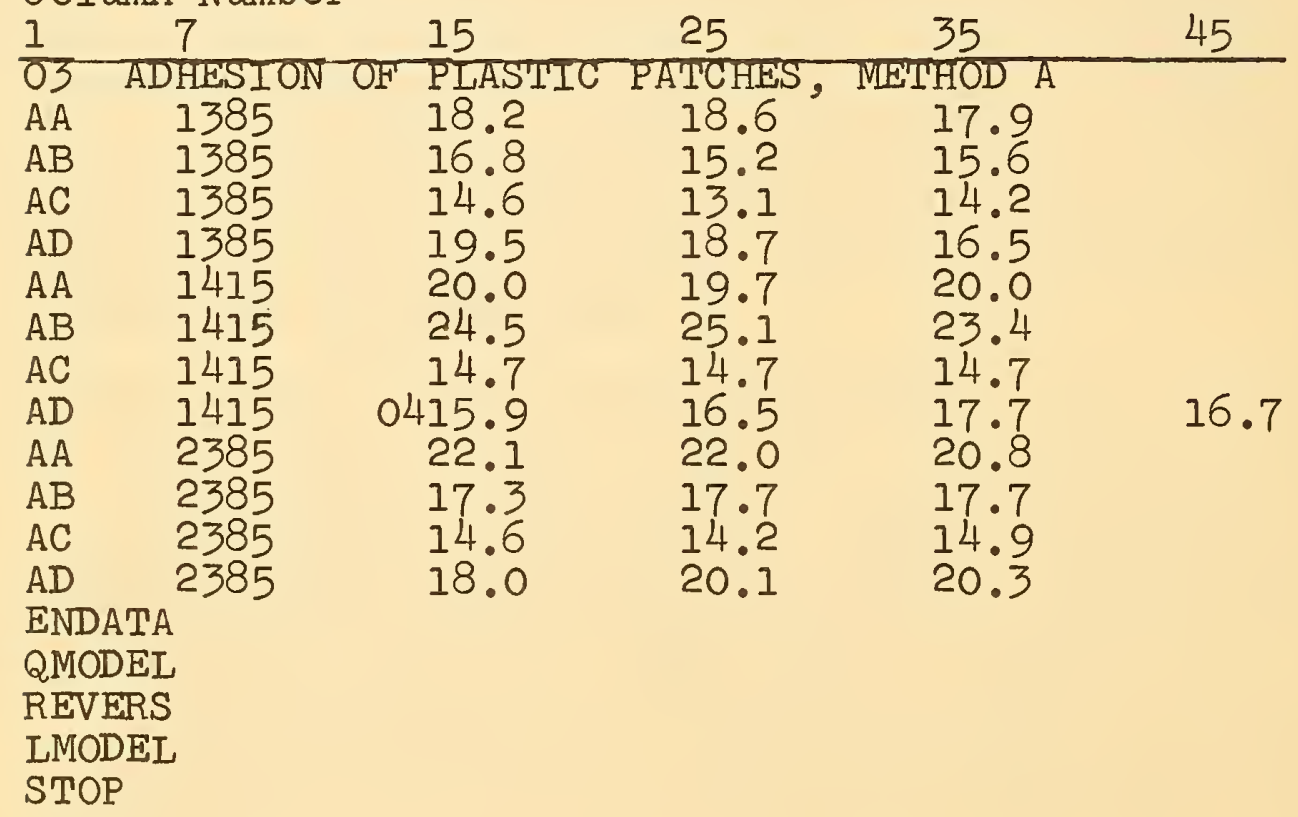


and 65 through 72. The column and row headings must all be different and each heading may consist of from 1 to 6 characters. All data must contain decimal points. If more than 7 columns of data are to be read, a card with MOREDA in columns $1-6$ is placed after the last row of data of the first group of columns. That is, all rows for each set of columns are read before additional column headings with their respective rows of data are introduced. After the MOREDA card, the next set of column headings, again beginning in column 7 are read, followed by rows of data corresponding to the new column headings. At this point it is important that the rows are in the exact order and the same in number as before, for the row headings are ignored after the first reading, the identity of the order is assumed, and no provision is made for a difference in the number of rows per column. The MOREDA card occurs only once, regardless of the number of columns over 7 that are to be read.

The reading of the data is concluded by placing a card with ENDATA in columns $1-6$ after the last row of data.

\subsection{An Example With Replicate Values In Each Cell}

In Example 2, the case in which replicate values occur in each cell, we note that 03 is placed in columns 1 andi?, followed by the title on the first card. On the second card, a row and column heading appear, for in the case of replicate measurements row and column headings and replicates for the cell thus designated, all appear on the same data card. The row heading is put in columns $1-6$ and the column heading in card columns 7-12. Columns $13-14$ are blank if the number of replicates in the cell is the same as the number appearing on the title card - in our example 03. If the number of replicates for any one cell differs from that on the title card, that number is placed in columns 13-14 (note 04 in line $A D 1415$ in Example 2). The data then follow on the same line beginning in columns $15,25,35,45,55,65$. If more than s1x replicates occur per cell, the additional data are placed in groups of six on successive cards, making certain that the number of replicates is either the same number indicated on the title card or that placed in columns 13-14 of the initial card of the cell listing. There may be as many as 99 replicate values per cell.

It is important that there be the same number of rows with the same row headings per column and the same number of columns with the same column headings per row, otherwise, the program will not mun. The data cards may be placed in any order. The program will handle a table of data containing as many as 120 rows and 50 columns. A card with ENDATA in columns $1-6$ is always placed after the final data card. 
After the data are read into the computer some basic calculations are made. In the case of replicate measurements per cell, the cell averages, standard deviations, and the coefficients of variation are computed.

Row and column averages are calculated for either the cell averages (in the case of replicate measurements per cell) or for the cell entries (in the case of single measurements in the cells). Then the data of the table are rearranged in such a way that the column-averages are in ascending order from left to right and the row-averages are in ascending order from top to bottom. A table of averages and, in the case of replicates, a table of standard deviations with the coefficients of variation are printed. Analysis of the data is accomplished by placing instruction cards for the desired analysis at the end of the data deck after the card ENDATA. The instruction cards are the same for data consisting of either single or replicate measurements per cell and the choice of instructions determines the analysis that will be performed on the data.

Examples 1 and 2 show the way in which the instruction cards appear in an input setup. Details for making these cards and notes on what the instruction accomplishes are given below.

\subsection{The Linear Model - LMODEL}

By placing LMODEL in columns $1-6$ of a card following the data, the equation $\mathrm{y}_{i j}=\mathrm{A}_{1}+\mathrm{B}_{1} \mathrm{C}_{j}$, the linear model, is fitted to the cell averages $\mathrm{y}_{i j}$. The residuals and their sums of squares are calculated and printed and the analysis of variance is computed. The analysis is then printed along with the values calculated for A, B and C. Interpretations of the computer output for this and other calculations are given in Section 3.

\subsection{The Weighted Linear Model - LMWCOL}

If one wishes to weight the columns before analyzing the data, LMWCOL is placed in columns $1-6$ on a card. A linear model analysis is then performed, in which the columns are weighted. Weights may be given or calculated. When the weights are given, they are placed on cards immediately following the LMWCOI card. One weight is given for each column and six weights may be read from a single card beginning in card columns $15,25,35,45,55$, and 65 , as in Example 3. If a column is not to be weighted, 1 . is given as its weight and of course the weights are given in the same 
order as the columns of data being weighted, $1 . e$. , in the ascending order of the column averages, from left to right, as ordered by the computer.

\section{Example 3}

Column Number

\begin{tabular}{|c|c|c|c|c|c|c|}
\hline $1 \quad 7$ & 15 & 25 & 35 & 45 & 55 & 65 \\
\hline $\begin{array}{l}\text { ENDATA } \\
\text { LNWCOI }\end{array}$ & & & & & & \\
\hline STOP & 1.35 & 1. & .5 & 1.5 & .75 & 1.45 \\
\hline
\end{tabular}

If the user wishes the weights to be calculated he places CAL in columns 7-9 following the LMWCOL, thus IMWCOLCAL appears on the instruction card. The calculation of weights is an iterative process discussed in reference [5]. When the weights are calculated, the analysis is not alid unless the data consist of a minimum of eight columns. The weights are derived from the original data themselves. It is well to note that if the user has sufficient information to provide his own weights, it is at this point in the program that they should be introduced.

After the weights have been read or computed, the square root of the weights, referred to as the weighting factor, is determined and both weights and weighting factors are printed. In addition to these, the weighted values for $A, B$, and $C$, the point of concurrence* and the analysis of variance are calculated and the results printed. The residuals with the sums of squares of both rows and columns are computed and the Table of Deviations, preceded by the number of rows and columns, is printed.

$$
\text { 2.33 The Quadratic Model - QMODEL }
$$

The quadratic model fits the data to the equation

$$
y_{i j}=A_{i}+B_{1} C_{j}+D_{1} E_{j}=A_{i}^{\prime}+B_{i} C_{j}+D_{i} C_{j}^{2} \text {, }
$$

Where $E_{j}$ is a quadratic function of $\mathrm{C}_{j}$. The instruction QMODEL Is placed on a card in columns $1-6$ when this model is desired. All the variables for the equation are calculated and printed as in the analysis of variance. In addition to the Table of Deviations with the row and column sums of squares for the quadratic model, this instruction also calculates and prints the linear model Table of Deviations with sums of squares.

* See Section 3.1 


\subsection{Modification of the Data}

It is frequently desirable to analyze a set of data, then modify it in some fashion and reanalyze the new set. Instructions are included to accomplish a number of these modifications.

\subsection{Omit Data - OMIT}

The OMIT instruction placed in columns $1-6$ of a card causes the designated rows and/or columns to be omitted in the analyses following it, or until another OMIT card is placed in the sequence of instructions.

On the same card with OMIT, in columns 13-14, appears the number of rows and columns to be omitted followed by their labels beginning in columns $15,25,35,45,55,65$. These may be given in any order. If there are more than 6 , the additional labels in groups of six appear on cards immediately following the first OMIT instruction.

An OMIT card cancels all previous omit cards. In other words a single set of data may be analyzed using different rows and columns within the same run by first placing the OMIT card followed by the card designating the analys is desired, followed by another OMIT card and another analysis card, etc.

Example 4

Column Number

\begin{tabular}{|c|c|c|}
\hline \multirow{2}{*}{\multicolumn{3}{|c|}{$\frac{1}{\text { ENDATA }}$}} \\
\hline & & \\
\hline $\begin{array}{l}\text { ONIT } \\
\text { QMODEL }\end{array}$ & O2AI & $B 2$ \\
\hline $\begin{array}{l}\text { OMIT } \\
\text { LMODEL } \\
\text { STOP }\end{array}$ & O2DUPONT & $\mathrm{Al}$ \\
\hline
\end{tabular}

In Example 4, the first QMODEL analysis will include all laboratories and materials, then materials $\mathrm{Al}$ and $\mathrm{B} 2$ will be omitted in the second QMODEL analysis. IMODEL will be computed omitting laboratory DUPONT and material Al but will include material B2 previously omitted.

\subsection{Transform Data - TRAFOR}

This instruction may be on a card in columns $1-6$ placed before or after the data. Placed before the data, after the title card, the function TRAFOR causes each measurement to be transformed before any other calculations are made. Any 
transformation may be employed. This program does not include a transformation, in order to use the instruction a special subprogram called TRAFOR must be written and added by the user.

If one wishes to transform the averages after all of the cell averages have been computed, TRAFOR is placed on a card in columns 1-6 after the ENDATA card. The subroutine TRAFOR will then transform the averages. As in the case of the function TRAFOR, any transformation may be used, and again no subroutine TRAFOR is included and it is left to the user to write his own.

It is important to note that the user must choose either one or the other of these two transformations and include only the one desired in using the program. Of course neither is necessary to the running of the program; the decision depends entirely on the nature of the data and the wishes of the user.

\subsection{Correct Data - CORECT}

The averages and standard deviations may be replaced by values corrected in the form $A X+B$ and $A \sigma$ respectively, where $A$ is a multiplicative correction, $B$ is an additive correction, $\bar{X}$ is the original average and $\sigma$ is the original standard deviation.

The data may be corrected before the initial printing of the Table of Averages and Standard Deviations, in which case CORECT should appear in columns 7-12 on the same card with ENDATA. (Example 5a) If one wishes the original data to be printed before correction is made, the CORECT in columns $1-6$ should appear on a separate card after ENDATA. (Example 5b)

In either case the row and column designations of those values to be corrected are placed on a card immediately following the CORECT card in columns $1-6$ and $7-12$, respectively, along with the multiplicative term (columns 15-24) and additive term (columns 25-34). These designations may be for single values or, by placing ALL in place of a single row or column heading, may include all row values for a single column or all column values for a single row, as shown in Example 5. After these instructions an END card (columns 13) is placed.

If a purely multiplicative correction is desired, it is not necessary to put 0 . in column 25 but if a purely additive correction is desired, a 1. must be placed in column .15 . 
Example 5

(a)

Column Number

\begin{tabular}{|c|c|c|c|}
\hline \multirow{2}{*}{\multicolumn{4}{|c|}{$\frac{1}{\text { ENDATACORECT }}$}} \\
\hline & & & \\
\hline $\begin{array}{l}\text { ALI } \\
\text { LABO3 }\end{array}$ & $\begin{array}{l}\text { MAT02 } \\
\text { MATII }\end{array}$ & $\frac{1}{2}$. & 2. \\
\hline $\begin{array}{l}\text { LABO7 } \\
\text { END }\end{array}$ & ALI & 2. & 5. \\
\hline
\end{tabular}

(b)

Column Number

$\begin{array}{lll}\frac{1}{1} & 7 & 25 \\ \text { ENDATA } & & \\ \text { CORECT } & & \\ \text { ROW3 COL7 } & 1 . & 3 . \\ \text { ALI COL2 } & 2 . & 1.5 \\ \text { ROW6 ALI } & 1 . & 2 .\end{array}$

END

\subsection{Reverse Data - REVERS}

This instruction card with REVERS in columns $1-6$ causes the rows and columns to be interchanged in the analyses that follow.

\subsection{Combine Data - COMBIN}

Sometimes data previously treated as two or more sets are found not to be significantly different and the experimenter wishes to treat them as one set. The instruction COMBIN serves the purpose of combining such sets into new averages. After the CONBIN in columns 1-6, the designation "ROWS" or "COIS" is placed on the card in columns 7-10 and the labels of the sets to be combined are placed in columns beginning at 15, 25, 35, 45, 55. This causes the cell averages in the rows and/or columns thus designated to be averaged together into a single row or column. The label for the newly formed row or column is placed on the card in the position immediately following the listing of the rows and columns to be combined. Thus it is possible to combine as many as 5, their new label being placed on the card beginning in position 65 .

If more than one combination is to be computed, additional lines are added as shown in Example 6. COMBIN is placed on the first card only, its place being left blank on the following lines. An instruction card with END in columns 7-9 completes the setup for this subroutine. 
It should also be noted that the new table of averages is treated as though it were a table of single values and no standard deviations are calculated.

Example 6

Column Number

\begin{tabular}{|c|c|c|c|c|c|c|}
\hline $1 \quad 7$ & 15 & 25 & 35 & 45 & 55 & 65 \\
\hline ENDATA & & & & & & \\
\hline $\begin{array}{r}\text { COMBINR OWS } \\
\text { COIS }\end{array}$ & $\begin{array}{l}\text { Al } \\
\text { CI }\end{array}$ & $\begin{array}{l}\mathrm{A} 2 \\
\mathrm{C} 3\end{array}$ & $\begin{array}{l}\text { A3 } \\
\text { C6 }\end{array}$ & A10 & & \\
\hline $\begin{array}{l}\text { ROWS } \\
\text { END }\end{array}$ & L7 & I8́ & L9 & LIO & $\operatorname{LI} 4$ & L15 \\
\hline
\end{tabular}

These instructions combine rows $A 1, A 2$ and $A 3$ in a single row labeled AlO; combine columns $\mathrm{Cl}$ and $\mathrm{C} 3$ in a single column called $\mathrm{C6}$; combine rows L7, L8, L9, L10, L14 in a single row called LI5.

\subsection{New Data - NEWDAT}

If the user wishes to analyze more than one set of data in a single run, a card with NEWDAT in columns $1-6$ is placed after the last analysis card of the preceding set of data. This is followed by the title card for the new set of data. The rest of the setup for the set follows the same rules as for the initial set. Again, the number of such sets to be run at one time is the user's choice.

\subsection{Stop - STOP}

The very last card in any analysis is the card with STOP in columns 1-4. If several sets of data are to be analyzed the STOP card is placed only at the end of the last set of data.

\section{Interpretation of Computer Output}

\subsection{The Table with A Single Value In Each Cell}

The output from the computer is illustrated by two examples. The data shown in table 1 will give the output shown in table 2. Each line of table 1 represents one card of computer input. The first line is the title preceded by Ol designating a table with a single value in each cell. The second line gives the column headings which, in this particular example, are numbers. The data follow and the instructions come after the data.

The first page of output, table $2 a$, gives the original data with row and column averages. The data have been rearranged so that the row and column averages are in 
ascending order of magnitude, from top to bottom and from left to right, respectively. The data were then fitted by the linear model with the results shown in table $2 \mathrm{~b}$. The instruction LMODEL is printed on the second line to identify the source of the print out; the -O following IMODEL indicates that no further information was on the instruction card. The parameters $A, B$, and $C$ fit the original data by the model equations

$$
\left.\begin{array}{l}
\mathrm{y}_{i j}=\hat{y}_{i j}+\text { residual error } \\
\hat{y}_{i j}=A_{i}+B_{i} C_{j}
\end{array}\right\}
$$
where $\hat{y}_{1}$ is the fitted value for the observation $y_{j}$ A and
$B$ values are given for each row; $C$ is given for each column.

The analysis of variance for the fitting is given next. The total sum of square, SS, and degrees of freedom, DF, are partitioned into the effect of the mean (MEAN), rows (ROWS), columns (COIS) and interaction ( $\mathrm{RXC}$ ). The mean squares (MS) for the row, column and interaction effects are also given. This part of the analysis of variance corresponds to the analysis of the data by the additive model given by

$$
\left(\hat{y}_{i j}\right)_{a}=A_{i}+C_{j}
$$

where $\left(\hat{y}_{1 j}\right)_{a}$ is the fitted value for the observation $y_{i j}$.

The interaction ( $\mathrm{RxC}$ ) is next partitioned into two components according to the following equation (which is just a different way of writing equation (1)):

$$
\begin{aligned}
\mathrm{y}_{1 j} & =\hat{y}_{1 j}+\text { residual error } \\
& =A_{i}+C_{j}+\underbrace{\left(B_{i}-1\right) C_{j}+\text { residual error }}_{\text {interaction }(\mathrm{RxC})}
\end{aligned}
$$

The component denoted linear (IIN) corresponds to the term $\left(B_{i}-1\right) C_{j}$, while the component denoted residual (RESID) corresponds to the residual error term in equation (3).

Mandel and McCrackin [1] have shown that if $B_{i}$ is a linear function of $A_{i}$, the linear model, equation (1), may be reduced to the simpler concurrent model given by

$$
\left(\hat{y}_{i j}\right)_{c}=y_{0}+P_{i} Q_{j}
$$


In particular, if

$$
\mathrm{B}_{i}=1+\alpha\left(\mathrm{A}_{i}-\overline{\mathrm{A}}\right)
$$

then $\mathrm{y}_{0}=\overline{\mathrm{A}}-1 / \alpha$

$$
P_{i}=A_{i}-y_{0}
$$

and $Q_{j}=1+a C_{j}$

To aid in determining the applicability of the concurrent model, the sum of squares for the linear part has been further divided into a concurrent (C) and non-concurrent (NC) part. The concurrent model, equation (4), applies when the non-concurrent part is sufficiently small.

The ratios, $F$, of mean squares are given to be compared with tabulated values of the F-statistic to determine the significance level of the various effects. The ratios given are

$\begin{array}{ll}\text { ROWS } & \text { MS (ROWS)/MS (RESID } \\ \text { COIS } & \text { MS (COIS)/MS (RESID } \\ \text { RXC } & \text { MS RXC)/MS (RESID) } \\ \text { IIN } & \text { MS (LIN)/MS (RESID) } \\ \text { C } & \text { MS C C)/MS (NC) } \\ \text { NC } & \text { MS (NC)/MS (RESID) }\end{array}$

For the example in table $2 b$, the $F$ value for rows (10000) is larger than Fio, 30 for the 0.005 significance level $(3.344)$, so the effect of rows is significant at better than the 0.005 level. Likewise, the columns, interaction, and linear parts are significant. Since the interaction and linear parts are significant, the data cannot be adequately represented by the additive model.

The $F$ values for both the concurrent and non-concurrent parts are also highly significant. Therefore, the data can be fitted approximately by equation (4), the concurrent model, but the fit by equation (4) is not as good as that by equation ( 1 ), the linear model.

The next page, table $2 c$, shows the deviations of the data from the linear model, $\hat{i}_{\text {.e., }} \mathrm{y}_{i j} \hat{\mathrm{y}}_{i j}$. The sums of squares of the deviations over both the rows and columns are also given. This table should be carefully scrutinized for trends, either in the rows or in the columns, and for excessive individual residuals. Trends can be detected by systematic patterns in the + and - signs. If a row or column contains excessive residuals, the analysis should be run 
omitting the suspect row or column, or else a weighted analysis should be run. Other systematic patterns or residuals may indicate that the linear model is inadequate to represent the data to within their precision. In this case, the data should be fitted by a more general model, such as the quadratic model. In order that conclusions drawn from the analysis of variance be valid, it is essential that the residuals be free of marked systematic effects or serious outliers.

The linear model may also be applied with rows and columns interchanged. For this purpose the data were reversed (i.e., the rows and columns were interchanged) by the instruction REVERS, and the data were reanalyzed by the linear model with the results shown in table $2 \mathrm{~d}$. The residual mean square $\left(0.233 \times 10^{-5}\right)$ is seen to be larger than the residual mean square $\left(0.879 \times 10^{-6}\right)$ in table $2 \mathrm{~b}$, before the data were reversed, so for this case the first analysis gave the better fit and is to be preferred.

\subsection{The Table With Replicate Values In Each Cell}

Table 3 is an example of a set of data with 2 replicate values in each cell. The computer output for these data are given in table 4. The title for the data appears as the first line of table 3 and the 02 preceding the title indicates that there are two values in each cell to be used in calculating the cell averages and standard deviations. The second line gives a row heading, followed by a column heading and the two replicate values of the designated cell.

The data are from an inter-laboratory test on natural rubber. The rows labeled LABI2 through IAB59 in table $4 a$ represent different laboratories that performed the test and the columns labeled MAT345 through MAT245 represent the materials on which the test of stress at 100 percent elongation was made. In table $4 \mathrm{a}$ the average of the two replicate measurements is given for each cell. The row and column averages are also given. The data have been arranged so that their row and column averages appear in ascending order of magnitude. Table $4 \mathrm{~b}$ gives the standard deviations per cell and the percent coefficient of variation for each column (material).

Table $4 \mathrm{c}$ is a print out of the COMBIN instructions which appear after the data cards in table 3 . It will be noted that in each line the instruction is given to combine four rows into a single row with a new label. (See section 2.45 COMBIN) The four rows in each case are really four tests within a single laboratory but with different labels. In a previous computer run of these data in which each of the four 
tests was analyzed as a separate laboratory, it was found that there was no significant difference within the set of four. Therefore in this run the computer has been instructed to combine each set of four - averaging the cell averages into a new "table of averages", table 4d. The result is that the cell averages from table 4 a for the rows labeled LABO9, LAB 10, LABI1, LABI2 are averaged in a single row of averages labeled LABOl in table 4d, etc. This new table is treated as a set of data with single measurements per cell and therefore no new standard deviations are computed. In table $4 e$ the first line after the heading, LMWCOLCAL, indicates that the computer was instructed to analyze the data using the linear model weighted by columns, with the weights to be calculated. Printed in this table are the computed weights (WEIGHT) and their square roots (SQRTW) for the various columns of combined data. $A, B$, and $C$ are the values obtained for the parameters in the model equation (1) discussed on page 12. B* (B STAR) is the estimate of $B$ based on the assumption that $B_{i}$ is a linear function of $A_{i}$. If $B_{i}^{*}=B_{i}$, equation (5) holds and the model is concurrent. To what extent equation (5) holds (i.e., to what extent the model is concurrent) can be judged by comparing B and B STAR: a close agreement indicates a high degree of concurrence. In table $4 \mathrm{e}$ they do not agree, so these data do not fit the concurrent model.

The calculated value of $a$ is also given in table $4 e$. The last line of table $4 \mathrm{e}$ gives the "Point of Concurrence" which is discussed in reference [4].

Table $4 \mathrm{f}$ gives the analysis of variance of the weighted data. The usual row and column SS are given and the row $\mathrm{x}$ column interaction. The latter is partitioned into "Fit" and "Slope". The value of the ratio

$$
F=\frac{M_{\text {slope }}}{M_{\text {fit }}}
$$

is compared with the tabulated value of the F-statistic with the degrees of freedom given in the column DF (in this case 5 and 30). A significant value for this $F$ indicates that the model is not additive; it may then be either concurrent or non-concurrent. To decide on this point, the sum of squares for "slope" is partitioned into "concurrence" and "non-concurrence". If the mean square for "non-concurrence is not "ppreciably larger than that for "fit" and the mean square for "concurrence" is significantly larger than that for "nonconcurrence", the model is probably a concurrent one. This must be verified by:

(a) comparing BSTAR with $B$ in table $4 e$

(b) plotting $B$ versus $A$ : a straight line indicates the 
concurrent model

(c) examining $R$ SQUARED which is the square of the correlation coefficient between $A$ and $B$. A value of $R$ squared close to unity indicates a tendency for concurrence. Conclusions drawn from the analysis of variance are always tentative subject to an examination of the residuals, as described below.

The Tabie of Deviations for this example is given in table $4 \mathrm{~g}$. These are the residuals in the weighted scale, i.e.

$$
\text { deviation }_{i j}=\sqrt{n_{j}}\left(y_{i j}-\widehat{y}_{i j}\right)
$$

As noted in the preceding example, the table should be carefully scrutinized for trends, either across the rows or down the columns, and for excessive individual residuals. Trend can be detected by systematic patterns in the + and signs. The total sum of squares in this table is identical with the sum of squares for "fit" in the analysis of variance. Again it should be emphasized that in order that conclusions drawn from the analysis of variance be valid, it is essential that the residuals be free of marked systematic effects or serious outliers.

In table $4 \mathrm{~h}$ the line below the title "QMODEL" indicates that the data were analyzed by the quadratic model as requested in the instructions at the end of Table 3 .

Analysis by the quadratic model is in accordance with the relation

$$
y_{i j}=A_{i}+B_{i} C_{j}+D_{i} E_{j}
$$

or the equivalent form:

$$
y_{i j}=A_{i}^{\prime}+B_{i}^{\prime} C_{j}+D_{i} C_{j}^{2}
$$

In equation (II), $A_{i}, B_{j}$, and $C_{j}$ are the estimates corresponding to a fit by the ${ }^{i}$ inear model. The set $E_{j}$ is orthogonal to $C_{j}$, i.e.: $\sum_{j} C_{j} E_{j}=0$.

$E_{j}$ is a quadratic function of $\mathrm{C}_{j}$. If terms of the same order are collected in equation (II), the expression given by equation (12) is obtained, where $\mathrm{C}_{j}$ and $\mathrm{D}_{i}$ are the same as in equation (II).

The analysis of variance for the quadratic model is given in table $4 i$. The total sum of squares, SS, and the total degrees of freedom, DF, are partitioned into the effect of the mean (MEAN), rows (ROWS), columns (COLS) and 
interaction ( $\mathrm{RxC})$. The row-column interaction is further partitioned into three parts: linear (IIN), quadratic (QUAD), and residual (RES). The mean squares (MS $)^{\prime}=(\mathrm{SS}) /(\mathrm{DF})$ are also computed.

By means of the F-test, both the mean squares of the "Iinear" and "quadratic" can be tested against "residual". Comparing the resulting quotients with the values in the $F$ table, a conclusion may be reached as to whether the model is essentially additive (both "linear" and "quadratic" nonsignificant against "residual"), linear ("linear" significant, "quadrat1c" non-significant), or quadratic ("quadratic" significant against "residual"). As pointed out in the previous examples of analysis of variance, the conclusions drawn here are not valid unless substantiated by a table of residuals free of large systematic effects.

The lower part of table $4 i$ contains the table of residuals from the linear fit. On careful examination for systematic patterns or excessive residuals in this example, it is obvious that material 745 gives rise to residuals that are substantially larger than those corresponding to all other materials. Therefore the analysis of variance is not usable for the drawing of valid inferences from the data.

Table $4 \mathrm{f}$ contains the quadratic model residuals. Again a careful scrutiny is necessary and for the present example, the residuals for material 745 are abnormally large as compared to all others. The analysis of variance can therefore not be trusted and the data are reanalyzed omitting the abnormal. material 745 .

Table $5 \mathrm{a}$ shows the instruction OMIT with 1 before the label MAT745 on the second line. Thus the computer is instructed to omit 1 column. The Table of Averages is the same as that in table $4 \mathrm{~d}$ except that material 745 is omitted and the row averages are therefore different.

Table 5b gives the values determined by the QMODEI, analysis on the data without material 745 , and table $5 \mathrm{c}$ gives the analysis of variance from the quadratic model and the table of residuals from the linear model both excluding material 745. Note the marked decrease in error variance resulting from the omission of the abnormal material. There also appears evidence in the new analysis of a quadratic effect.

The sums of squares of residuals from the linear model for the materials are now all of the same order of magnitude. And in table 5d the sums of squares of the residuals from the quadratic model are also all of the same order of magnitude. Therefore the quadratic effect observed in the analysis of 
variance appears to be real.

This program was written as a research tool. The first program "multiple curve fitting" was written by Alfred E. Beam. Necessary changes were made as the research progressed and the present FORTRAN program was written as a result of the experiences gained in the use of Mr. Beam's program.

\section{References}

[1] Mandel, John and McCrackin, F. L., Analysis of Families of Curves, J. Res. Natl. Bur. Standards 67A (Phys. and Chem.), No. 3, 259-267 (May-Jüe 1963).

[2] Mandel, John and Lashof, T. W., The Interlaboratory Evaluation of Testing Methods, ASTM Bull. 239, 53-61 (July 1959).

[3] Mandel, John, The Measuring Process, Technometrics, I, 251-267 (Aug. 1959).

[4] Mandel, John, Non-Additivity in Two-Way Analysis of Variance, J. Am. Stat. Assoc. 56, 878-888 (Dec. 1961).

[5] Mandel, John, Estimation of Weighting Factors in Linear Regression and Analysis of Variance, Technometrics 6, $1-25$ (Feb. 1964). 
COMPUTER INPUT WITH A SINGLE VALUE IN EACH CELL

01 SPECIFIC VOLUME OF RUBBER - WEIR

$\begin{array}{llllll} & 81.5 & 64.0 & 50.2 & 38.5 & 21.0 \\ 0 & .96677 & .95639 & .94826 & .94143 & .93397 \\ 1 & .94077 & .93344 & .92673 & .92204 & .91678 \\ 2 & .91360 & .90953 & .90464 & .90189 & .89941 \\ 3 & .89436 & .89231 & .88880 & .88645 & .88447 \\ 4 & .87937 & .87864 & .87572 & .87336 & .87214 \\ 5 & .86680 & .86697 & .86424 & .86188 & .86056 \\ 6 & .85636 & .85654 & .85410 & .85134 & .85038 \\ 7 & .84708 & .84717 & .84480 & .84201 & .84113 \\ 8 & .83828 & .83828 & .83608 & .83345 & .83263 \\ 9 & .83074 & .82996 & .82859 & .82563 & .82647 \\ 10 & .82360 & .82249 & .82129 & .81829 & .81834 \\ \text { ENDATA } & & & & \\ \text { LMODEL } & & & & \\ \text { REVERS } & & & & \\ \text { LMODEL } & & & & \\ \text { STOP } & & & & \end{array}$


TABLE OF AVERAGES

$$
21.0
$$

$10 \quad 0.818339996$

90.826469995

$8 \quad 0.832629994$

0.841129996

0.850379996

0.860560000

0.872139999

0.884469993

0.899409994

0.916779995

0.933969997

0.866934516
38.5

0.818289995 0.825629994 0.833449997 0.842009799

0.851339996

0.861879997 0.873359943 0.886449993 0.961899995 $0.922 C 39993$

0.941429995 0.868888147
$5 c .2$

0.821289994 0.828589998 0.836080000 0.844799995

0.854099996

0.864234998 0.875719994 0.888799995 0.904639997

0.926729 .999

0.948259994 0.872113600
64.0

0.822489999 0.829959996 0.838280000 0.847169995 0.856539994

0.866969995 0.878639996 0.892309994 0.909529999

0.933440000

0.956389993 0.875610881
81.5

$A \vee G$

0.823599994 0.830739997 0.838280000 $0.84708000 \mathrm{C}$ 0.856359996

0.866799995 0.879369996 0.894359998 0.913599998 0.940769993

0.966769993 0.877975419
0.820801981 0.828277975 0.835743986 0.844437987 0.853743978

0.864089988 0.875845976 C. 889277980 0.905813977 0.927951992

0.949363977 0.872304499

LMOOEL $\quad-0$

\begin{tabular}{llcl} 
& \multicolumn{1}{l}{ A } & \\
10 & 0.820801981 & 0.51668030 & 4 \\
9 & 0.828277975 & 0.45763269 & 3 \\
8 & 0.835743986 & 0.56575614 & 2 \\
7 & 0.844437987 & 0.59856942 & 1 \\
6 & 0.853743978 & 0.60197268 & 0 \\
5 & 0.864089988 & 0.61487932 & \\
& & & $C$ \\
21.0 & -0.005369984 & 64.0 & 0.003306381 \\
38.5 & -0.003416352 & 81.5 & 0.005670920
\end{tabular}

$A$

0.875845976

0.839277980

0.905813977

0.927951992

0.949363977

0.68988606 0.89047448 1.24970494 2.04841876 2.77372935 TABLE OF OEVIATIONS

21.0

38.5

$0.312582 E-C 3-0.746824 E-03$ $0.649504 \mathrm{E}-03-0.108454 \mathrm{E}-02$ $-0.758842 E-04-C .361167 E-03$ $-0.936761 E-04-C .383057 E-03$ $-0.131398 E-03-0.347428 E-03$

$-0.228092 E-03-C .109345 E-03$ $-0.129040 \mathrm{E}-05-0.129089 \mathrm{E}-03$ $-0.129640 \mathrm{E}-05$

$-0.261515 \mathrm{E}-04$

$0.306919 E-03$

C. $345454 E-03-0.935413 E-03-0.415973 E-03$

$0.108612 E-02-0.830948 E-03-0.128485 E-02$

$-0.499092 \mathrm{E}-\mathrm{C3}$

C. $154205 \mathrm{E}-02$

$-0.574477 E-03-C .214498 E-C 2$

$0.910076 \mathrm{E}-05$
64.0

81.5

SUM SO 
SPECIFIC VOLUME OF RUB8ER - HEIR

REVERS - 0

SPECIFIC VOLUME OF RUB8ER - WEIR

LMODEL $\quad-0$

$\begin{array}{lll} & \text { A } & 8 \\ 21.0 & 0.866934516 & 0.90821072 \\ 38.5 & 0.868888147 & 0.96198194 \\ 50.2 & 0.872113600 & 0.98464904\end{array}$

$c$

$-0.051502518$

$-0.044026524$

$-0.036560513$

$-0.027866513$

$-0.018560521$

$-0.008214511$

ANALYSIS OF VARIANCE

oF

SS

$$
\begin{aligned}
& 4 \\
& 3 \\
& 2 \\
& 1 \\
& 0
\end{aligned}
$$$$
c
$$

0.003541477

0.016973481

0.033509478

0.055647492

0.077059478

41.9396214

$\begin{array}{lrr}\text { TOTAL } & 55 & 41.9396214 \\ \text { MEAN } & 1 & 41.8503323 \\ \text { ROYS } & 4 & 0.000910990\end{array}$

ROHS 40.000919990

$\begin{array}{lll}\text { COLS } & 10 & 0.087871805\end{array}$

0.000494681

0.000494681084

0.000410840

0.000391461

$\stackrel{\text { C }}{\mathrm{NC}}$

RESIO

MS

\subsection{2}

0.008787177

$0.123672 \mathrm{E}-04$

0.000102706

0.00039146

$\begin{array}{rll}3 & 0.193813 E-04 & 0.646044 E-05 \\ 36 & 0.838441 E-04 & 0.232900 E-05\end{array}$

Table 2d

\begin{tabular}{lll} 
& \multicolumn{1}{l}{ A } & \multicolumn{1}{l}{8} \\
64.0 & 0.875610881 & 1.03570965 \\
81.5 & 0.877975419 & 1.10952595
\end{tabular}

\section{F}

98.7544155

3772.93661

5.31006300

44.1007395

60.5937004

2.77390614

5 ROWS 11 COLUMNS

SPECIFIC VOLUME OF RU8BER - WEIR

Table $2 e$

TABLE OF OEVIATIONS
9

8

7

$21.0 \quad-0.181938 \mathrm{E}-02-0.479154 \mathrm{E}-03-0.109987 \mathrm{E}-02-0.495851 \mathrm{E}-03$

$50.2-0.111699 \mathrm{E}-03-0.172928 \mathrm{E}-03-0.343248 \mathrm{E}-04$

$64.0 \quad 0.220776 \mathrm{E}-03-0.521839 \mathrm{E}-04 \quad 0.535198 \mathrm{E}-03$

$81.5 \quad 0.276796 \mathrm{E}-02 \quad 0.161316 \mathrm{E}-02 \quad 0.869423 \mathrm{E}-03$

.

$\begin{array}{rlrrr}0.125133 \mathrm{E}-03 & 0.262000 \mathrm{E}-03 & 0.214815 \mathrm{E}-03 & 0.119284 \mathrm{E}-03 & -0.265241 \mathrm{E}-04 \\ 0.420734 \mathrm{E}-03 & 0.152431 \mathrm{E}-03 & -0.133030 \mathrm{E}-03 & -0.638820 \mathrm{E}-03 & -0.0380480 \mathrm{E}-03\end{array}$

$0.232011 \mathrm{E}-04-0.102204 \mathrm{E}-02-0.206121 \mathrm{E}-02-0.253478 \mathrm{E}-02-0.244793 \mathrm{E}-02$
-0.02

SUM SQ

$0.368429 E-05$

$0.232483 E-05 \quad 0.444132 E-06$

$0.132195 \mathrm{E}-05$

SPECIFIC VOLUME OF RU88ER - WEIR

TABLE OF OEVIATIONS

$$
2
$$

1

0

SUM SQ

$\begin{array}{lrrrr}21.0 & 0.204182 \mathrm{E}-02 & -0.694163 \mathrm{E}-03 & -0.295076 \mathrm{E}-02 & 0.280748 \mathrm{E}-04 \\ 38.5 & 0.766337 \mathrm{E}-03 & -0.380032 \mathrm{E}-03 & -0.158797 \mathrm{E}-02 & 0.880963 \mathrm{E}-05 \\ 50.2 & -0.468679 \mathrm{E}-03 & -0.176847 \mathrm{E}-03 & 0.269860 \mathrm{E}-03 & 0.512698 \mathrm{E}-06 \\ 64.0 & -0.786968 \mathrm{E}-03 & 0.194475 \mathrm{E}-03 & 0.967875 \mathrm{E}-03 & 0.333311 \mathrm{E}-05 \\ 81.5 & -0.155506 \mathrm{E}-02 & 0.105224 \mathrm{E}-02 & 0.329509 \mathrm{E}-02 & 0.431139 \mathrm{E}-04 \\ \text { SUM SQ } & 0.801346 \mathrm{E}-05 & 0.180259 \mathrm{E}-05 & 0.230958 \mathrm{E}-04 & 0.838441 \mathrm{E}-04\end{array}$

SPECIFIC VOLUME OF RU88ER - WEIR

STOP $-0$ 
Table 3. Computer Input With Replicate Values In Each Cell

02 ISO NATURAL RUBBFR TEST
LABO9 MAT 145
$\angle A B \cap 9$ MAT245
LABO9 MAT345
LABO9 MAT445
LABO9 MAT545
LABO9 MAT645
LABO9 MAT745
LABO9 MAT 845
LAB 10 MAT 145
LAB 10 MAT 245
LAB IO MAT345
LAB 10 MAT 445
LAB 10 MAT 545
LAB10 MAT 645
LAB 10 MAT 745
LAB 10 MAT 845
LAB 11 MAT 145
LAB 11 MAT 245
LAB 11 MAT 345
LAB 11 MAT445
LAB 11 MAT545
$L A B I 1$ MAT645
LAR 11 MAT745
LAB 11 MAT845
LAB 12 MAT 145
LAB 12 MAT245
LAB 12 MAT345
LAB 12 MAT 445
LAB 12 MAT545
LAB 12 MAT645
LAB 12 MAT745
LAB 12 MAT 845
$L A B 21$ MAT 145
LAB2 I MAT245
LAB 21 MAT345
LAB2 1 MAT445
LAB 21 MAT545
LAB2 1 MAT645
LAB 21 MAT745
LAB2 1 MAT 845
LAB22 MAT145
LAB22 MAT245
LAB2 2 MAT345
LAB22 MAT 445
LAB 22 MAT545
LAB22 MAT 645
LAB22 MAT745
LAB 22 MAT 845

6.93

8.86

4.26

$6 \cdot 48$

5.17

4. 58

4.37

5.50

6.96

9.13

4.39

6.32

5.13

4.58

4.48

5.55

6.81

9.12

$4 \cdot 32$

6.29

5.15

4. 50

4.44

5.51

6.82

8.57

4.41

6.46

5.13

4.48

4.20

5.52

6.99

8.03

4.29

6.44

4.95

4.57

6.61

5.58

6.91

8.75

4.45

6.46

5.02

4.53

4.89

5.41
STRESS AT $100 \quad 40$

6.78

8.76

4. 24

6.46

5.82

4.56

4. 38

5.47

6. 81

9.09

4.40

6.42

5.12

4. 57

4. 51

5.55

6.94

9.29

4.37

6. 30

5. 12

4. 55

4. 41

5.54

6.82

8.61

4. 37

6.41

5.11

4.46

$4 \cdot 16$

5.48

7.14

8.80

4.37

6.43

5.12

4.59

6.21

5. 54

7.10

8.82

4.49

6.47

5.21

4.50

4.72

5.48 
Table 3. Computer Input with Replicate Values in Each Cell (Cont.)

\begin{tabular}{|c|c|c|c|}
\hline LAB 23 & MATI 45 & 7.09 & 7.14 \\
\hline$\angle A B 23$ & MAT 245 & 8.40 & 8.46 \\
\hline$\angle A B 23$ & MAT 345 & $4 \cdot 34$ & $4 \cdot 35$ \\
\hline$\angle A B 23$ & MAT 445 & $6 \cdot 35$ & 6.19 \\
\hline$\angle A B 23$ & MAT 545 & 5.16 & $5 \cdot 18$ \\
\hline$\angle A B 23$ & MAT 645 & $4 \cdot 45$ & $4 \cdot 40$ \\
\hline$\angle A B 23$ & MAT 745 & 4.83 & $4 \cdot 82$ \\
\hline LAB 23 & MAT 845 & $5 \cdot 52$ & $5 \cdot 47$ \\
\hline LAB 24 & MAT 145 & $7 \cdot 18$ & 7.81 \\
\hline$\angle A B 24$ & MAT 245 & 8.83 & 8.87 \\
\hline $\operatorname{LAB} 24$ & MAT 345 & $4 \cdot 45$ & 4.45 \\
\hline$\angle A B 24$ & MAT 445 & 6.51 & 6.46 \\
\hline$\angle A B 24$ & MAT 545 & 5.44 & $5 \cdot 26$ \\
\hline$\angle A B 24$ & MAT 645 & 4.61 & 4.64 \\
\hline LAB 24 & MAT 745 & 6.82 & 6.62 \\
\hline$\angle A B 24$ & MAT 845 & 5.56 & 5.67 \\
\hline LAB 57 & MAT 145 & 6.97 & 6.97 \\
\hline$\angle A B 57$ & MAT 245 & 9.29 & 9.25 \\
\hline LAB 57 & MAT 345 & 4.51 & $4 \cdot 54$ \\
\hline LAB 57 & MAT 445 & 6.61 & 6.67 \\
\hline LAB 57 & MAT 545 & $5 \cdot 24$ & 5.29 \\
\hline$\angle A B 57$ & MAT 645 & 4.77 & 4.79 \\
\hline LAB 57 & MAT 745 & 7.60 & 7.51 \\
\hline$\angle A B 57$ & MAT 845 & 5.85 & 5.88 \\
\hline LAB 58 & MAT 145 & 7.14 & 7.14 \\
\hline LAB 58 & MAT 245 & 9.37 & 9.28 \\
\hline LAB 58 & MAT 345 & $4 \cdot 60$ & 4.57 \\
\hline LAB 58 & MAT 445 & 6.72 & 6.64 \\
\hline LAB 58 & MAT 545 & $5 \cdot 31$ & $5 \cdot 37$ \\
\hline LAB 58 & MAT 645 & $4 \cdot 86$ & 4.85 \\
\hline LAB 58 & MAT 745 & 8.41 & 8.34 \\
\hline LAB 58 & MAT 845 & 6.02 & 5.86 \\
\hline LAB 59 & MAT 145 & 7.11 & $7 \cdot 14$ \\
\hline LAB 59 & MAT 245 & 9.70 & 9.68 \\
\hline LAB 59 & MAT 345 & 4.67 & 4.61 \\
\hline LAB 59 & MAT 445 & 6.76 & 6.71 \\
\hline LAB 59 & MAT 545 & $5 \cdot 41$ & 5.37 \\
\hline LAB59 & MAT 645 & $4 \cdot 94$ & 4.84 \\
\hline LAB 59 & MAT 745 & $8 \cdot 32$ & $8 \cdot 32$ \\
\hline LAB 59 & MAT 845 & 5.90 & $5 \cdot 99$ \\
\hline LAB60 & MAT 145 & 7.04 & $7 \cdot 06$ \\
\hline LAB 60 & MAT 245 & 9.16 & 9.21 \\
\hline$\angle A B 60$ & MAT345 & 4.63 & 4.59 \\
\hline LAB 60 & MAT 445 & 6.74 & 6.76 \\
\hline$\angle A B 60$ & MAT 545 & $5 \cdot 43$ & $5 \cdot 39$ \\
\hline$\angle A B 60$ & MAT 645 & $4 \cdot 78$ & 4.78 \\
\hline$\angle A B 60$ & MAT 745 & $8 \cdot 28$ & $8 \cdot 22$ \\
\hline$\angle A B 60$ & MAT 845 & 5.88 & 5.99 \\
\hline LAB6 I & MAT 145 & 6.90 & 6.95 \\
\hline$\angle A B 6 I$ & MAT 245 & $9: 59$ & 9.90 \\
\hline$\angle A B 61$ & MAT 345 & $4 \cdot 97$ & 5.06 \\
\hline LAB6 1 & MAT 445 & 6.91 & 6.88 \\
\hline
\end{tabular}


Table 3. Computer Input With Replicate Values in tach Cell (Cont.)

\begin{tabular}{|c|c|c|c|}
\hline LAB 61 & MAT 545 & 5.42 & 5.37 \\
\hline LAB 61 & MAT 645 & 4.92 & 5.12 \\
\hline$L A B 61$ & MAT 745 & $4 \cdot 47$ & $4 \cdot 42$ \\
\hline$L A B 61$ & MAT 845 & 5.73 & 5.65 \\
\hline LAB 62 & MAT 145 & $7 \cdot 14$ & 7.07 \\
\hline$\angle A B 62$ & MAT 245 & 9.33 & 9.65 \\
\hline $\operatorname{LAB} 62$ & MAT 345 & 4.92 & 5.13 \\
\hline LAB 62 & MAT 445 & 6.51 & 6.50 \\
\hline$\angle A B 62$ & MAT 545 & $5 \cdot 44$ & 5.37 \\
\hline$\angle A B 62$ & MAT 645 & 5.07 & 5.12 \\
\hline$\angle A B 62$ & MAT745 & $7 \cdot 34$ & 7.25 \\
\hline$\angle A B 62$ & MAT 845 & 6.01 & 6.13 \\
\hline LAB63 & MAT 145 & $7 \cdot 20$ & 7.16 \\
\hline LAB63 & MAT 245 & 9.77 & 10.07 \\
\hline $\operatorname{LAB} 63$ & MAT 345 & 4.59 & 4.57 \\
\hline LAB 63 & MAT 445 & 6.02 & 6.20 \\
\hline LAB 63 & MAT545 & 5.27 & 5.20 \\
\hline$L A B 63$ & MAT 645 & 4.99 & 5.17 \\
\hline LAB63 & MAT 745 & 6.53 & 6.46 \\
\hline LAB 63 & MAT 845 & 5.80 & 5.90 \\
\hline LAB 64 & MAT 145 & 7.09 & 7.01 \\
\hline LAB 64 & MAT 245 & 9.20 & 9.26 \\
\hline $\operatorname{LAB} 64$ & MAT345 & $4 \cdot 16$ & $4 \cdot 35$ \\
\hline $\operatorname{LAB} 64$ & MAT445 & 6.28 & 6.29 \\
\hline LAB 64 & MAT 545 & 5.26 & 5.16 \\
\hline $\operatorname{LAB} 64$ & MAT 645 & $4 \cdot 84$ & 4.88 \\
\hline LAB 64 & MAT 745 & $7 \cdot 54$ & 7.72 \\
\hline$\angle A B 64$ & MAT 845 & 5.91 & 5.94 \\
\hline LAB 69 & MAT 145 & $7 \cdot 16$ & $7 \cdot 14$ \\
\hline$\angle A B 69$ & MAT 245 & 8.85 & 8.89 \\
\hline$\angle A B 69$ & MAT 345 & $4 \cdot 5$ & $4 \cdot 42$ \\
\hline$\angle A B 69$ & MAT 445 & $6 \cdot 56$ & 6.64 \\
\hline LAB 69 & MAT 545 & $5 \cdot 34$ & 5.39 \\
\hline$\angle A B 69$ & MAT645 & 4.77 & 4.73 \\
\hline LAB69 & MAT 745 & $7 \cdot 39$ & $7 \cdot 43$ \\
\hline $\operatorname{LAB69}$ & MAT 845 & 5.72 & 5.83 \\
\hline$\angle A B 70$ & MAT 145 & 7.13 & 7.15 \\
\hline$L A B 70$ & MAT 245 & 9.16 & 9.81 \\
\hline$\angle A B 70$ & MAT 345 & $4 \cdot 73$ & 4.68 \\
\hline$\angle A B 70$ & MAT 445 & 6.82 & 6.87 \\
\hline$\angle A B 70$ & MAT 545 & $5 \cdot 58$ & $5 \cdot 48$ \\
\hline LAB 70 & MAT 645 & 5.05 & 5.05 \\
\hline$\angle A B 70$ & MAT 745 & 7.64 & 7.59 \\
\hline$\angle A B 70$ & MAT 845 & $5 \cdot 81$ & 5.77 \\
\hline LAB 71 & MAT 145 & 7.03 & 7.03 \\
\hline$L A B 71$ & MAT 245 & $9 \cdot 34$ & 9.29 \\
\hline$L A B 71$ & MAT 345 & 4.46 & 4.47 \\
\hline LAB 71 & MAT 445 & 6.61 & $6 \cdot 66$ \\
\hline$L A B 71$ & MAT 545 & $5 \cdot 28$ & 5.23 \\
\hline$\angle A B 71$ & MAT 645 & $4 \cdot 83$ & 4.83 \\
\hline$L A B 71$ & MAT 745 & 7.51 & 7.52 \\
\hline$L A B 71$ & MAT 845 & 5.84 & 5.79 \\
\hline
\end{tabular}


Table 3. Computer Input With Replicate Values in Each Cell (Cont.)

\begin{tabular}{|c|c|c|c|}
\hline$\angle A B 72$ & MAT 145 & 7.17 & 7.10 \\
\hline$\angle A B 72$ & MAT 245 & $9 \cdot 22$ & 9.14 \\
\hline$\angle A B 72$ & MAT 345 & 4.47 & 4.47 \\
\hline$\angle A B 72$ & MAT 445 & 6.62 & 6.67 \\
\hline$\angle A B 72$ & MAT 545 & 5.48 & $5 \cdot 5$ \\
\hline LAR7 2 & MAT 645 & 4.76 & 4.86 \\
\hline LAB 7? & MAT 745 & $6 \cdot 94$ & 7.05 \\
\hline$L A B 72$ & MAT 845 & 5.86 & 5.72 \\
\hline LAB 85 & MAT 145 & 7.0 & 7.0 \\
\hline LAB 85 & MAT 245 & $8 \cdot 8$ & 8.7 \\
\hline LAB 85 & MAT 345 & $4 \cdot 5$ & $4 \cdot 5$ \\
\hline LAB 85 & MAT 445 & 6.6 & 6.7 \\
\hline LAB 85 & MAT 545 & $4 \cdot 9$ & $5 \cdot 3$ \\
\hline$\angle A B 85$ & MAT 645 & $4 \cdot 5$ & $4 \cdot 5$ \\
\hline LAB 85 & MAT 745 & $4 \cdot 8$ & $5 \cdot 0$ \\
\hline LAB 85 & MAT 845 & 5.7 & 5.7 \\
\hline LAB 86 & MAT 145 & $7 \cdot 0$ & 7.0 \\
\hline LAB 86 & MAT 245 & $8 \cdot 7$ & 8.9 \\
\hline LAB 86 & MAT 345 & $4 \cdot 4$ & $4 \cdot 5$ \\
\hline LAB 86 & MAT 445 & $6 \cdot 6$ & 6.6 \\
\hline LAB 86 & MAT 545 & $5 \cdot 3$ & $5 \cdot 3$ \\
\hline$\angle A B 86$ & MAT 645 & $4 \cdot 6$ & 4.7 \\
\hline LAB 86 & MAT 745 & $4 \cdot 5$ & 4.7 \\
\hline$\angle A B 86$ & MAT 845 & $5 \cdot 9$ & 5.9 \\
\hline LAB 87 & MAT 145 & 7.0 & $7 \cdot 1$ \\
\hline LAB 87 & MAT 245 & $9 \cdot 0$ & 9.1 \\
\hline$\angle A B 87$ & MAT 345 & 4.4 & $4 \cdot 5$ \\
\hline LAB 87 & MAT 445 & 6.5 & 6.6 \\
\hline LAB 87 & MAT 545 & $4 \cdot 9$ & 5.0 \\
\hline$\angle A B 87$ & MAT645 & $4 \cdot 5$ & $4 \cdot 6$ \\
\hline$\angle A B 87$ & MAT 745 & 5.0 & $5 \cdot 2$ \\
\hline$\angle A B 87$ & MAT 845 & 5.6 & 5.7 \\
\hline LAB 88 & MAT 145 & 7.0 & 7.0 \\
\hline LAB 88 & MAT 245 & $9 \cdot 2$ & 9.2 \\
\hline LAB 88 & MAT 345 & $4 \cdot 5$ & $4 \cdot 5$ \\
\hline LAB 88 & MAT 445 & 6.7 & 6.8 \\
\hline LAB 88 & MAT545 & $5 \cdot 1$ & $5 \cdot 2$ \\
\hline LAB 88 & MAT 645 & $4 \cdot 8$ & $4 \cdot 8$ \\
\hline LAB 88 & MAT 745 & $5 \cdot 1$ & $5 \cdot 3$ \\
\hline LAB 88 & MAT 845 & 5.7 & 5.8 \\
\hline
\end{tabular}

ENDATA

COMB INROWS

COMB INROWS

LABO9

LAB 21

$L A B I 0$

LAB I 1

$\operatorname{LAB} 12$

$\angle A B O I$

LAB 57

$L A B 22$

$L A B 23$

$L A B 24$

$\angle A B O 2$

$\operatorname{LAB} 58$

$\angle A B 59$

$L A B 60$

$\angle A B O 3$

COMBINROWS

$L A B 62$

LAB 63

$L A B 64$

$\angle A B O 4$

$\operatorname{LAB} 69$

COMBINROWS

$L A B 70$

$L A B 71$

$L A B 72$

$\angle A B O 5$

LAB 85

LAB 87

LAB 88

LABO6

L.MWCOLCAL

QMODEL

OMIT

OIMAT 745

QMODEL

STOP 
TABLE OF AVERAGES

\begin{tabular}{|c|c|}
\hline & MAT 345 \\
\hline $\begin{array}{l}\text { LAB } 12 \\
\text { LAB } 23\end{array}$ & $\begin{array}{l}4.38999993 \\
4.34499997\end{array}$ \\
\hline LABO9. & 4.24999994 \\
\hline LAB 11 & 4.34499997 \\
\hline LAB 10 & 4.39499998 \\
\hline$\angle A B 22$ & 4.46999997 \\
\hline $\begin{array}{l}\text { LAB B } 5 \\
\text { LAB B6 }\end{array}$ & $\begin{array}{l}4.50000000 \\
4.44999999\end{array}$ \\
\hline $\begin{array}{l}\angle A B 87 \\
\angle A B 21\end{array}$ & $\begin{array}{l}4.44999999 \\
4.32999992\end{array}$ \\
\hline$\angle A B Q B$ & 4.50000000 \\
\hline LAB 61 & 5.01499993 \\
\hline LAB 24 & 4.44999999 \\
\hline LAB 69 & 4.45999998 \\
\hline LAB 64 & 4.25499994 \\
\hline $\begin{array}{l}\text { LAB } 63 \\
\text { LAB72 }\end{array}$ & $\begin{array}{l}4.57999998 \\
4.46999997\end{array}$ \\
\hline LAB 71 & 4.46499997 \\
\hline$\angle A B 57$ & 4.52499998 \\
\hline LAB 60 & 4.60999995 \\
\hline$\angle A B 62$ & 5.02499998 \\
\hline$\angle A B 70$ & 4.70499992 \\
\hline$\angle A B 58$ & 4.58499998 \\
\hline LABS9 & 4.63999993 \\
\hline AVG & 4.50874972 \\
\hline
\end{tabular}

MAT 645

4.46999997 4.42499995 4.4249995 4.56999993 99998 4.57499999

4.51499999 4.50000000 4. 64999998 4.54999995 4.57999998

4.79999995 5.01999992 4.62499994 4. 74999994 4.85999995

5.07999992 4.80999994 4.82999998 4.77999997 4.77999997

\subsection{7} 5.04999995 4.85499996 4. 88999999 4.73270798
MAT 545

5.11999995 5. 16999996 5.49499995 5.13499993 5.13499993
5.12499994

5. 11499995 5.09999996 5.29999995 4.94999999 5. 03499997

5. 14999998 5. 39499992 5.34999996

5. 36499995

5.20999998

5.23499995 5.48999995 5.25499994 5.26499993 5.40999997

5.40499997 5.52999997 5.33999991

5. 38999993

5.26395798
MAT845

5.49999994 5. 49499995 5.48499995 5.52499998 5. 54999995

5.44499993 5.69999999 5. 89999998 5.64999998 5.55999994

5.74999994 5.68999994 5.61499995 5.77499998 5.92499995

5. 84999996 5. 78999996 5.81499994 5.86499995 5.93499994

6.06999999 5.78999996 5.93999994 5. 94499993

5.73187459
MAT 745

4.17999995 4.82499999 4.37499994 4.42499995 4. 49499995

4.80499995 4.89999998 4.59999996 5.09999996 6.40999997

5.19999993 4.44499993 6.71999997 7.40999997 7.62999994

6.49499995 6.99499995 7.51499999 7.55499995

8. 24999988

\section{29499996} 7.61499995 8. 37499988 8.31999993 6.16395783
MAT445

MAT 145

6.43499994 6.26999998 6.46999997 6.29499996 6.36999995

6.46499997 6.64999998 6. 59999996 6.54999995 6.43499994

6.74999994 6.89499998 6.48499995 6.59999996 6.28499997

6.10999995 6.64499992 6.63499993 6.63999993

6.74999994

6.50500000 6.84499997 6.67999995 6.73499995 6.54583275
6. 81999999 7.11499995 6.85499996 6.87499994 6. 88499993

7.00499994 7.00000000 7. 00000000 7.04999995 7.06499994

7. 00000000 6.92499995 7.49499995 7.14999998 7.04999995

7.17999995 7.13499993 7.02999997 6.96999997 7. 04999995

7.10499996 7.13999999 7.13999999 7.12499994 7.04854119
MAT 245

8.58999991 8.42999995 8. 80999994 9.20499992 9.10999990

8.78499997 8.74999988 8.79999995 9.04999995 8.41499996

9.19999993 9.74499989 8.84999990 8.86999989

9.22999990

9.91999996 9.17999995 9.31499994 9.26999998 9.18499994

9.48999989 9.48499990 9.32499993 9.68999994 9.11249936

ISO NATURAL RUBBER TEST STRESS AT 10040

TABLE OF AVERAGES

AVG

$\begin{array}{ll}\text { LAB 12 } & 5.68812484 \\ \text { LAB23 } & 5.75937486 \\ \text { LAB 09 } & 5.78874981 \\ \text { LAB 11 } & 5.79124975 \\ \text { LAB 10 } & 5.81312484 \\ & \\ \text { LAB22 } & 5.82562482 \\ \text { LAB B5 } & 5.88749987 \\ \text { LAB 86 } & 5.91249985 \\ \text { LAB87 } & 5.91874981 \\ \text { LAB 21 } & 5.97874987 \\ \text { LAB B8 } & 6.04374981 \\ \text { LAB61 } & 6.14124978 \\ \text { LAB24 } & 6.19874978 \\ \text { LAB69 } & 6.29749978 \\ \text { LAB64 } & 6.30562478 \\ \text { LAB63 } & 6.30624992 \\ \text { LAB 72 } & 6.31437486 \\ \text { LAB71 } & 6.35749984 \\ \text { LAB57 } & 6.35874981 \\ \text { LAB60 } & 6.49624979 \\ & \\ \text { LAB62 } & 6.49874979 \\ \text { LAB70 } & 6.51999986 \\ \text { LAB58 } & 6.52999973 \\ \text { LAB59 } & 6.59187484 \\ \text { AVG } & 6.13851511\end{array}$


ISO NATURAL RUBBER TEST

STRESS AT $100 \quad 40$

TABLE OF STANOARO OEVIATIONS

MAT 345

0.028284281 0.028284281 0.007071055 0.014142163 0.035355300

0.028284244

0.070710689 0.070710689 0.070710689
0.056568526

0 . 0.063639589 0 .

0.056568570 0.134350285

0.014142118 0 .

0.007071055 0.02121318 0.028284281

0.148492448 0.035355344 0.021213181 0.042426407 0.037123099
NAT645

MAT 545

$0.014142118 \quad 0.014142163$ $0.035355344 \quad 0.014142118$ $0.014142163 \quad 0.459619425$ $0.035355300 \quad 0.021213219$ 0.007071055 0.007071100

0.021213181

0.070710689 0.070710652 0.014142118

0.

0.141421340 0.021213219

0.028284281

0.028284281

0.127279222 0.070710652 0 .

0.014142118 0 .

0.035355300

0.

0.007071055 0.070710689 0.034471445
0.134350285 0.282842688 0 .

0.070710689 0.120208122

0.070710689 0.035355344 0.127279222 0.035355344 0.070710689

0.049497463 0.014142163 0.035355344 0.035355344 0.028284244

0.049497508 0.070710689 0.07071068 028284281 0.028284281
0.075719349
MAT 845

0.028284281 0.035355344 0.021213219 0.02121318

0.049497463 0 .

0.070710689 0.070710689
0.028284281

0.070710652 0.056568526 0.077781752 0.077781752 0.021213219

0.070710689 0.098994933 0.035355344 0.021213219 0.077781707

0.084852815 0.028284244 0.113137096 0.063639589 0.048024334
STRESS AT $100 \quad 40$

I SO NATURAL RUBBER TEST

MAT 745

0.028284281 0.007071055 0.007071100 0.021213219 0.021213219

0.120208159 0.141421385 0.141421340 0.141421340 0.282842688

0.141421340 0.035355344 0.141421385 0.028284244 0.127279222

0.049497463 0.077781707 0.007071055 0.063639589 0.042426445

0.063639589 0.035355344 0.049497508

$0.07395158 \mathrm{C}$
MAT 445

MAT145

0.035355344 0.113137059 0.014142118 0.007071055

0.007071055 0.070710689

0.070710652 C. 007071100

0.070710652 0.021213181

0.035355344 0.056568570 0.007071055

c. 127279222 0.035355344 0.035355344 0.042426407 0.014142163

0.007071055 0.035355300 0.056568526 0.035355344 0.040658630
0 .

0.035355344 0.106065996 0.091923915 0.106066041

0.134350285 0.

0.070710652 0.106066041

0 . 0.035355344 0.445477262 0.014142118 0.056568526

0.028284281 0.049497463 0 . 0.014142118

0.049497463 0.014142118 0.

0.021213219 0.057452418
MAT 245

0.028284244 0.042426363 0.070710607 0.120208204 0.028284326

0.049497426 0.070710689 0.141421385 0.070710607 0.544472203

0.219203144 0.028284244 0.028284326 0.042426445

0.212131999 0.056568488 0.035355300 0.028284244 0.035355300

0.226274200 0.459619388 0.063639544 0.014142118 0.109012276

TABLE OF STANOARO OEVIATIONS

AVG

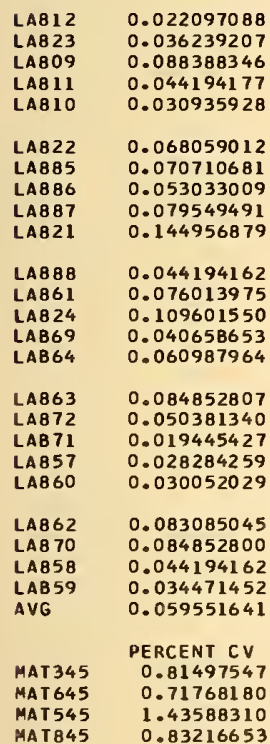

PERCENT CV 1.27107066 0.62585288 0.80329586

1.19633342
MAT 745 MAT 445

MAT 145

MAT245 
ISO NATURAL RUBBER IEST

STRESS AT $100 \quad 40$

$\begin{array}{rrrlll}\text { COMBINROWS } & - \text { OLAB09 } & \text { LAB1C } & \text { LAB11 } & \text { LAB12 } & \text { LAB01 } \\ \text { ROWS } & \text { LA821 } & \text { LA822 } & \text { LA823 } & \text { LAB24 } & \text { LA802 } \\ \text { ROWS } & \text { LAB57 } & \text { LAE58 } & \text { LA859 } & \text { LAB60 } & \text { LA803 } \\ \text { ROWS } & \text { LAB61 } & \text { LAE62 } & \text { LAB63 } & \text { LA864 } & \text { LABO4 } \\ \text { ROWS } & \text { LAB69 } & \text { LAE70 } & \text { LA871 } & \text { LAB72 } & \text { LA805 } \\ \text { ROWS } & \text { LABB5 } & \text { LAEB6 } & \text { LA887 } & \text { LA888 } & \text { LA806 }\end{array}$

Table $4 \mathrm{~d}$

6 ROWS

8 COLUMNS

ISO NATURAL RU88ER TEST STRESS AT $100 \quad 40$

TABLE OF AVERAGES

MAT 345

MAT 645

MAT545

\subsection{1 \\ 4.39874989 \\ 4.47499996 \\ 4.71874988 \\ 4.52499992}

4. 53499991

4.53624994

4.62499994

5.01374990

4. B5 999990

5.21874988

5. 16749990

5.12499994

5.31124985

5.40999985

LA803

4.5B999991

4.82624996

5. 35124987

$4.50 B 74984$

$4.73270 \mathrm{~B} 22$

STRESS AT $100 \quad 40$

ISO NATURAL RU88ER TEST

TABLE OF AVERAGES

AVG

$\begin{array}{ll}\text { LABO1 } & 5.77031231 \\ \text { LABO2 } & 5.940624 B 3 \\ \text { LABO6 } & 5.940624 B 3 \\ \text { LABO4 } & 6.31296849 \\ \text { LABO5 } & 6.37234348 \\ \text { LA803 } & 6.49421853 \\ \text { AVG } & 6.13851535\end{array}$

MATB 45

5.51499987

$5.528749 B B$

5.7499998

$5.8 B 374990$

5.79249996

5.92124993

5.73187476
MAT 745

4. $36 B 74992$

$5.6899998 \mathrm{~B}$

4.94999993

$6.466249 \mathrm{BE}$

$7.3837499 \mathrm{C}$

B. 12499988

$6.16395 B 13$
MA T445

MAT 145

MAT 245

6.39249992 6.41374993

$6.637499 \mathrm{B7}$

$6.44 B 74990$

$6.6 B 1249 B 6$

6.85874993

7.16999990

7.01249999

7.06499994

7.11374992

\subsection{4}

7.07124990

7.04854143
8.92874992 8.61999989 $8.949999 B 1$ 9.59624982 $9.212499 \mathrm{~B} 6$

9. 36749983 9.11249971
Table $4 e$

ISO NATURAL RU88ER TEST STRESS AT 10040
LMWCOLCAL -0

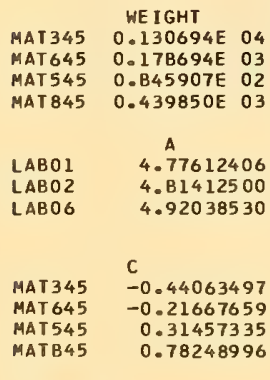

ALPHA $=$

POINT OF CONCURRENCE =

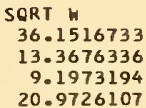

$0.9 B 501815$

0.98501815

1.02875741
MAT 745

MAT 445

MAT 145

MAT 245 D. 575277 E 00 $0.904790 E^{02}$ 0.294502 E 02 $0 . B B 5176 E$ OI

$$
\text { B STAR }
$$

1.00000301

1.00000304

1.00000310

C

\begin{tabular}{lr} 
MAT745 & \multicolumn{1}{c}{ C 1.21457332} \\
MAT445 & 1.59644830 \\
MAT145 & 2.09915662 \\
MAT245 & 4.16311491
\end{tabular}

$0.632179 E-06$

$-1581831.50$
SQRT

$0.75 B 4704$

9.5120463

5.4268070

2.9751900

A

5.1324415B

4.99554825

$5.0576 \mathrm{~B} 50 \mathrm{~B}$
B

0.93052941

1.03660026

1. 04903851
B STAR

1. 00000323

1.00000314

1. 00000319 
ANALYSIS OF HEIGHTEO OATA

\begin{tabular}{lrrr} 
SOURCE & OF & SS & \multicolumn{1}{c}{ MS } \\
ROWS & 5 & 206.509474 & 41.3018947 \\
COLS & 7 & 6326.78949 & 903.827065 \\
RXC & 35 & 40.9357047 & 1.16959156 \\
$\quad$ FIT & 30 & 29.8441887 & 0.994806290 \\
SLOPE & 5 & 11.0915161 & 2.21830320 \\
$\quad$ CONC & 1 & $0.939660 E-04$ & $0.939660 E-04$ \\
NONC & 4 & 11.0914221 & 2.77285552
\end{tabular}

R SQUAREO=

$\mathbf{R}=$

$0.847188 E-05$

0.002910644

Table $4 \mathrm{~g}$
6 ROHS
8 COLUMNS

ISO NATURAL RU88ER TEST

STRESS AT $100 \quad 40$

TABLE OF OEVIATIONS

\section{MAT 345}

0.105176158 0.436184779

0.286363162

$-0.132600397$

$-0.498385459$

$\begin{array}{lr}\text { LA803 } & -0.196740396 \\ \text { SUM SQ } & 0.588000752\end{array}$

ISO NATURAL RU88ER TEST

MAT 645

MAT 545

$-0.37019988$

$-0.90481069$

$-0.96885531$

1.10860850

1.10860850
1.19050403

1.22108589

0.44350605

$-1.09452666$

$-1.04767998$

0.81271965

$-0.05524824$

$-0.33510166$

4.75617659

STRESS AT $100 \quad 40$
TABLE OF OEVIATIONS

\section{SUM SQ}

LABO 1

LABO2

LA806

LABO4

LABO5

5.8483440

4.5484633

8.2887406

3.4183493

14803

SUM SQ

3.9698453

29.8441887
MAT 845

$-0.66883728$ $-0.93189596$ 0.51639310 0.48611278 $-0.29734046$

0.89558908 2.70923194

\section{MAT 745}

$-1.21639760$ $-0.22930755$ $-0.92524794$ 0.15443379 0.85644557

$1.3600744 t$
MAT445

MAT 145

0.41705905 0.48493462

0.71108788

1.60975917

0.29318916

$-0.29649965$

3.67994228
0.08095985 1.73427707 $-0.36581131$ $-0.11270709$ $-0.31358596$

$-1.02312286$ 4. 30590874
MAT 245

0.15435924 $-0.69196562$ $-0.75337961$ 1.75508659 $-0.29315839$

\section{$-0.17093369$} 4.26571304
ISO NATURAL RU88ER TEST STRESS AT 10040

QMOOEL

$\begin{array}{lc} & \text { A } \\ \text { LABO1 } & 5.77031231 \\ \text { LABO2 } & 5.94062483 \\ \text { LABO6 } & 5.94062483 \\ \text { LABO4 } & 6.31296849 \\ \text { LABO5 } & 6.37234348 \\ \text { LABO3 } & 6.49421853\end{array}$

8

0.98995132

0.94821443

0.98772637

1.03774434

1.00552733

0

0.086043470

$-0.027748495$

0.038834378

0.055445835

$-0.063444003$

1.03083800

$-0.089132071$

MAT $345 \quad$ C $\quad-1.62976551$

MAT $645 \quad-1.40580714$

MAT545 -0.87455720

E

2.77118859

1.81097460

$-0.06553726$

$-1.25081283$
AP

5.60465795

5.99404734

5.86585927

6.20622188

6.49448842

6.66581917

$c$

MAT 745

MAT 445

MAT 145

MAT 245
0.02544278

0.40731782

0.91002607

2.97398436
$8 \mathrm{P}$

0.88223404

0.98295260

0.93910985

0.96833204

1.08495247

1.14242187

E

$-1.95644450$ $-2.26925 C 99$

$-2.23634863$

$3.19623 C 44$ 
ANALYSIS OF VARIANCE

DF S5

MS

$\begin{array}{lrrr}\text { TOTAL } & 48 & 1912.73088 & \\ \text { MEAN } & 1 & 1808.70580 & \\ \text { ROHS } & 5 & 3.40423223 & 0.680846445 \\ \text { COLS } & 7 & 92.4115286 & 13.2016469 \\ \text { RXC } & 35 & 8.20929074 & 0.234551162 \\ \text { LIN } & 5 & 0.082239047 & 0.016447805 \\ \text { QUAD } & 5 & 0.907975405 & 0.181595080 \\ \text { RES } & 25 & 7.21907640 & 0.288763054\end{array}$

ISO NATURAL RU8BER TEST

STRESS AT $100 \quad 40$

TABLE OF OEVIATIONS LINEAR MODEL

MAT 345

NAT 645

\section{$\angle A B 01$}

LABO2

LABO4

LABO5

$\angle A B 03$

SUM SO
MAT 545

0.314206660 0.056142867 0.048198342 $-0.094151855$ $0.003492236 \quad-0.071368277$ $0.144137502 \quad 0.072927892$

$0.097061336 \quad 0.159649849$

$-0.098766088-0.082952440$

$-0.224194407-0.218809128$

$0.159345828 \quad 0.117983185$
$-0.241441846$

0.178240769

ISO NATURAL RU88ER TEST STRESS AT 10040

TABLE OF DEVIATIONS LINEAR NDOEL

SUM SO

$\begin{array}{ll}\text { LABO1 } & 2.34490645 \\ \text { LABO2 } & 0.24606062 \\ \text { LABO6 } & 1.22657490 \\ \text { LABO4 } & 0.21806434 \\ \text { LABO5 } & 1.12407701 \\ & \\ \text { LABO3 } & 2.96736929 \\ \text { SUM SO } & 8.12705255\end{array}$

6 ROWS

8 COLUNNS

ISO NATURAL RUBBER TEST

STRESS AT $100 \quad 40$

TABLE OF OEVIATIONS

MAT 345

$-0.050366543$ 0.080388561 0.036520094 $-0.056589536$ -0.056589536
-0.032754466

10

$$
0.022807382
$$

0.015128233
NAT 645

0.000545710 $-0.021116443$

0.002599806

0.059238844
0.016129389

-0.057393201
0.007516332

ISO NATURAL RUBBER TEST STRESS AT $100 \quad 40$

MAT 845

0.147241950 0.026292443 $-0.007229567$ $-0.170955241$

0.153788030 0.119831622

\section{MAT 745 \\ $-1.42674947$ $-0.27475011$ 0.12687832 0.98582304 \\ $1.6045540 \mathrm{C}$ 6.70539916}

MAT 445

0.218962848 C. 086900473 0.294556499 $-0.286910295$ $-0.100662768$

$-0.212847352$ C. 280014448
MAT 145

0.187556148 0.366475224 0.173018456 $-0.192342937$

$-0.173649609$

$-0.361058056$ 0.396929681
MAT245

0.214337945 $-0.140599728$ 0.071892261 0.197045922 $-0.150266170$

$-0.192414761$ 0.169307984

TABLE OF OEVIATIONS

SUM 50

$\begin{array}{ll}\text { LABO1 } & 2.07303306 \\ \text { LABO2 } & 0.21778555 \\ \text { LABO6 } & 1.17119324 \\ \text { LA804 } & 0.10517071 \\ \text { LA805 } & 0.97626529 \\ \text { LABO3 } & 2.67562920 \\ \text { SUM SO } & 7.21907705\end{array}$

MAT 845 $-0.061000615$ 0.259599246 0.062122792 $-0.250311807$

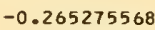
0.272956006
MAT745

$-1.25841019$ $-0.32903851$ $-0.93977804$ 0.23535502 0.86169836

1.43017203
MA T 445

0.414217077 0.023932159 0.382681459 $-0.161089770$ $-0.244633131$

$-0.415110402$ C. 576705560
MAT 145

MAT 245

$0.379979342-0.060676813$ $0.304419905-0.051909126$ $0.259865671-0.052231379$ $\begin{array}{rr}-0.068346709 & 0.019828245\end{array}$ $\begin{array}{ll}-0.315532513 & 0.052515484\end{array}$

$-0.560388446 \quad 0.092471890$
0.722853191 $0.722853191 \quad 0.020806432$ 
ISO NATURAL RUBBER TEST STRESS AT $100 \quad 40$

OMI T

IMAT 745

6 ROWS ANO 7 COLUMNS

ISO NATURAL - RUBBER TEST STRESS AT $100 \quad 40$

Table $5 a$

TABLE OF AVERAGES

$\begin{array}{lccc} & \text { MAT345 } & \text { MAT645 } & \text { MAT } 545 \\ \text { LABO1 } & 4.34499991 & 4.53499991 & 5.21874988 \\ \text { LABO2 } & 4.39874989 & 4.53624994 & 5.16749990 \\ \text { LABO6 } & 4.47499996 & 4.62499994 & 5.1249994 \\ \text { LABO5 } & 4.52499992 & 4.85999990 & 5.40999985 \\ \text { LABO3 } & 4.58999991 & 4.82624996 & 5.35124987 \\ \text { LABO4 } & 4.71874988 & 5.01374990 & 5.31124985 \\ \text { AVG } & 4.50874984 & 4.73270822 & 5.26395816\end{array}$

MAT 845
5.51499987
5.52874988
5.7499988
5.79249996
5.92124993
5.88374990
5.73187476

ISO NATURAL RUBBER TEST

STRESS AT $100 \quad 40$

$\begin{array}{cc}\text { MAT } 445 & \text { MAT145 } \\ 6.39249992 & 6.85874993 \\ 6.41374993 & 7.16999990 \\ 6.63749987 & 7.01249999 \\ 6.68124986 & 7.11374992 \\ 6.70124984 & 7.07124990 \\ & \\ 6.4487499 C & 7.06499994 \\ 6.54583311 & 7.04854143\end{array}$

6.54583311

\section{MAT 245}

8. 92874992 8.61999989 8.94999981 9.21249986

9.21249986
9.36749983

9. 59624982 9.11249971
AVG

5.97053552 5.97642833 6.08214265 6.22785687 6.26124978

6.29107118 6.13488066

QMODEL $\quad-0$

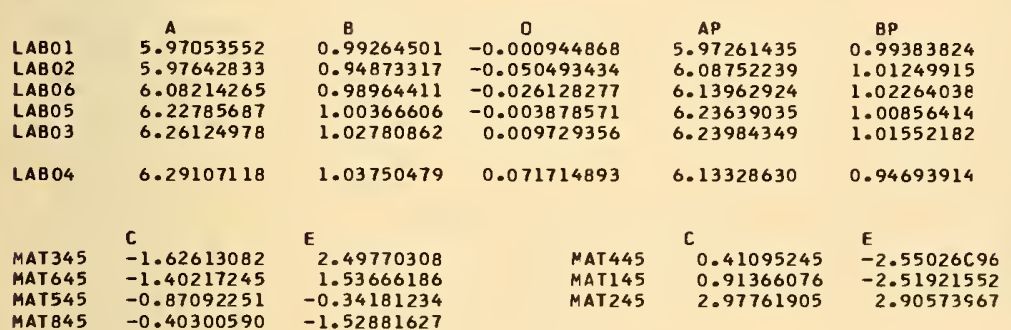

ANALYSIS DF VARIANCE

OF

SS

MS

$\begin{array}{lrrr}\text { TOTAL } & 42 & 1674.41855 & \\ \text { MEAN } & 1 & 1580.74394 & \\ \text { ROWS } & 5 & 0.727348790 & 0.145469755 \\ \text { COLS } & 6 & 92.4070892 & 15.4011815 \\ \text { RXC } & 30 & 0.540115476 & 0.018003844 \\ \text { LIN } & 5 & 0.076744035 & 0.015348807 \\ \text { QUAD } & 5 & 0.274498112 & 0.054899618 \\ \text { RES } & 20 & 0.188873298 & 0.009443663\end{array}$

ISO NATURAL RUBBER TEST STRESS AT $100 \quad 40$

TABLE OF DEVIATIONS LINEAR MOOEL

MAT 345 MAT645

MAT545

LABOI

$\angle A B O 2$

LABO6

LABO5

LABO3

$\begin{array}{ll}-0.011364937 & -0.043676138 \\ -0.034914196 & -0.109890878\end{array}$

$0.002148092-0.069490969$

$-0.070764661$

0.000101447

0.039455950

0.006165147

0.017344654

$-0.095239341$

$-0.014858246$

LABO4

0.114797235

0.177439392

$-0.076235056$

0.031277262

6 ROWS

7 COLUMNS

ISO NATURAL RUBBER TEST

STRESS AT $100 \quad 40$

TABLE OF DEVIATIONS

MAT 345

$\begin{array}{lrrr}\text { LABO1 } & -0.009004921 & -0.042224184 & 0.112408 E-00 \\ \text { LABO2 } & 0.091203421 & -0.032299533 & 0.853722 E-04 \\ \text { LAB06 } & 0.067408770 & -0.029340632 & -0.104170 E-00 \\ \text { LAB05 } & -0.061077125 & 0.045416005 & 0.549326 E-01 \\ \text { LAB03 } & -0.024199605 & -0.008785583 & -0.115326 E-01 \\ & & & \\ \text { LAB04 } & -0.064325280 & 0.067237847 & -0.517220 E-01 \\ \text { SUM SO } & 0.021396868 & 0.010347739 & 0.293129 E-01\end{array}$
MAT 845

$-0.055493832$ $-0.065333366$ 0.066689670 $-0.030873537$ 0.074213088

0.010799289 0.018372908
MAT 445

$0.01403451 \mathrm{C}$ 0.047437429 $0.14866060 \mathrm{C}$ 0.040933967 $0.01761961 \mathrm{C}$

$-0.268686354$ 0.098725647
MAT 145

$-0.018726349$ 0.326751292 0.026158392 $-0.031117201$ $-0.129068255$

$-0.173998654$ 0.155703768
Table 5b

Table $5 c$

MAT 245

0.002495766 $-0.181394339$ $-0.078925967$ $-0.003892183$ 0.045827627

0.215884686 0.087860957

laule at,
SUM So

0.018378541 0.159784913 0.047365196 0.013341606 0.024835601

0.199665628 0.463371493

\section{MATB 45}

$-0.056938365$ $-0.142528556$ 0.026744328 $-0.036803164$ 0.089087486 0.120438181
0.048068032

\section{MAT 445}

0.011624835 $-0.081334017$ 0.082026668 $0.03104257 \mathrm{C}$ $0.04243201 \mathrm{C}$

$-0.085794650$ 0.023603573
MAT 145

-C. 021106683 0.199547432 $-0.039664373$ $-0.040888168$ -C. 104557894 0.006666623
0.054486565
MAT245

0.005241312 $-0.034673542$ $-0.003003985$ 0.007377952 0.017556638

0.007499866 0.001657665
SUM SC

0.018349670 0.077312373 0.025282182 0.012855016 0.021773450

0.033300601 0.188873313 
A PROGRAM FOR FITTING FUNCTIONS OF TOO VARIABLES

DIMENSION AV $(120,50), Z(120,50), X R(120), X C(50), A(120), B(120), C(50)$,

1 TITLE (12), XNS(26), R(99),D (120), WT (120), WFAC (120), XL(120)

COMMON AV, Z,XR,XC,A,B,C,M,N,WT,WFAC,MT,NT,NREP, NR, NX,XNS, T I TLE, XY, $1 \times L, D, R$

C BOOLEAN STATEMENTS FOR INSTRUCTIONS AND GETTING TO SUBROUTINES

B $\quad$ XNS $(1)=626346476060$

B XNS $(2)=452566242163$

B $\quad X N S(3)=434446242543$

B $\quad X N S(4)=504446242543$

B XNS $(5)=234446242543$

B XNS $(6)=444446242543$

B $\quad X N S(7)=434466514666$

B XNS $(8)=434466234643$

B $\quad X N S(9)=626422016060$

B $\quad X N S(10)=234651252363$

B $\quad X N S(11)=464431636060$

B $\quad X N S(12)=314523436424$

$B \quad X N S(13)=635121264651$

$B \quad X N S(14)=474666255160$

B $\quad X N S(15)=234644223145$

B $\quad X N S(16)=626422026060$

B $\quad X N S(17)=512565255162$

B XNS(18) $=314563432122$

B $\quad X N S(19)=254524216321$

B $\quad X N S(20)=232143606060$

B $\quad X N S(21)=606060606060$

B $\quad X N S(22)=626444606250$

$X N S(23)=444651252421$

XNS $(24)=606060606060$

$X N S(25)=216527606060$

100 READ 110 , NR, TITLE

PROGRAM RETURNS TO THIS STATEMENT FOR EACH NEW SET OF DATA

110 FORMAT (I 2,11A6,A4)

PRINT $120, N R$, T ITLE

120 FORMAT ( IHII $2,11 \mathrm{~A} 6, \mathrm{~A} 4$ )

$M=0$

$N=0$

TRANS $=0$ 。

DO $130 \quad I=1,120$

$130 \times R(I)=0$.

DO $140 \quad J=1,50$

$140 \times C(J)=0$

C IF NR IS GREATER THAN 1, REPLICATE VALUES FOR EACH CELL ARE READ

C AT STATEMENT 250

C IF NR EQUALS 1 PROGRAM CONTINUES AND READS IN SINGLE VALUES / CELL I $F(N R-1) 200,200,250$

200 READ $210, X R X,(X C(J), J=1,7)$

READ COLUMN HEADINGS XC

210 FORMAT $(2 A 6,2 X, 5(A 6,4 X), A 6)$ DO $220 \quad J=2,7$

I $F(X C(J)-X N S(21)) 220,221,220$

BLANK

220 COHTINUE

$N=7$

60 TO 222

$221 \mathrm{~N}=\mathrm{J}-1$

C READ ROW HEADINGS XR AND DATA AV

222 DO $227 \quad I=1,120$

READ 225,XR(I), (AV (I,J), $J=1, N)$

225 FORMAT $(A G, F 8,0,5 F 10.0, F 8.0)$

IF (XR(I)-XNS(19)) $226,228,226$

ENDATA

C ENDATA - END OF DATA

226 IF (XR(I)-XNS(23)) $227,230,227$

C MOREDA - MORE OATA, WHEN MORE THAN 7 COLUMNS

MOREDA 


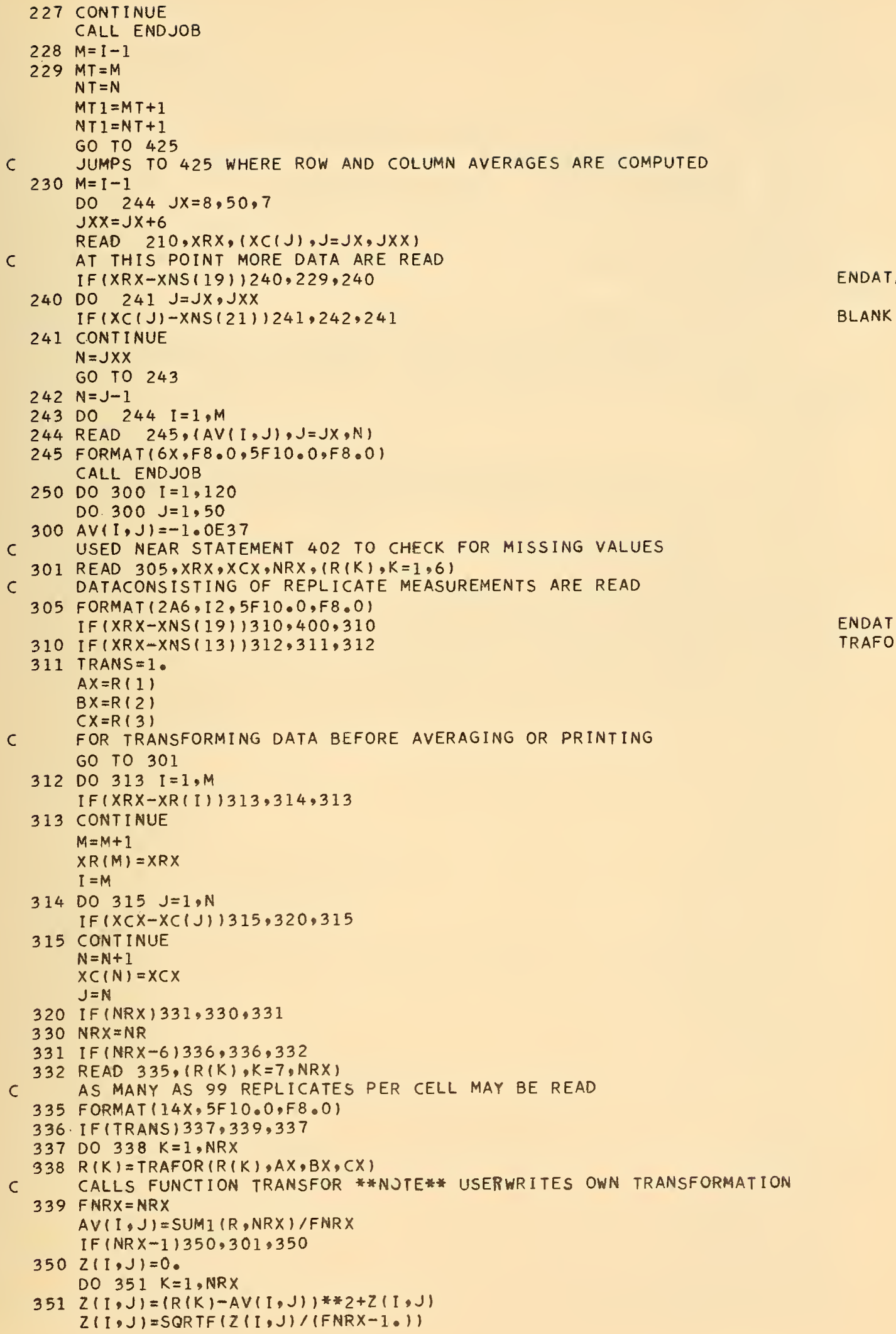


GO TO 301

$400 M T=M$

$N T=N$

$M T 1=M T+1$

$N T 1=N T+1$

MEMOR $Y=0$

401 DO $408 \quad I=1, M$

DO $408 \mathrm{~J}=1, \mathrm{~N}$

IF (AV I I,J)+1.0E37) 402,402,408

C CHECK FOR MISSING VALUES

402 PRINT $405, X R(I), X(I)$

405 FORMAT (I6HOMISSING VALUE A6,2X,A6)

MEMOR $Y=1$

408 CONTINUE

409 IF (MEMORY) $420,421,420$

420 CALL ENDJOB

C CUTS OFF BAD PROGRAM WITH MISSING VALUES

421 IF (XCX-XNS(10) $425,422,425$

C CORECT IN COLUMNS 7-12 AFTER ENDATA - CORRECTS DATA BEFORE

CORECT

C

422 CALL CORECT

$425 M P I=M+1$

$N P 1=N+1$

$F M=M$

$F N=N$

C CALCULATES ROW AND COLUMN AVERAGES FOR TABLE OF AVERAGES AND IF

C REPLICATE MEASUREMENTS, FOR TABLE OF STANDARD DEVIATIONS

450 DO $451 \mathrm{~J}=1, \mathrm{~N}$

$451 \quad A V(M+1, J)=\operatorname{SUM} I(A V(I, J), M) / F M$

452 DO $453 \quad I=1, M P 1$

453 AV $(I, N+I)=S U M 2(A V, I, N) / F N$

454 IF (NR -1$) 500,500,455$

455 DO $456 \mathrm{~J}=1, \mathrm{~N}$

$456 Z(M+1, J)=\operatorname{SUM} I(Z(I, J), M) / F M$

457 DO $458 \quad I=1, M P I$

$458 Z(I, N+1)=\operatorname{SUM} 2(Z, I, N) / F N$

C

ORDER AV, $Z, X R, X C$ IN ASCENDING ORDER OF AVERAGES OF AVERAGE

500 DO $505 \mathrm{I}=1, \mathrm{M}$

I $S=I$

DO 502 IX $=I, M$

IF (AV (IX,N+I)-AV(IS,N+I) $1501,502,502$

501 I $S=I X$

502 CONTINUE

$H O L D=X R(I)$

$X R(I)=X R(I S)$

$X R(I S)=H O L D$

DO $505 \mathrm{~J}=1, \mathrm{NT} 1$

HOLD $=A . V(I, J)$

$A V(I, J)=A V(I S, J)$

$A V(I S, J)=H O L D$

I $F(N R-1) 505,505,503$

$503 \mathrm{HOLD}=\mathrm{Z}(\mathrm{I}, \mathrm{J})$

$\mathrm{Z}(\mathrm{I}, \mathrm{J})=\mathrm{Z}(\mathrm{IS}, \mathrm{J})$

$504 Z(I S, J)=$ HOLD

505 CONTINUE

DO $520 \mathrm{~J}=1, \mathrm{~N}$

$\mathrm{JS}=\mathrm{J}$

DO $507 \mathrm{JX}=\mathrm{J}, \mathrm{N}$

IF (AV $(M+1, J X)-A V(M+1, J S)) 506,507,507$

$506 \mathrm{JS}=\mathrm{JX}$

507 CONT I NUE

HOLD $=X C(J)$

$x C(J)=x C(J S)$

$X C(J S)=H O L D$

DO $520 \quad I=1, M T 1$

$H O L D=A V(I, J)$

$A V(I, J)=A V(I, J S)$

$A V(I, J S)=H O L D$

I F (NR-1) 520,520,508 


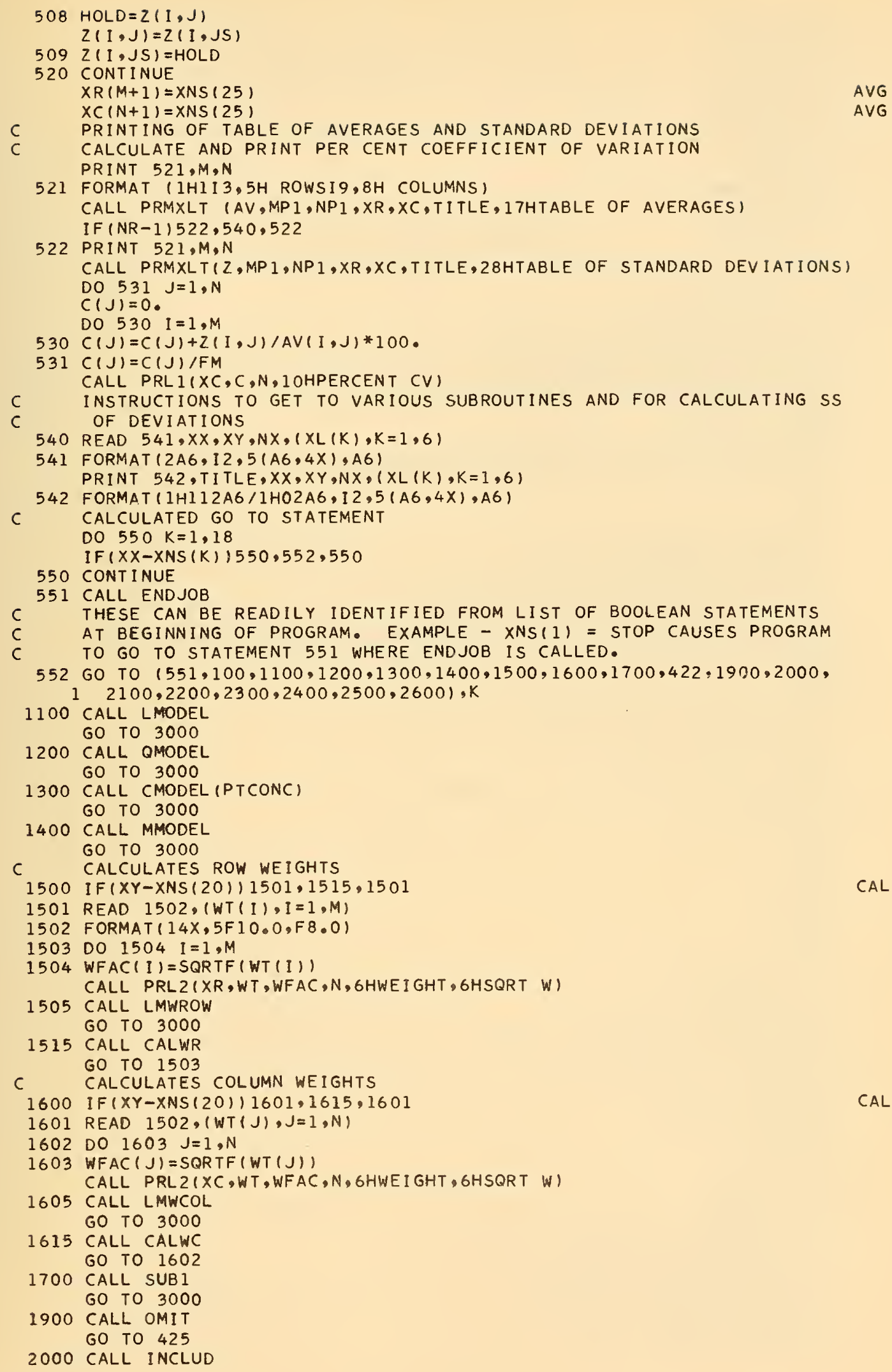




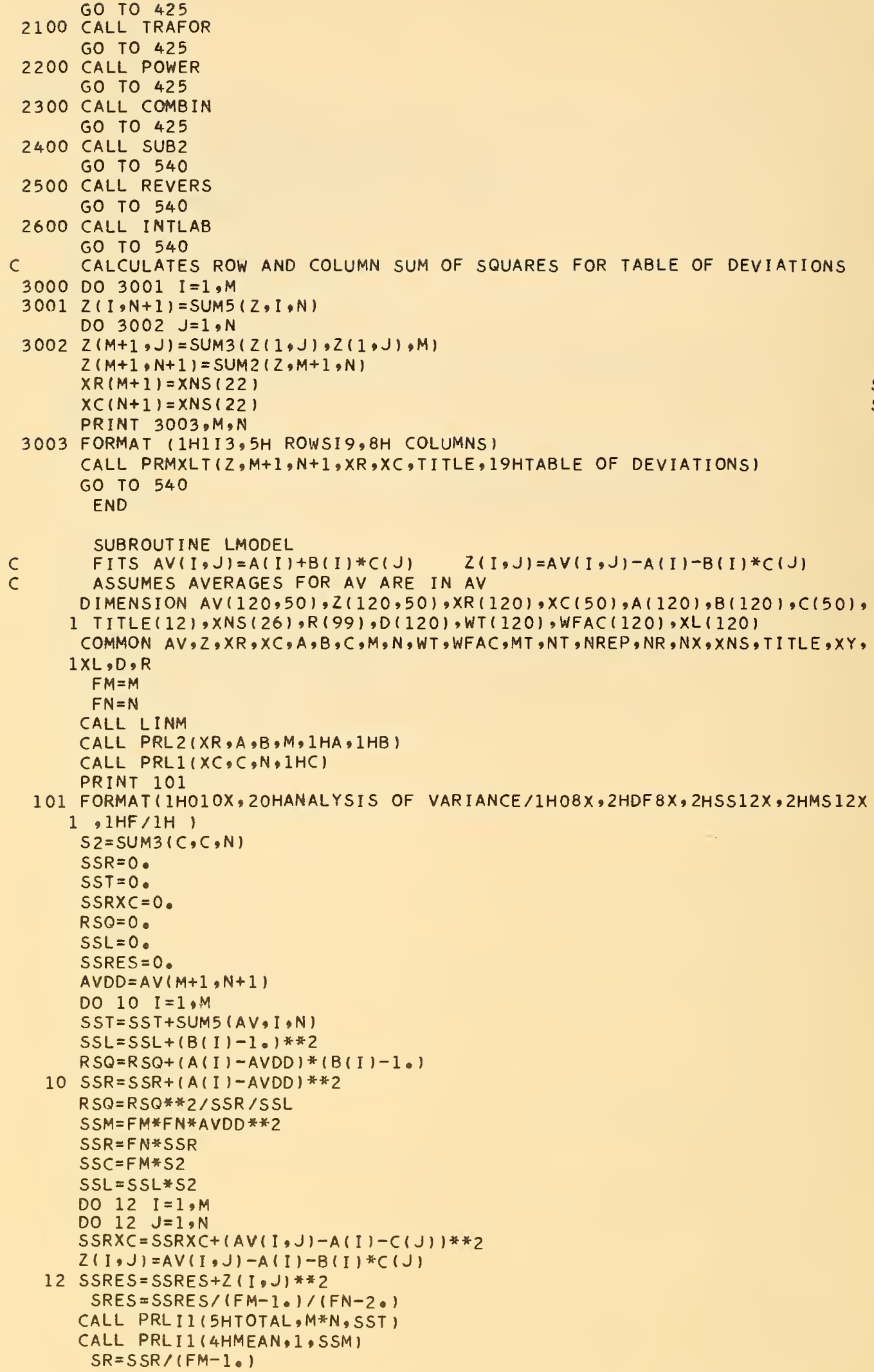

101 FORMAT 1 HO $10 \mathrm{X}, 2$ OHANALYSIS OF VARIANCE/1H08X,2HDF $8 \mathrm{X}, 2 \mathrm{HSS} 12 \mathrm{X}, 2 \mathrm{HMS} 12 \mathrm{X}$ 
CALL PRLI3/4HROWS, M-1,SSR, SR, SR/SRES) $S C=S S C /(F N-1 \cdot)$

CALL PRLI3(4HCOLS, N-1,SSC, SC, SC/ SRES)

$S R \times C=S S R \times C /(F M-1 \cdot) /(F N-1 \cdot)$

CALL PRLI3 (3HRXC, $(M-1) *(N-1), S S R \times C, S R \times C, S R \times C / S R E S)$

$S L=S S L /(F M-1 \cdot)$

CALL PRLI315H LIN,M-1,SSL, SL,SL/SRES)

$S S C N=S S L * R S Q$

SSNC $=S S L-S S C N$

$S N C=S S N C /(F M-2 \cdot)$

CALL PRLI3(5H C, $1, S S C N, S S C N, S S C N / S N C)$

CALL PRLI316H NC, M-2,SSNC, SNC, SNC/SRES)

CALL PRLI2(5HRESID, $(M-1) *(N-2)$, SSRES, SRES)

RETURN

END

SUBROUTINE LINM

TO DO BASIC CALCULATIONS FOR LINEAR AND QUADRATIC MODELS

DIMENSION AV $(120,50), Z(120,50), X R(120), X C(50), A(120), B(120), C(50)$,

1 TITLE (12), XNS (26), R(99),D(120),WT(120), WFAC(120), XL(120)

COMMON AV, Z,XR,XC,A,B,C,M,N,WT,WFAC,MT,NT,NREP,NR,NX,XNS,TITLE,XY,

$1 \times L, D, R$

DO $1 \mathrm{~J}=1, \mathrm{~N}$

$1 C(J)=A V(M+1, J)-A V(M+1, N+1)$

$S 2=S U M 3(C, C, N)$

DO $2 \quad I=1, M$

$A(I)=A V(I, N+I)$

$2 B(I)=\operatorname{SUM} 4(A V, C, I, N) / S 2$

RETURN

END

SUBROUTINE LMWCOL

C WEIGHTED WITH WFAC。 $Z(I, J)=W F A C(J) *(Y(I, J)-A(I)-B(I) * C(J))$

DIMENSION AV $(120,50), Z(120,50), X R(120), X C(50), A(120), B(120), C(50)$,

1 TITLE (12), XNS (26),R(99),D(120),WT(120),WFAC(120),XL(120),U(50), BE 2STAR( 120 )

COMMON $A V, Z, X R, X C, A, B, C, M, N, W T, W F A C, M T, N T, N R E P, N R, N X, X N S, T I T L E, X Y$,

$1 X L, D, R$

CALL LMWCL

$F M=M$

$S B I M I=0$.

SAIMAV $=0$.

DO $106 \quad I=1, M$

$105 S B I M I=S B I M I+(B(I)-1 \cdot) *(A(I)-A V A)$

106 SAIMAV $=$ SAIMAV+(A(I) -AVA)**2

ALPHA $=$ SBIMI $/$ SAIMAV

PTCONC $=$ AVA-1 $1 /$ ALPHA

DO $107 \mathrm{I}=1, \mathrm{M}$

$107 \operatorname{BESTAR}(I)=1 \bullet+A L P H A *(A(I)-A V A)$

DO $109 \mathrm{~J}=1, \mathrm{~N}$

$109 Z(M+1, J)=\operatorname{SUM} 3(Z(1, J), Z(1, J), M)$

$Z(M+1, N+1)=\operatorname{SUM} 2(Z, M+1, N)$

CALL PRL3 ( $X R, A, B, B E S T A R, M, I H A, 1 H B, 6 H B$ STAR)

CALL PRLI $(X C, C, N, 1 H C)$

CALL PLINE 1 (6HALPHA =, ALPHA)

CALL PLINEI (21HPOINT OF CONCURRENCE $=, P T C O N C)$

$A S=S U M I(A, M)$

$W=S U M 3(W F A C, W F A C, N)$

$A B A R=A S / F M$

$A Z A=0$.

DO $1 \quad I=1, M$

$1 \quad A Z A=A Z A+(A(I)-A B A R) * * 2$

$S S R=W * A Z A$

$S W C=0$.

DO $2 \mathrm{~J}=1, \mathrm{~N}$

$2 S W C=S W C+W F A C(J) * 2 * C(J) * 2$

$S S C=F M * S W C$

$S S F=Z(M+1, N+1)$

$B Z B=0$ 。 
DO $3 \quad 1=1, M$

$3 B Z B=B Z B+(B(I)-1) *$,

$S S S=S W C * B Z B$

RSQ $\left.=\left(S_{U}\right) 3(A, B, M)-A S\right) * 2 /(A Z A * B Z B)$

$S S C O=S S S * R S Q$

SSNC $=S S S *(1,-R S Q)$

$S S R C=S S F+S S S$

PRINT 110

110 FORMAT (26HIANALYSIS OF WEIGHTED DATA/7HOSOURCE $4 \mathrm{X}, 2$ HDF $8 \mathrm{X}, 2 \mathrm{HSS} 12 \mathrm{X}$, 12 HMSI

CALL PRLI2 (4HROWS,M-1,SSR,SSR/FLOATF (M-1))

CALL PRLI2 (4HCOLS,N-1,SSC,SSC/FLOATF (N-1))

CALL PRL 12 (3HRXC, $(M-1) *(N-1)$, SSRC,SSRC)FLOATF $(M-1) *(N-1)))$

CALL PRL 12 (5H FIT, $(M-1) *(N-2), S S F, S S F / F L O A T F((M-1) *(N-2)))$

CALL PRL 12 (5HSLOPE, M-1, SSS,SSS/FLOATF(M-1))

CALL PRL 12 (6H CONC, $1, S S C O, S S C O)$

CALL PRL12 $(6 \mathrm{H}$ NONC,M-2,SSNC,SSNC/FLOATF(M-2))

CALL PLINEI(IOHR SQUARED $=$, RSQ $)$

CALL PLINEI(2HR=,SQRTFIRSQ))

RETURN

END

SUBROUTINE LMWCL

C DOES BASIC CALCULATIONS FOR SUBROUTINES LMWCOL AND CALWC

DIMENSION AV $(120,50), Z(120,50), X R(120), X C(50), A(120), B(120), C(50)$,

1 TITLE (12), XNS (26),R(99),D(120), WT (120), WFAC (120), XL (120)

COMMON AV, $Z, X R, X C, A, B, C, M, N, W T$, WFAC,MT, NT, NREP, NR, NX, XNS, TI TLE, XY,

$1 X L, D, R$

$F M=M$

DO $100 \quad I=1, M$

DO $100 \quad J=1, N$

$100 \quad Z(I, J)=A V(I, J) * W F A C(J)$

DO $101 \mathrm{~J}=1, \mathrm{~N}$

$101 D(J)=\operatorname{SUM} 1(Z(1, J), M) / F M$

$S W=S U M 3(W F A C, W F A C, N)$

DO $102 \quad 1=1, M$

$102 \quad A(I)=\operatorname{SUM} 4(Z, W F A C, I, N) / S W$

$A V A=S U M I(A, M) / F M$

DO $103 \mathrm{I}=1, \mathrm{M}$

$103 B(I)=(\operatorname{SUM} 4(Z, D, I, N)-S W * A(I) * A V A) /(\operatorname{SUM} 3(D, D, N)-S W * A V A * * 2)$

DO $104 \mathrm{~J}=1, \mathrm{~N}$

$104 C(J)=\operatorname{SUMI}(A V(1, J), M) / F M-A V A$

DO $108 \quad 1=1, M$

DO $108 \quad J=1, N$

$108 Z(I, J)=(A V(I, J)-A(I)-B(I) * C(J)) * W F A C(J)$

RETURN

END

SUBROUTINE CALWC

ITERATIVE F-PROCEDURE WITH ADJUSTMENT FOR HIGH WEIGHTS

DIMENSION AV $(120,50), 2(120,50), X R(120), X C(50), A(120), B(120), C(50)$, 1 TITLE (12), XNS $(26), R(99), D(120)$, WT (120),WFAC(120), XL $(120)$, XM(50), L $2 Y(50)$

COMMON $A V, Z, X R, X C, A, B, C, M, N, W T, W F A C, M T, N T, N R E P, N R, N X, X N S, T I T L E, X Y$,

$1 \times L, D, R$

$F M=M$

NUM $=25$

NUMX $=20$

DO $1 \mathrm{~J}=1, \mathrm{~N}$

$1 W T(J)=1$.

DO $50 \quad L X=1$, NUM

DO $17 \mathrm{~J}=1, \mathrm{~N}$

17 WFAC (J) $=$ SQRTF $(W T(J))$

CALL LMWCL

DO2 $J=1, N$

$2 X M(J)=\operatorname{SUM} 3(Z(1, J), Z(1, J), M) /(F M-1$,

$W=$ SQRTF $\left(\operatorname{SUM}_{1}(W T, N)\right)$

SUM $=0$. 
DO $3 \mathrm{~J}=1, \mathrm{~N}$

$3 S U M=S U M+W T(J) * C(J) * 2$

SUM $=$ SQRTF $($ SUM $)$

DO $4 \mathrm{~J}=1, \mathrm{~N}$

$A(J)=W F A C(J) / W$

$4 B(J)=W F A C(J) * C(J) / S U M$ DO $5 \mathrm{~J}=1, \mathrm{~N}$

$A(J)=1 .-A(J) * * 2-B(J) * * 2$

$5 W T(J)=W T(J) * A(J) / X M(J)$

IF $($ LX-NUMX) $50,50,18$

18 DO $19 \mathrm{~J}=1, \mathrm{~N}$

$19 L Y(J)=J$

$\mathrm{NI}=\mathrm{N}-1$

DO $8 \mathrm{~J}=1, N 1$

SMALL $=W T(J)$

$J X=J$

DO $7 \mathrm{~K}=J, N$

IF (SMALL-WT (K) $) 7,7,6$

$6 \mathrm{JX}=\mathrm{K}$

SMALL $=W T(K)$

7 CONTINUE

$W T(J X)=W T(J)$

$W T(J)=S M A L L$

I HOLD $=L Y(J X)$

$L Y(J X)=L Y(J)$

$8 L Y(J)=$ IHOLD

$F D=N-5$

$R=\operatorname{LOGF}(W T(N-2) / W T(3))$

$N X=(N+1) / 2$

$N Y=(N+2) / 2$

$S=0.5 * \operatorname{LOGF}(W T(N X) * W T(N Y))$

$S F 1=\operatorname{EXPF}(R *(.5501+1.0553 / F D)+S)$

$S F 2=\operatorname{EXPF}(R *(.6529+2.5405 / F D)+S)$

IF (WT $(N-1)-S F 1) 11,11,9$

9 PRINT $10, L Y(N-1), W T(N-1), S F 1$

10 FORMAT (14HOREPLACED WT I $2, E 15.6,5 \mathrm{H}$ BYE 15.6)

$W T(N-1)=S F 1$

11 IF (WT (N) -SF2) 13,13,12

12 PRINT $10, L Y(N), W T(N), S F 2$

$W T(N)=S F 2$

$130016 \mathrm{~J}=1, \mathrm{~N} 1$

DO $16 \mathrm{~K}=\mathrm{J}, \mathrm{N}$

IF $(J-L Y(K)) 16,15,14$

14 CALL ENDJOB

$15 L Y(K)=L Y(J)$

HOLD $=W T(K)$

$W T(K)=W T(J)$

$W T(J)=H O L D$

16 CONTINUE

50 CALL PRNI (WT, N, 6HWEIGHT)

RETURN

END

SUBROUTINE QMODEL

C SUBROUTINE TO FIT AV $(I, J)=A(I)+B(I) * C(J)+D(I) * E(J)$.

C

$A V(I, J)=A P(I)+B P(I) * C(J)+D(I) * C(J) * * 2$

$Z(I, J)=A V(I, J)-A(I)-B(I) * C(J)-D(I) * E(J)$

DIMENSION AV $(120,50), Z(120,50), X R(120), X C(50), A(120), B(120), C(50)$, 1 TITLE (12), XNS (26), R(99),D(120),WT(120),WFAC (120), XL(120), E(50), AP $2(120), B P(120)$

COMMON $A V, Z, X R, X C, A, B, C, M, N, W T, W F A C, M T, N T, N R E P, N R, N X, X N S, T I T L E, X Y$, $I X L, D, R$

$F M=M$

$F N=N$

CALL LINM

$S 2=\operatorname{SUM} 3(C, C, N)$

$53=0$.

DOI $J=1, N$ 
$1 \mathrm{~S} 3=\mathrm{C}(\mathrm{J}) * 3+\mathrm{S} 3$

DO $2 \mathrm{~J}=1, \mathrm{~N}$

$2 E(J)=C(J) * 2-S 3 / S 2 * C(J)-S 2 / F N$

$Q=\operatorname{SUM} 3(E, E, N)$

DO $4 \quad I=1, M$

$R=0$.

DO $3 \mathrm{~J}=1, \mathrm{~N}$

$3 R=A V(I, J) * C(J) * * 2+R$

$4 D(I)=(R-B(I) * S 3-A(I) * S 2) / Q$

DO $5 \quad I=1, M$

$A P(I)=A(I)-D(I) * S 2 / F N$

$5 B P(I)=B(I)-D(I) * S 3 / S 2$

$A \vee D D=A V(M+1, N+1)$

CALL PRL 5( $X R, A, B, D, A P, B P, M, 1 H A, 1 H B, 1 H D, 2 H A P, 2 H B P$ )

CALL PRL2 (XC, C,E, N, $1 \mathrm{HC}, 1 \mathrm{HE})$

PRINT 101

101 FORMAT $11 \mathrm{H} 110 \mathrm{X}, 21 \mathrm{H}$ ANALYSIS OF VARIANCE/1HO8X,2HDF $8 \mathrm{X}, 2 \mathrm{HSS} 12 \mathrm{X}$,

1 $2 \mathrm{HMS} / 1 \mathrm{H}$,

SST $=0$.

DO $10 \quad I=1, M$

$10 S S T=S S T+S U M 5(A V, I, N)$

$S S M=F M * F N * A V D D * 2$

$S S R=0$.

DO $11 \quad I=1, M$

$11 S S R=S S R+(A(I)-A V D D) * * 2$

$S S R=F N * S S R$

$S S C=F M * S 2$

$S S R \times C=0$.

DO $12 I=1, M$

DO $12 \mathrm{~J}=1, \mathrm{~N}$

$12 \operatorname{SSRXC}=\operatorname{SSR} \times C+(A V(I, J)-A(I)-C(J)) * 2$

$S S L=0$.

DO $13 \quad I=1, M$

$13 S S L=S S L+(B(I)-1 \cdot 1) * 2$

$S S L=S 2 * S S L$

$S S Q=Q * \operatorname{SUM} 3(D, D, M)$

SSRES $=0$.

DO $14 \quad I=1, M$

DO $14 \mathrm{~J}=1, \mathrm{~N}$

14 SSRES $=S S R E S+(A V(I, J)-A(I)-B(I) * C(J)-D(I) * E(J)) * 2$

CALL PRLII (5HTOTAL,M*N,SST)

CALL PRLII (4HMEAN, $1, S S M)$

CALL PRLI2 (4HROWS, M-1,SSR,SSR/FLOATF(M-1))

CALL PRLI2 (4HCOLS,N-1,SSC,SSC/FLOATF $(\mathrm{N}-1)$ ))

CALL PRLI2 (3HRXC, $(M-1) *(N-1), S S R \times C, S S R \times C / F L O A T F((M-1) *(N-1))$

CALL PRLI2 (6H LIN,M-1,SSL,SSL/FLOATF(M-1))

CALL PRLI2 (6H QUAD,M-1,SSQ,SSQ/FLOATF(M-1))

CALL PRLI 2 (6H RES, $(M-1) *(N-3)$, SSRES,$S S R E S / F L O A T F((M-1) *(N-3))$

DO $20 \quad I=1, M$

DO $20 \mathrm{~J}=1, \mathrm{~N}$

$20 Z(I, J)=A V(I, J)-A(I)-B(I) * C(J)$

DO $21 \quad I=1, M$

$21 Z(I, N+1)=\operatorname{SUM} 5(Z, I, N)$

DO $22 \mathrm{~J}=1, \mathrm{~N}$

$22 Z(M+1, J)=\operatorname{SUM} 3(Z(1, J), Z(1, J), M)$

$Z(M+1, N+1)=\operatorname{SUM} 2(Z, M+1, N)$

$X R(M+1)=X N S(22)$

$X C(N+1)=X N S(22)$

CALL PRMXLT $(Z, M+1, N+1, X R, X C, T I T L E, 33 H$ TABLE OF DEVIATIONS LINEAR M 1ODEL)

DO $23 \quad I=I, M$

DO $23 \mathrm{~J}=1, \mathrm{~N}$

$23 Z(I, J)=Z(I, J)-D(I) * E(J)$

RETURN

END

SUBROUTINE OMIT

C TO OMIT COLS OR ROWS OR BOTH - READ NX AND XL (K)

C EXAMPLE 


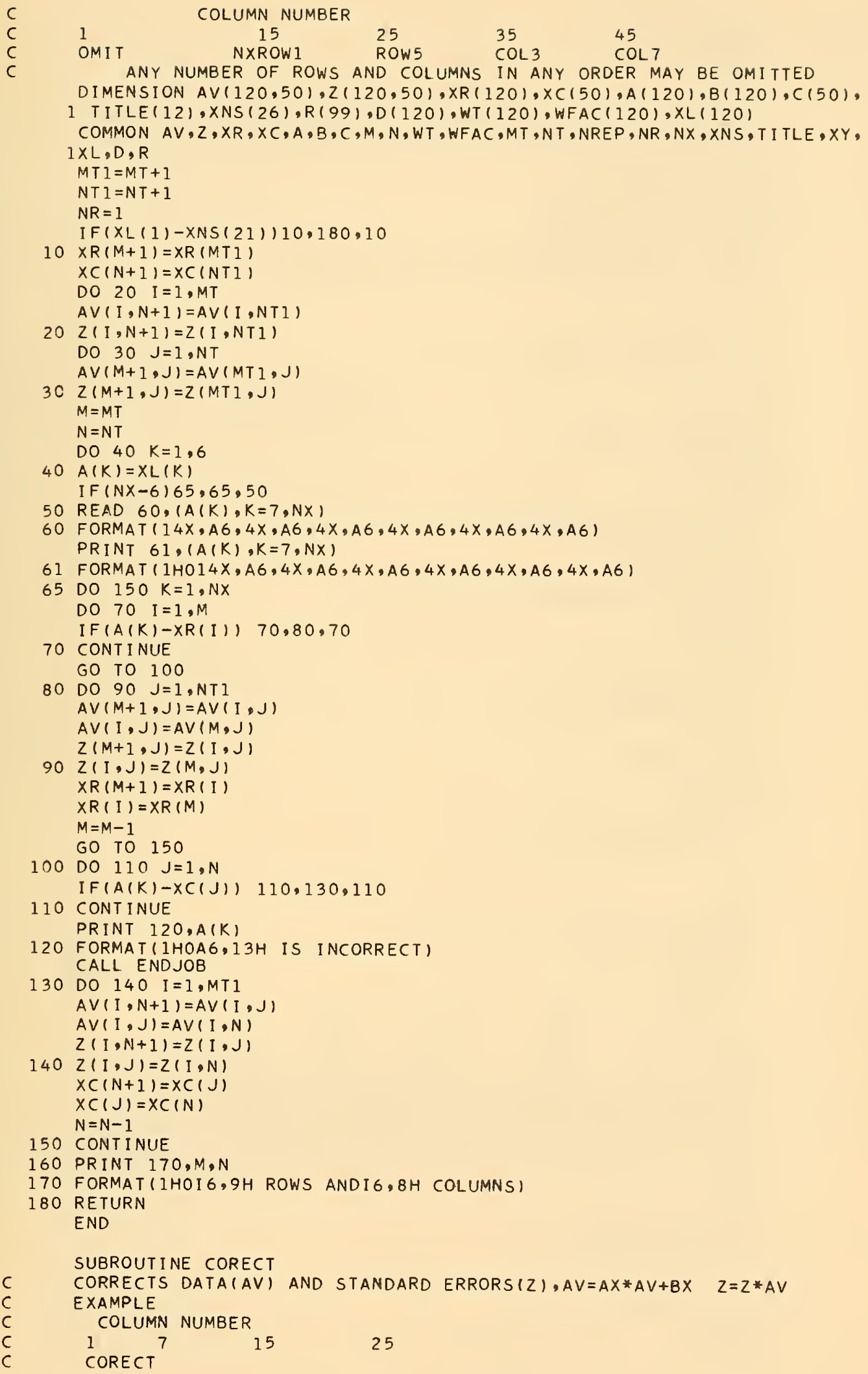




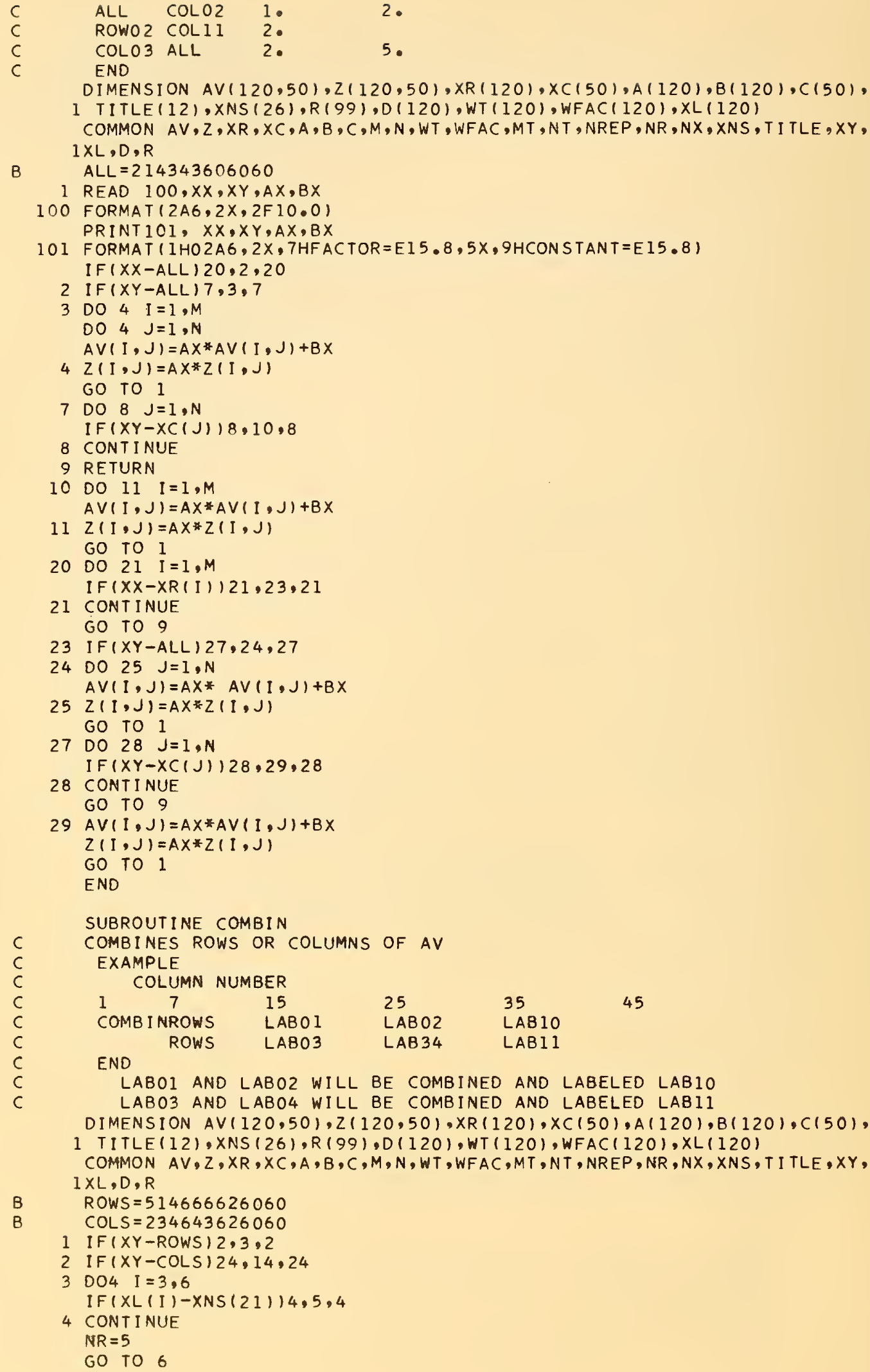


$5 \quad \mathrm{NR}=\mathrm{I}-2$

6 DO $30 \mathrm{~J}=1, \mathrm{~N}$

$30 A(J)=0$.

DO $11 \mathrm{~K}=1$, NR

DO $7 \quad I=1, M$

I $F(X L(K)-X R(I)) 7,8,7$

7 CONT INUE

CALL ENDJOB

8 DO $10 \mathrm{~J}=1, \mathrm{~N}$

$9 A(J)=A(J)+A V(I, J)$

$10 A V(I, J)=A V(M, J)$

$X R(I)=X R(M)$

$11 M=M-1$

$M=M+1$

$F N R=N R$

DO $12 \mathrm{~J}=1, \mathrm{~N}$

$12 A V(M, J)=A(J) / F N R$

$X R(M)=X L(N R+1)$

13 READ $100, X Y,(X L(K), K=1,6)$

100 FORMAT $(6 X, A 6,2 X, 5(A 6,4 X), A 6)$

PRINT $101, X Y,(X L(K), K=1,6)$

101 FORMAT $(1 H 6 X, A 6,2 X, 5(A 6,4 X), A 6)$

GO TO 1

14 DO $15 \quad I=3,6$

15 CONT INUE

I $F(X L(I)-X N S(21)) 15,16,15$

$N R=5$

GO TO 17

16 NR $=\mathrm{I}-2$

17 DO $31 \quad \mathrm{I}=1, \mathrm{M}$

$31 \mathrm{~A}(\mathrm{I})=0$.

DO $22 K=1, N R$

DO $18 \quad J=1, N$

$\operatorname{IF}(X L(K)-X C(J)) 18,19,18$

18 CONTINUE

CALL ENDJOB

19 DO $21 \mathrm{I}=1, \mathrm{M}$

$20 A(I)=A(I)+A V(I, J)$

$21 A V(I, J)=A V(I, N)$

$X C(J)=X C(N)$

$22 \mathrm{~N}=\mathrm{N}-1$

$\mathrm{N}=\mathrm{N}+\mathrm{l}$

DO $23 \quad I=1, M$

$23 A V(I, N)=A(I) / F N R$

$X C(N)=X L(N R+1)$

GO TO 13

$24 M T=M$

$N T=N$

$N R=1$

RETURN

END

C REVERSES ROWS AND COLUMNS OF DATA AV FOR MATRIX CURVE FITTING

DIMENSION AV $(120,50), Z(120,50), X R(120), X C(50), A(120), B(120), C(50)$,

1 TITLE (12), XNS(26), R(99),D(120), WT (120), WFAC $(120), X L(120)$

COMMON AV, $Z, X R, X C, A, B, C, M, N, W T, W F A C, M T, N T, N R E P, N R, N X, X N S, T I T L E, X Y$,

$1 X L, D, R$

$M X=X M A X O F(M, N)$

$M \times P 1=M X+1$

DO $9 \quad I=1, M X$

$H O L D=X R(I)$

$X R(I)=X C(I)$

$X C(1)=$ HOLD

$M 2=I+1$

DO $9 \mathrm{~J}=\mathrm{M} 2, M \times P 1$

$H O L D=A V(I, J)$

$A V(I, J)=A V(J, I)$ 


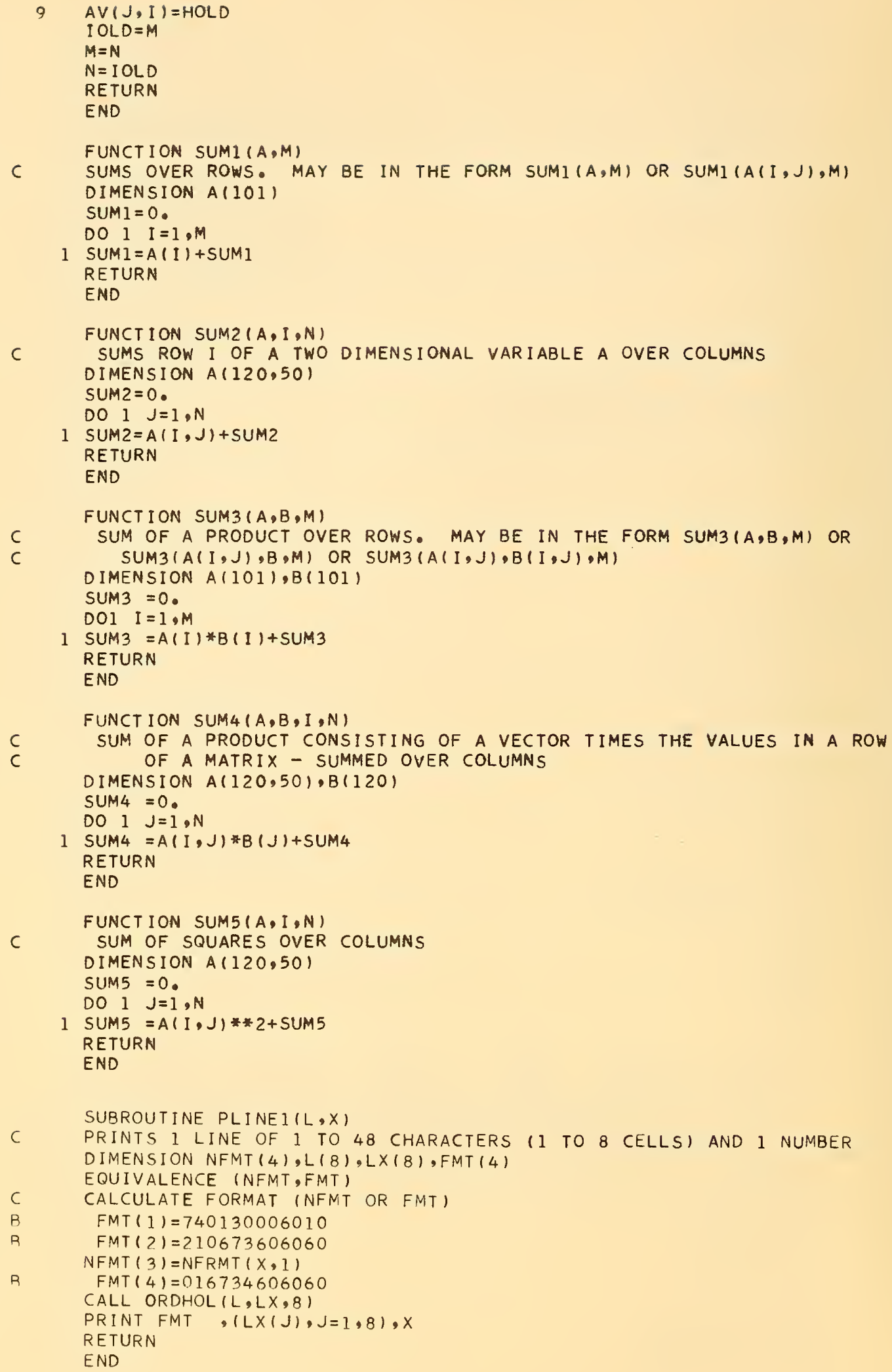




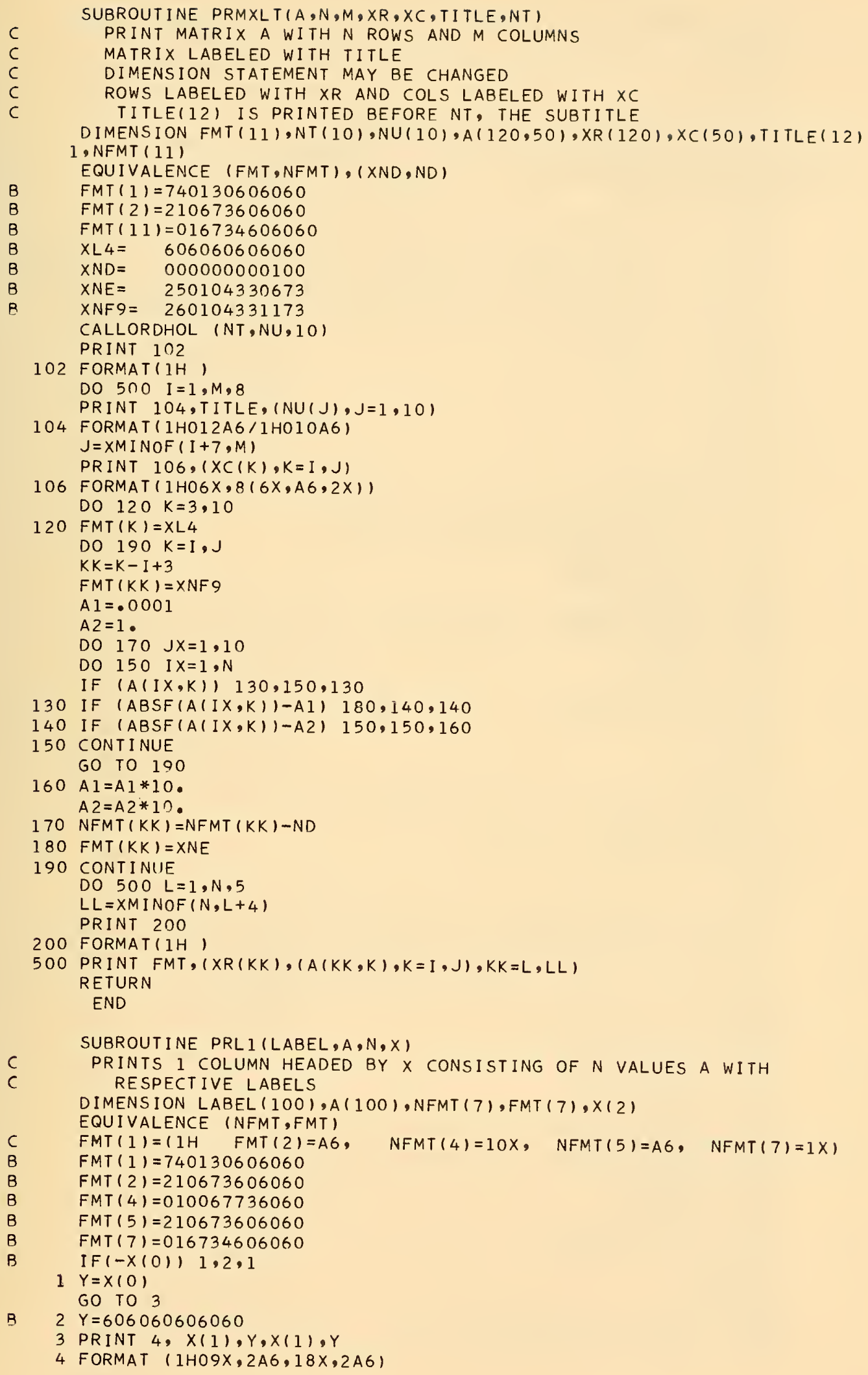


$\operatorname{NFMT}(3)=\operatorname{NFRMT}(A, N)$

NFMT $(6)=$ NFMT $(3)$

$N D 2=N / 2$

$\mathrm{J}=\mathrm{N}-\mathrm{ND} 2$

DO $5 \mathrm{~K}=1, \mathrm{ND2}$

$K X=K+J$

5 PRINT FMT, LABEL $(K), A(K), L A B E L(K X), A(K X)$

IF $(J-N D 2) 6,7,6$

6 PRINT FMT, LABEL $(J), A(J)$

7 RETURN

END

SUBROUTINE PRL2 ( $L A B E L, A, B, N, X A, X B$ )

C PRINTS 2 COLUMNS HEADED BY XA AND XB CONSISTING OF $N$ VALUES EACH OF A AND B WITH THEIR RESPECTIVE LABELS

DIMENSION LABEL $(100), A(100), B(100), N F M T(9), F M T(9), X A(2), X B(2)$

EQUIVALENCE (NFMT, FMT)

B

$I F(-X A(O)) 1,2,1$

$1 X=X A(0)$

GO TO 3

R $2 X=606060606060$

B 3 IF $(-X B(0)) 4,5,4$

$4 Y=X B(0)$

GO TO 6

B

$5 Y=606060606060$

6 PRINT 7, XA $(1), X, X B(1), Y, X A(1), X, X B(1), Y$

7 FORMAT ( 1 HO9X, 2A6, $2 X, 2 A 6,18 X, 2 A 6,2 X, 2 A 6)$

B FMT $(1)=740130606060$

B $\quad F M T(2)=210673606060$

NFMT $(3)=$ NFRMT $(A, N)$

NFMT $(4)=N F R M T(B, N)$

B

FMT $(5)=010067736060$

FMT $(6)=F M T(2)$

NFMT $(7)=$ NFMT $(3)$

B

NFMT $(8)=$ NFMT $(4)$

FMT $(9)=016734606060$

$\mathrm{ND} 2=\mathrm{N} / 2$

$\mathrm{J}=\mathrm{N}-\mathrm{ND} 2$

DO $8 K=1, N D 2$

$K X=K+J$

8 PRINTNFMT, LABEL $(K), A(K), B(K), L A B E L(K X), A(K X), B(K X)$

I $F(J-N D 2) 9,10,9$

9 PRINTNFMT, LABEL $(J), A(J), B(J)$

10 RETURN

END

SUBROUTINE PRL 3 (LABEL, $A, B, C, N, L A, L B, L C$ )

C PRINTS 3 COLUMNS HEADED BY LA,LB AND LC CONSISTING OF $N$ VALUES

C EACH OF $A, B$ AND $C$ WITH THEIR RESPECTIVE LABELS

$\operatorname{NFMT}(1)=(1 \mathrm{H}(2)=A 6, \quad(6)=10 X,(7)=A 6, \quad(11)=1 X)$

DIMENSION LABEL $(100), A(100), B(100), C(100), N F M T(11), F M T(11)$

EQUIVALENCE (NFMT,FMT)

B $\quad$ FMT (I) $=740130606060$

B $\quad F M T(2)=210673606060$

$\operatorname{NFMT}(3)=\operatorname{NFRMT}(A, N)$

$\operatorname{NFMT}(4)=\operatorname{NFRMT}(B, N)$

$\operatorname{NFMT}(5)=N F R M T(C, N)$

B FMT $(6)=010067736060$

B FMT $(7)=210673606060$

NFMT $(8)=$ NFMT $(3)$

NFMT $(9)=$ NFMT $(4)$

NFMT $(10)=$ NFMT $(5)$

B

FMT $(I I)=016734606060$

ND2 $=N / 2$

$I=N-2 * N D 2+1$

$J=N-N D 2$

PRINT I, LA, LB, LC , LA, LB, LC

1 FORMAT $(I H O 4 X, 3(8 X, A 6), 16 X, 3(8 X, A 6))$

DO $2 \mathrm{~K}=1$, ND2 
$K X=K+J$

2 PRINT NFMT, LABEL $(K), A(K), B(K), C(K), L A B E L(K X), A(K X), B(K X), C(K X)$

GO TO $(4,3)$, I

3 PRINT NFMT, LABEL $(J), A(J), B(J), C(J)$

4 RETURN

END

SUBROUTINE PRL5 (LABEL, A,B, C,D,E,N,LA,LB,LC,LD,LE)

PRINTS 5 COLUMNS HEADED BY LA, LB, LC, LD AND LE CONSISTING OF $N$ VALUES EACH OF $A, B, C$, D AND $E$ WITH THEIR RESPECTIVE LABELS

$\operatorname{NFMT}(1)=(1 \mathrm{H} \quad(2)=A 6, \quad(8)=1 \times)$

DIMENSION LABEL $(99), A(99), B(99), C(99), E(99), N F M T(8), F M T(8)$

EQUIVALENCE (NFMT, FMT)

B $\quad F M T(1)=740130606060$

B $\quad F M T(2)=210673606060$

$\operatorname{NFMT}(3)=\operatorname{NFRMT}(A, N)$

$\operatorname{NFMT}(4)=\operatorname{NFRMT}(B, N)$

NFMT $(5)=\operatorname{NFRMT}(C, N)$

NFMT $(6)=N F R M T(D, N)$

NFMT $(7)=N F R M T(E, N)$

B

$F M T(8)=016734606060$

PRINT 1,LA, LB, LC, LD, LE

1 FORMAT $(1 H 04 X, 5(8 X, A 6))$

DO $2 I=1, N, 5$

$J=X M I N O F(I+4, N)$

PRINT NFMT, $(L A B E L(K), A(K), B(K), C(K), D(K), E(K), K=I, J)$

2 PRINT NFMT

RETURN

END

SUBROUTINE PRLII (L, INT, A)

C PRINTS 1 LINE OF LABEL, INTEGER AND 1 FLOATING POINT NUMBER

C NFMT $(1)=(1 \mathrm{H} \quad(2)=A 6, I 6, \quad(4)=1 X)$

DIMENSION NFMT (4), FMT (4)

EQUIVALENCE (NFMT, FMT)

B $\quad F M T(1)=740130606060$

B $\quad F M T(2)=210673310673$

$\operatorname{NFMT}(3)=\operatorname{NFRMT}(A, 1)$

B $\quad$ FMT $(4)=016734606060$

PRINT NFMT, L, INT,A

RETURN

END

SUBROUTINE PRLI 2 (L, INT, A,B)

C

PRINTS 1 LINE OF LABEL, INTEGER AND 2 FLOATING POINT NUMBERS DIMENSION NFMT (5), FMT (5)

EQUIVALENCE (NFMT, FMT)

C $\quad N F M T(1)=(1 H \quad(2)=A 6,16, \quad(5)=1 \times)$

B FMT (1) $=740130606060$

B $\quad F M T(2)=210673310673$

$\operatorname{NFMT}(3)=\operatorname{NFRMT}(A, 1)$

$\operatorname{NFMT}(4)=\operatorname{NFRMT}(B, 1)$

B $\quad F M T(5)=016734606060$

PRINT NFMT, L, INT, A, B

RETURN

END

SUBROUTINE PRLI3 ( L, INT, A, B, C)

C PRINTS 1 LINE OF LABEL, INTEGER AND 3 FLOATING POINT NUMBERS DIMENSION NFMT $(6)$, FMT (6)

EQUIVALENCE (NFMT, FMT)

B FMT $(1)=740130606060$

B $\quad F M T(2)=210673310673$

B $\quad$ FMT $(6)=016734606060$

$\operatorname{NFMT}(3)=\operatorname{NFRMT}(A, 1)$

$\operatorname{NFMT}(4)=\operatorname{NFRMT}(B, 1)$

$\operatorname{NFMT}(5)=\operatorname{NFRMT}(C, 1)$

PRINT NFMT, L, INT, $A, B, C$

RETURN

END 


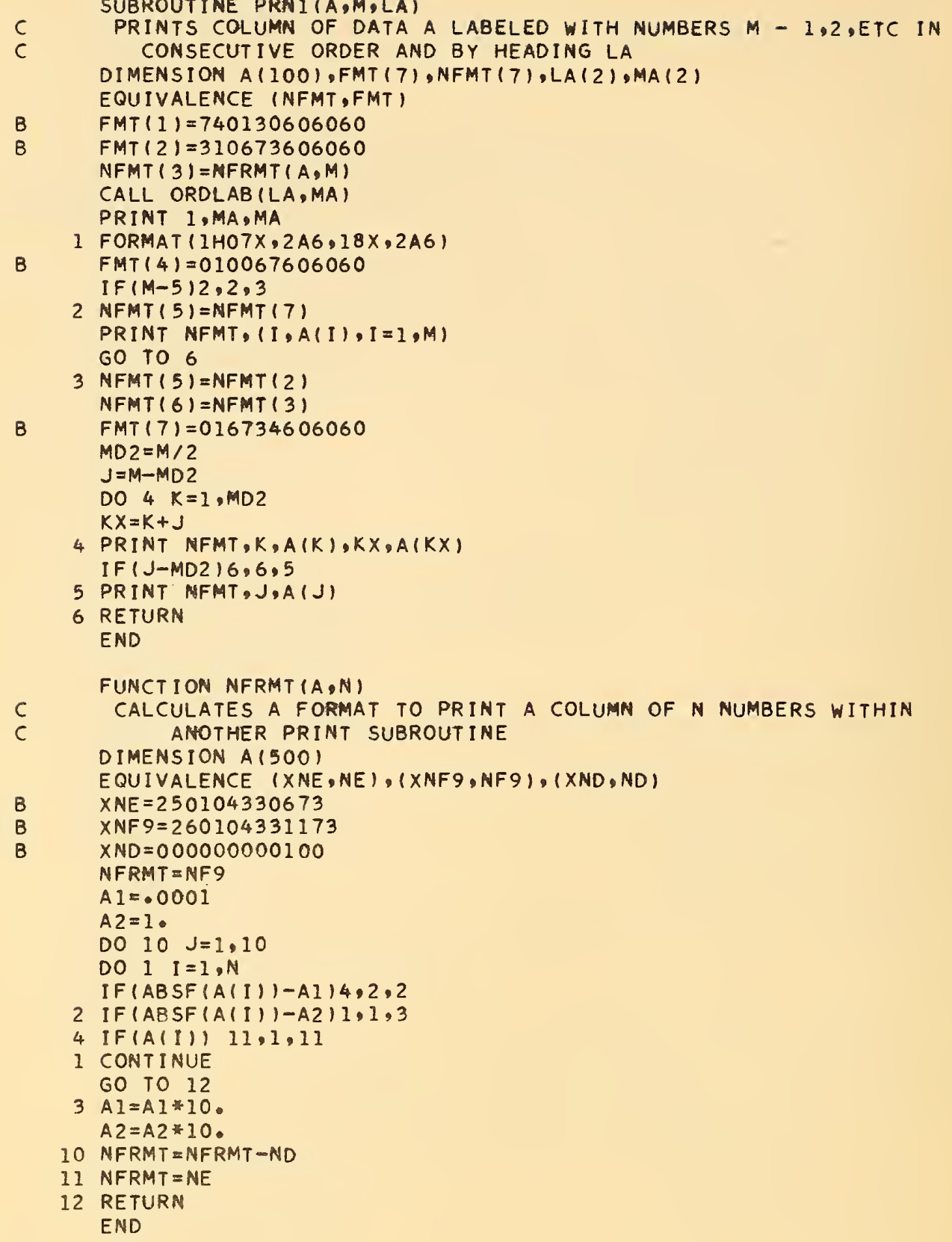

1 FORMAT $(1 \mathrm{HO} 7 \mathrm{X}, 2 \mathrm{A6}, 18 \mathrm{X}, 2 \mathrm{A6})$

B FMT $(4)=010067606060$ 
SUBROUTINE ORDHOL $(G, C, M)$

C ORDERS HOLLERI TH CHARACTERS

C PRINTING,M IS DIMENSION OF

C C IS FILLED WITH BLANKS

$G$ FROM CALL STATEMENT TO C FOR

DIMENSION G(10) $C(10)$
$X M A S K=777777777777$

B

$K=1$

DO $1 \quad I=1, M$

$C(I)=G(K)$

IF (XMASK-G(K)) 1,2,1

C

INCREMENT $K$ BY -1

$1 K=K+32767$

GO TO 4

$2 D O 3 J=I, M$

B $3(J)=606060606060$

4 RETURN

END

SUBROUTINE ORDLAB ( $G, C)$

C CALCULATES A COLUMN HEADING FOR A TABLE FROM HEADING OF 1 TO 12

C CHARACTERS $(I$ OR 2 CELLSI GIVEN IN A CALL STATEMENT DIMENSION $G(2), C(2)$

B IF $(-G(0)) \quad 1,2,1$

$1 \quad C(1)=G(1)$

$C(2)=G(0)$

GO TO 3

B 2 ( $(1)=606060606060$

$C(2)=G(1)$

3 RETURN

END 
Functions and Subroutines Used By Program

ABSF

CALWC

COMBIN

CORECT

ENDJOB

EXXPF

LINM

LMODEL

LMWCL

LMWC OL

LOGF

NFRMT

OMIT

ORDHOL

ORDLAB

PIINEI

PRII

PRI2

PRI3

PRL5

PRIII

PRII2

PRII3

PRMXLT

PRNI

QMODEL

REVERS SQRTF
Absolute Value

Calculates weights by columns for LMWCOL. Uses IMWCL

Combines into one average 2 or more rows or columns Corrects averages in the form $A X+B$ and standard deviations by factor $\mathrm{C}$

End of computation

Exponential

Calculates A, B and C for both LMODEL and QMODEL Fits $\mathrm{y}_{1 \mathrm{j}}=\mathrm{A}+\mathrm{BC}$ to averages

Calculates weighted values for $A, B$ and $C$ and $a$ table of residuals for LMWCOL and CALWC Weights the columns then fits $y_{1 j}=A+B C$ to
averages

Logarithm to base e

Calculates part of a format statement. Used with printing subroutines

Omits rows and/or columns, as designated, from analysis

Orders labels for printing. Used with printing subroutines

Orders column labels for printing. Used with printing subroutines

Prints 1 line 1 to 48 characters ( 1 to 8 cells) and 1 number

Prints 1 column of values with heading and labels

Prints 2 columns of values with their respective headings and labels

Prints 3 columns of values with their respective headings and labels

Prints 5 columns of values with their respective headings and labels

Prints 1 line consisting of label, integer and a floating point value

Prints 1 line consisting of a label, integer and 2 floating point values

Prints 1 line consisting of a label, integer and 3 floating point values

Prints a table of values with row and column headings and a title and subtitle

Prints 1 column of values with heading and labeled by numbers in consecutive order

Fits $y_{i j}=A_{i}+B_{i} C_{j}+D_{i} E_{j}=A_{i}+B_{i} C_{j}+D_{i} C_{j}^{2}$ to averages

Interchanges rows and columns

Square root 
SUM1

Sums over rows ${\stackrel{\sum}{=}{ }_{1}^{M} A_{i}}_{\text {or }} \sum_{i=1}^{M} A_{i j}$

SUM2

Sums over columns $\sum_{j=1}^{N} A_{i j}$

SUM3

Sum over rows $\sum_{i=1}^{M} A_{i} B_{i}$ or $\sum_{i=1}^{M} A_{i j} B_{i}$ or $\sum_{i=1}^{M} A_{i j} B_{i j}$

SUM4

Sum over columns $\sum_{j=1}^{N} A_{i j}{ }^{B} j$

SUM5

Sum of squares over columns $\sum_{j=1}^{N} A_{i j} 2$

TRAFOR

See section 2.42

XMINOF

\section{Chooses the smallest value}

The following subroutines are called in the program to facilitate its use as a research tool. They are not included in this note for they are not necessary to the program's use as outlined in the preceding paragraphs.

CALWR

CMODEL

INCLUD

INTLAB

IMWROW

MMODEL

POWER

SUB1

SUB2
Calculates weights by rows

Research model

To include data previously omitted

A complex subroutine for interlaboratory test analysis. A note will be written explaining this process [Reference 2]

Weights the rows then fits $\mathrm{y}_{i j}=\mathrm{A}+\mathrm{BC}$ to averages

Research model

Research tool

Research tool

Research tool

APPENDIX D

Variables Used in Main Program

a. Dimensional Variables

(AIl are included in COMMON)

A (120) Row averages

AV(120,50) Averages of original data or original single values per cell

$B(120) \quad$ Slopes

C $(50)$

D $(120)$

Column main effect

Variable in calculations

$\mathrm{R}(99)$

Replicates per cell; with TRAFOR, transformation constants

TITLE(12) Title to identify run

WFAC(120) Weighting factor = square of weight

WT (120)

Weight

Column labels 


$$
\begin{aligned}
& \mathrm{XI}(120) \quad \text { Storage variables } \\
& \text { XNS(26) Instructions in Boolean statements } \\
& \mathrm{XR}(120) \text { Row labels } \\
& \mathrm{Z}(120,50) \text { Standard deviations for cells with replicate } \\
& \text { values; residuals from fitting various models } \\
& \text { b. Non-dimensional Variables } \\
& \text { In COMMON }
\end{aligned}
$$

M

MT

$\mathrm{N}$

NT

NR

NREP

NX

$X Y$

AX

BX

CX

FM

FN

FNRX

HOID

I

IS

IX

$\mathrm{J}$

JS

$J X$

JXX

$\mathrm{K}$

MEMORY

MPI

MTI

NPI

NRX

NTI

PTCONC

TRANS

$\mathrm{XCX}$

$\mathrm{XRX}$

XX
Number of rows

Total number of rows

Number of columns

Total number of columns

Original number of replicates per cell Number of replicates

Variable integer

Variable label in card columns 7-12

\section{Other}

For transforming data

For transforming data

For transforming data

Floating point $M$

Floating point $\mathrm{N}$

Floating point NRX

Storage variable for ordering

Index for rows

Index for ordering rows

Index for ordering rows

Index for columns

Index for ordering columns

Index for column count; for ordering

Index for column count

Index for replicates; for computed go to

Check for missing values

$\mathrm{M}+\mathrm{I}$

$\mathrm{MT}+1$

$\mathrm{N}+\mathrm{I}$

Integer in card columns 13-14; number of replicates; number of omissions, etc. $\mathrm{NT}+1$

Point of concurrence

For transformation instruction

Label in card columns 7-12

Label in card columns $1-6$

Label in card columns $1-6$ 
Appendix E. Flow Diagrams of Progen and Suppograms

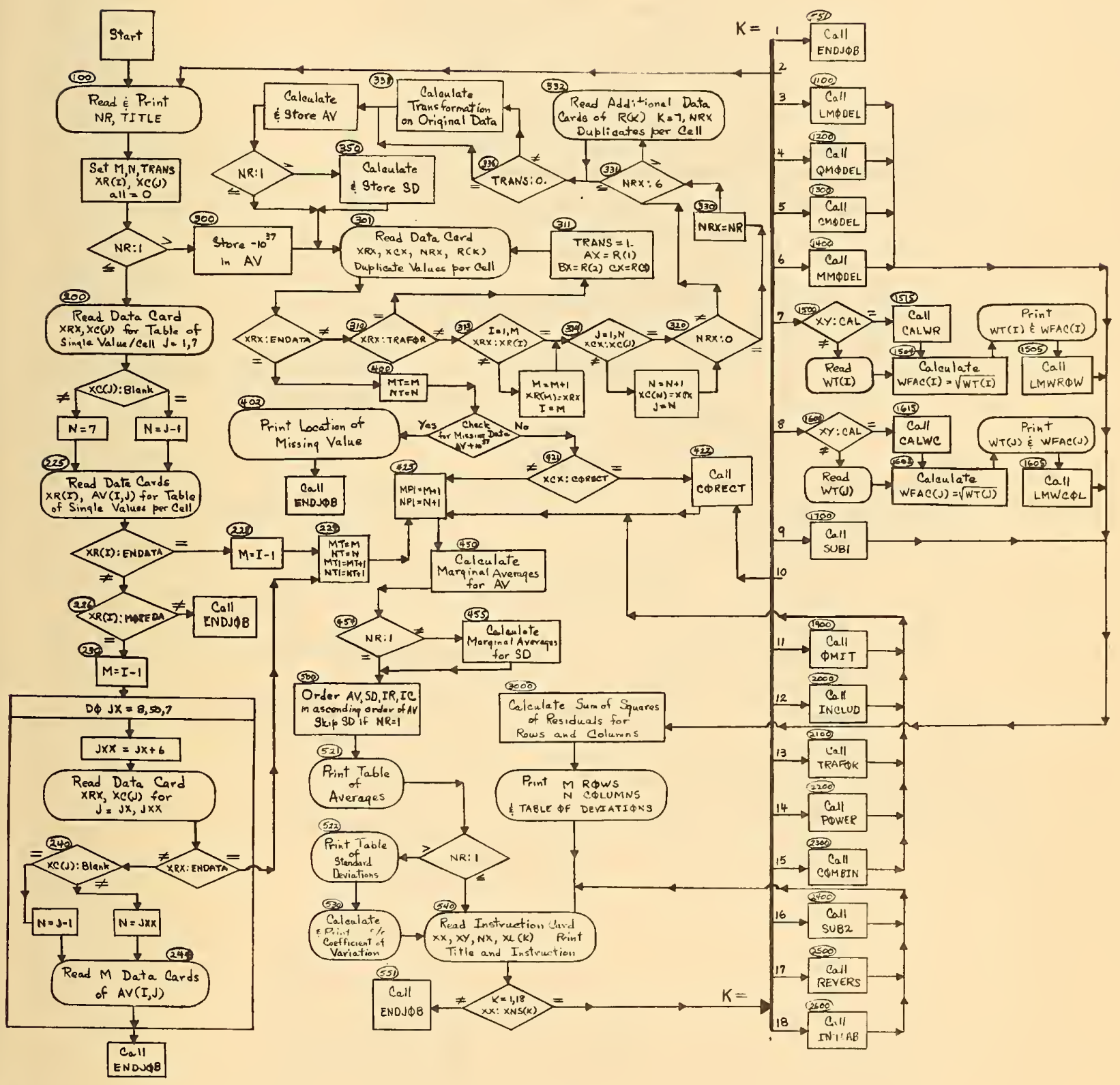

Figure 1. Flow Diagram of Computer Program. Numbers in ovals refer to statement numbers in Fortran program 


\section{SUBRфUTINE LMфDEL}

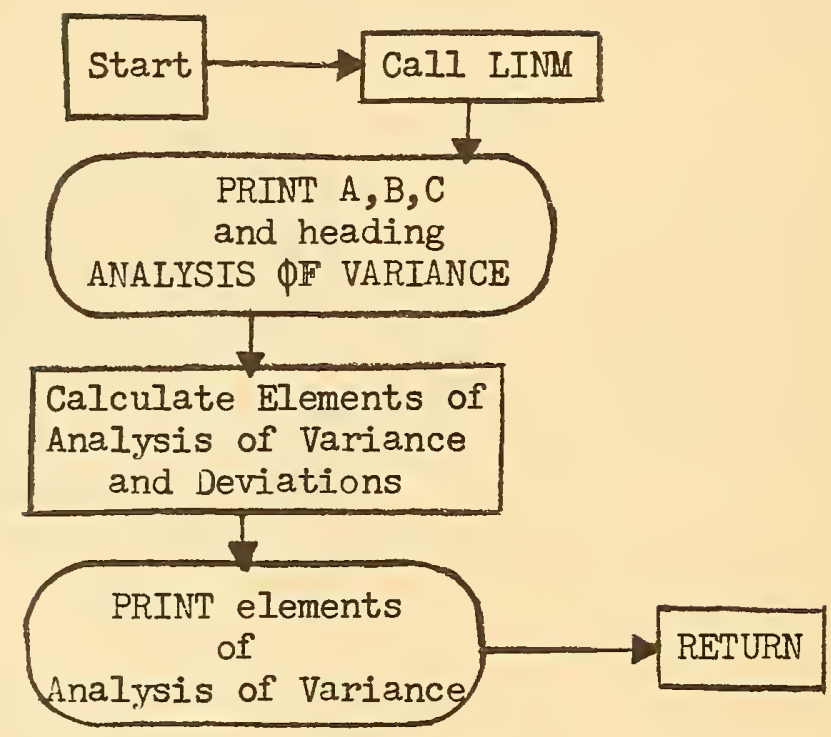

SUBR申UTINE LIMM

(1)

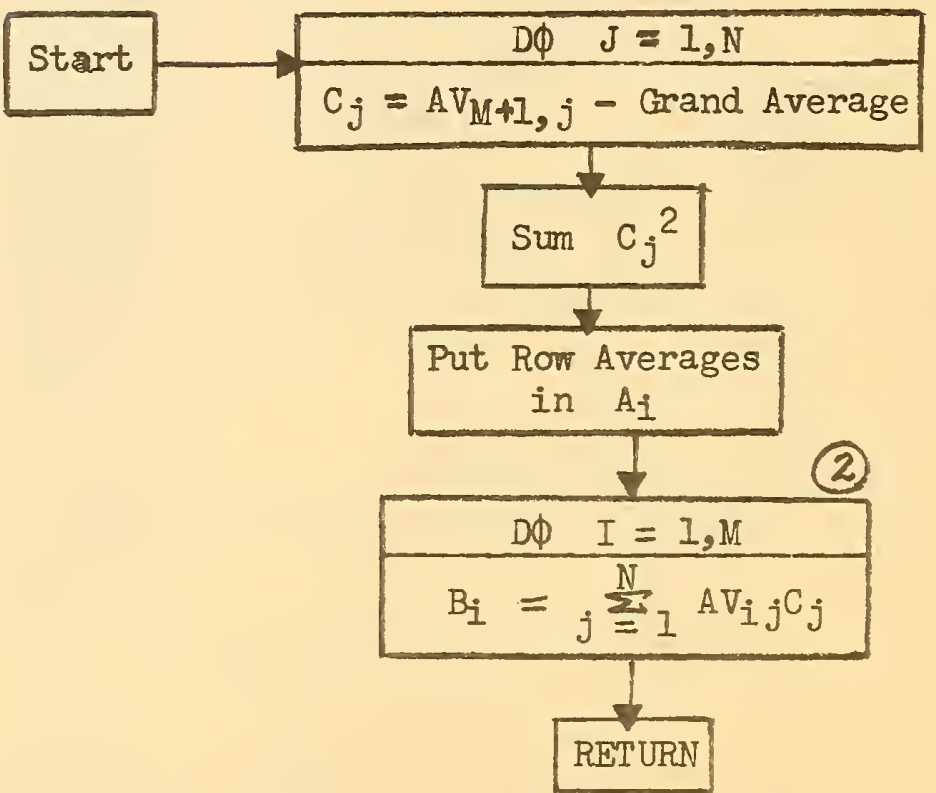

Figure 2. A. Flow Diagram for Subroutine LMODEL B. Flow Diagram for Subroutine LINM 
SUBRAPUTINE LMTCL

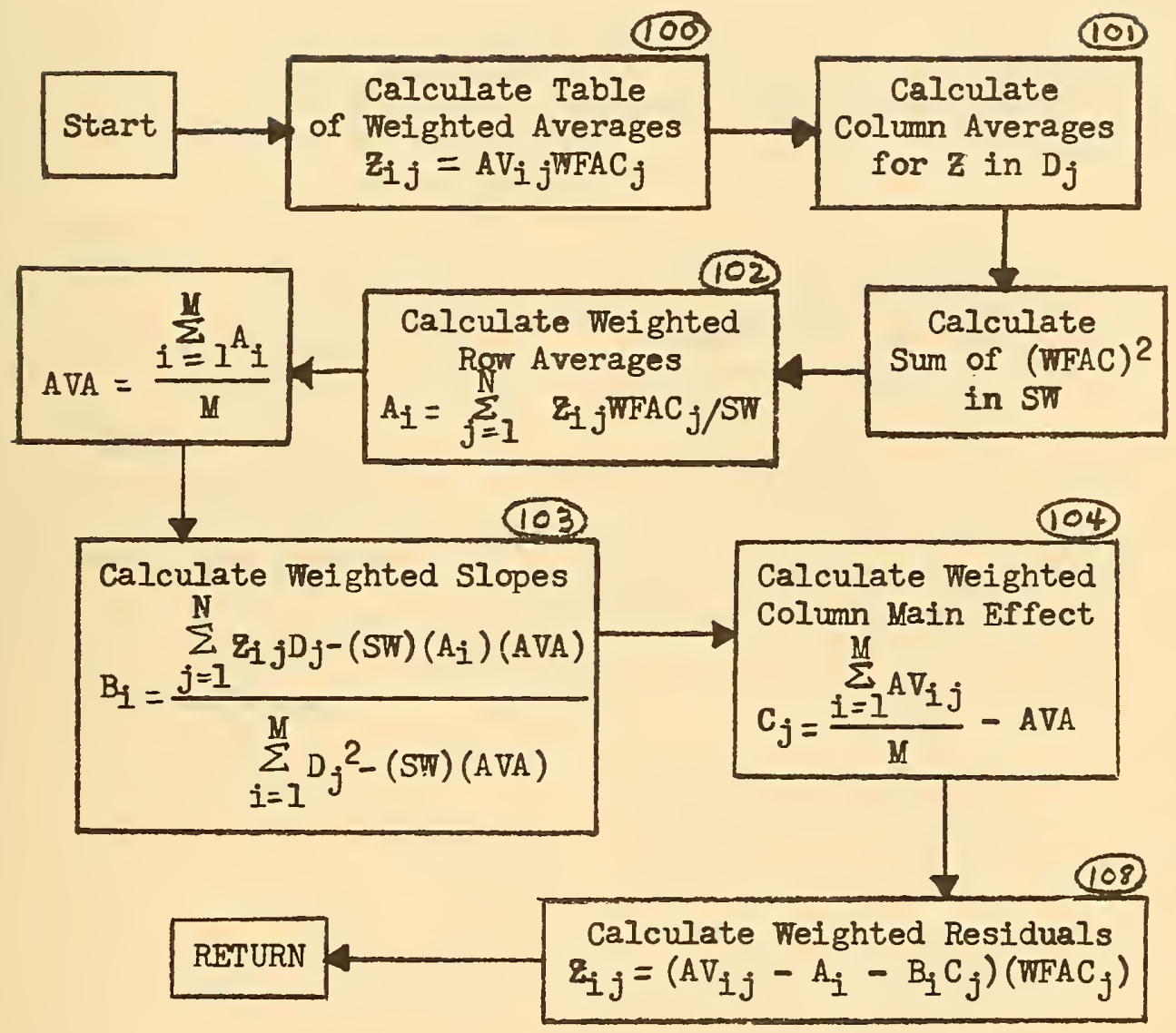

Figure 3. Flow Diagram for Subroutine IMWCL 
SUBR申UTINE LMWC $\phi L$

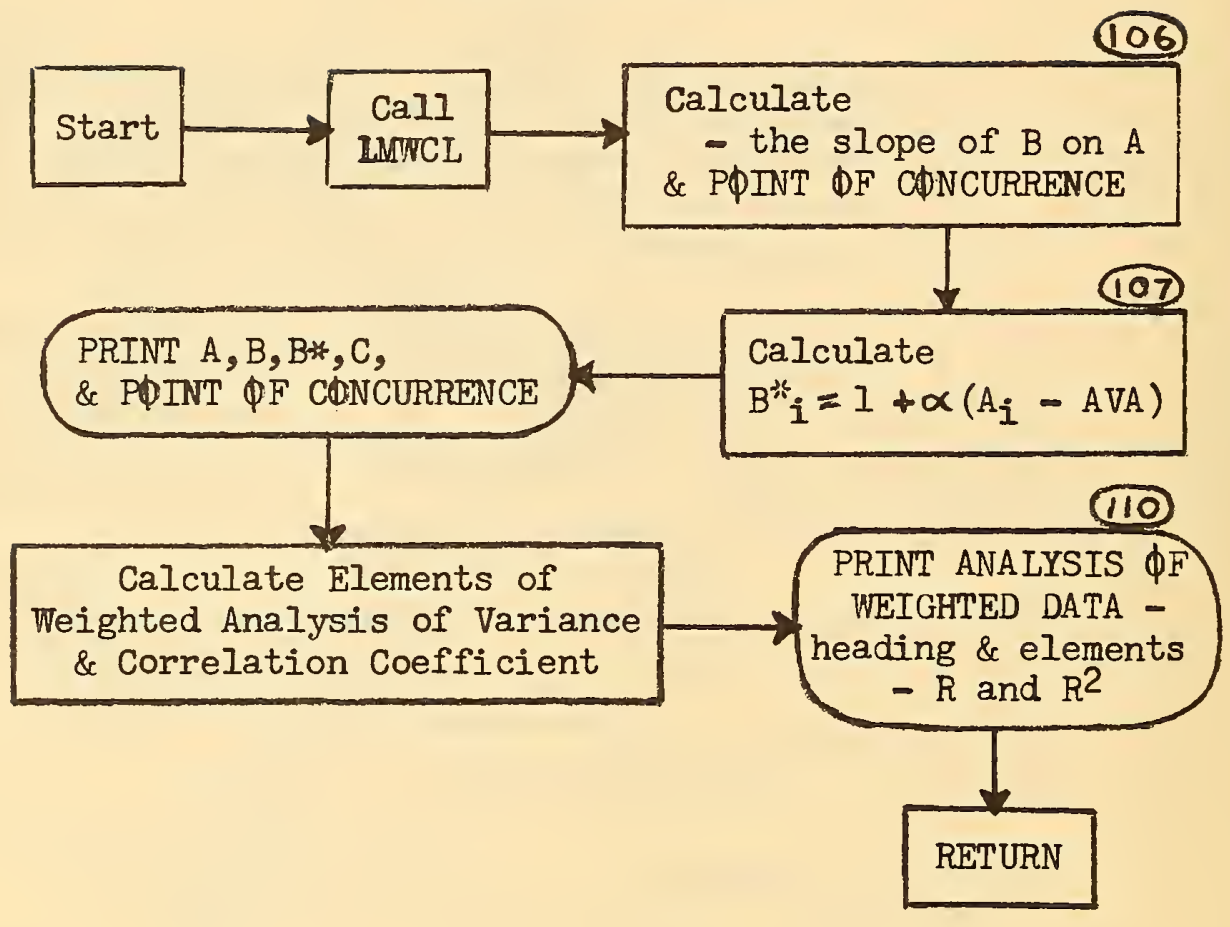

Figure 4. Flow Diagram for Subroutine LMWCOL 


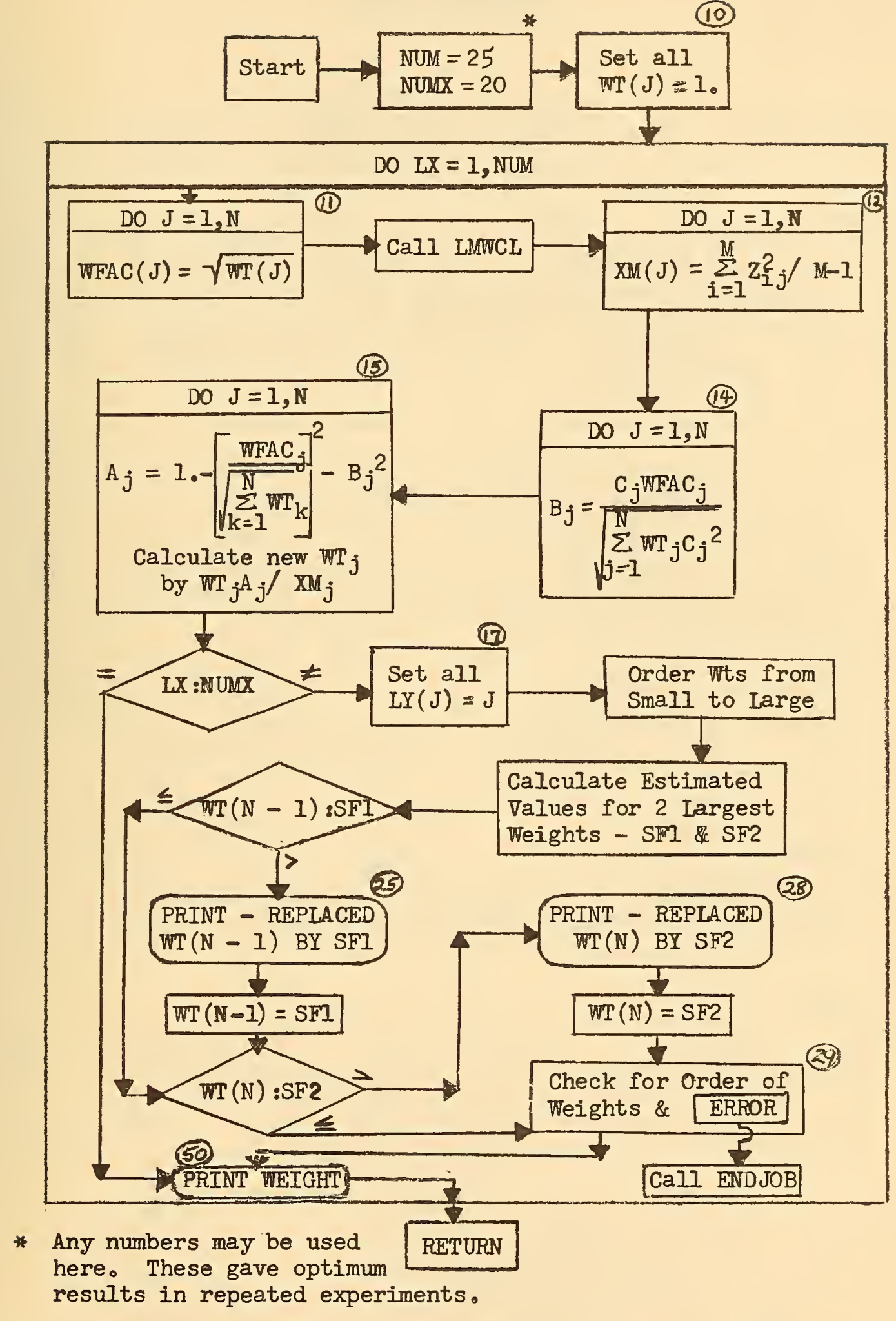

Figure 5. Flow Diagram for Subroutine CALWC 
(4)

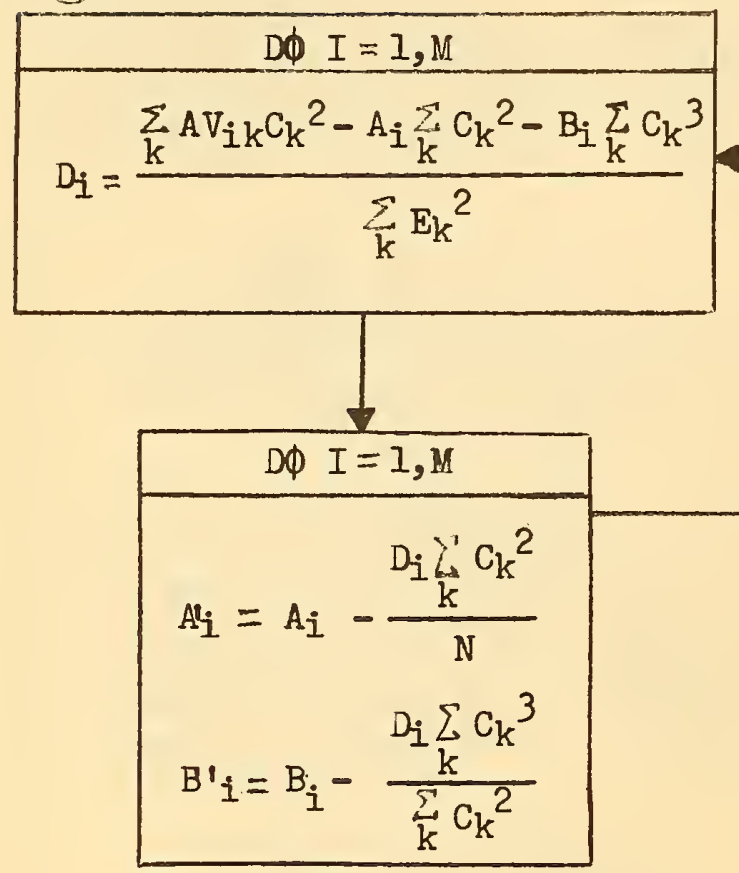

(2)

$$
\frac{D \phi \quad J=I, N}{E_{j}=C_{j}^{2}-\frac{\sum_{k} c_{k}^{3}}{\sum_{k} c_{k}^{2}} c_{j}-\frac{\sum c_{k}^{2}}{N}}
$$

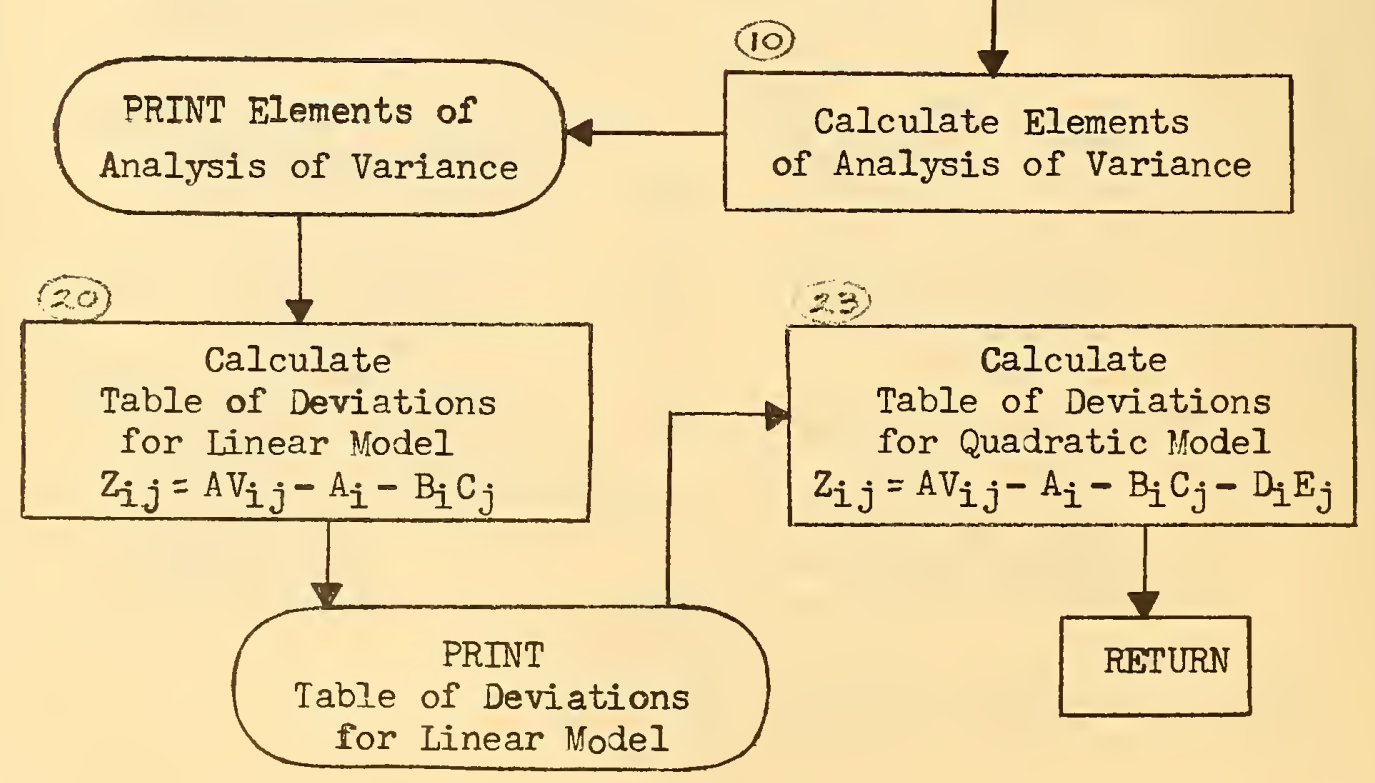

Figure 6. Flow Diagram for Subroutine QMODEL 


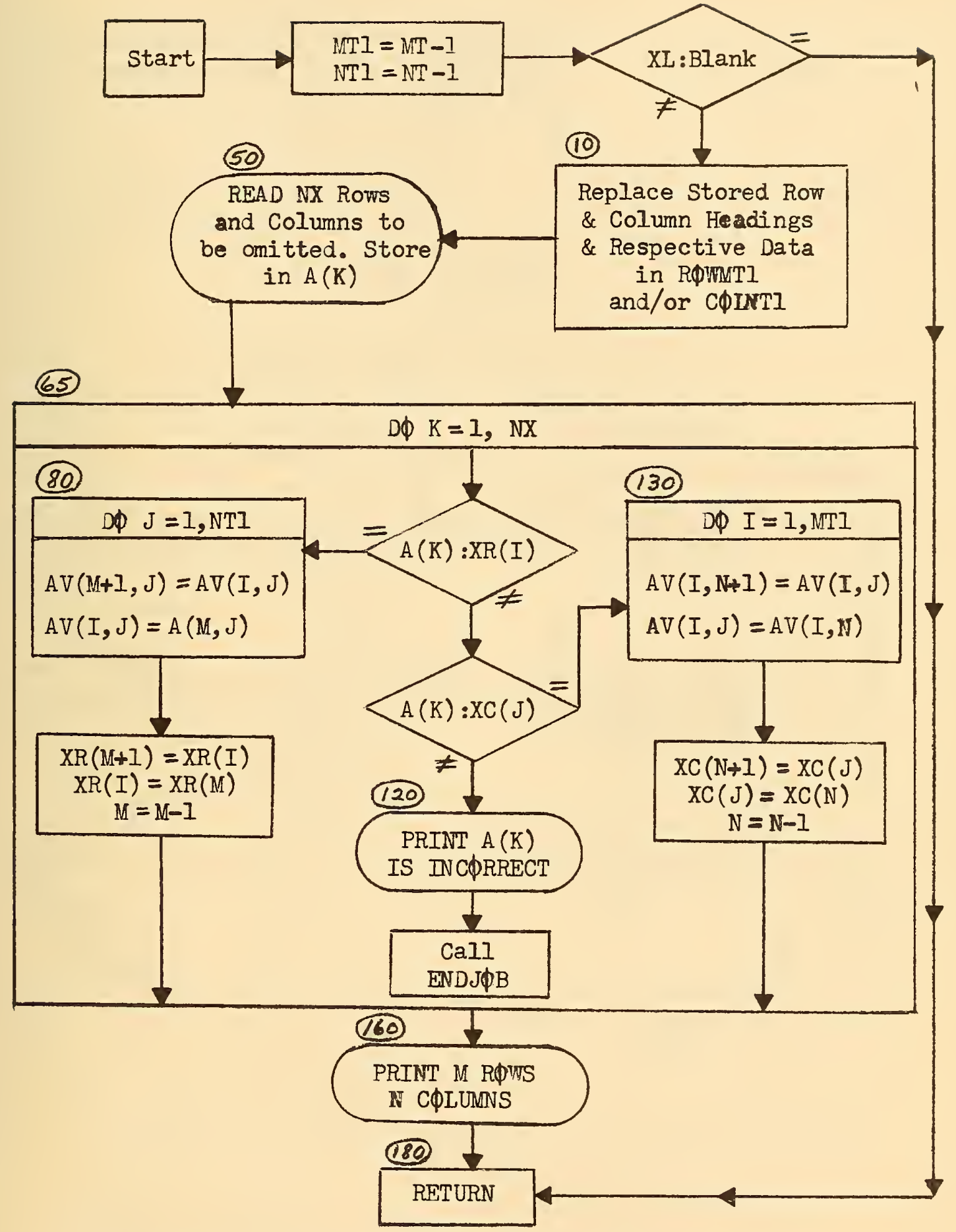

Figure 7. Flow Diagram for Subroucine ONIT 


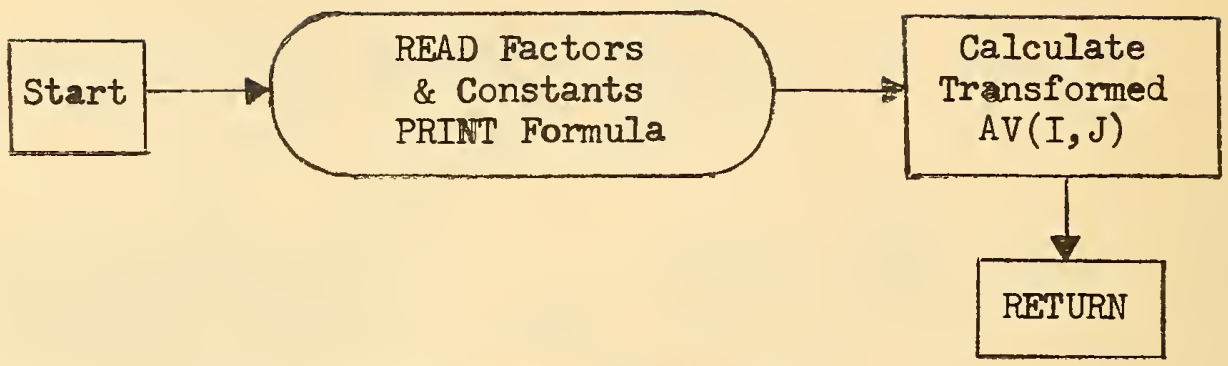

SUBRфUTINE C\&RECT

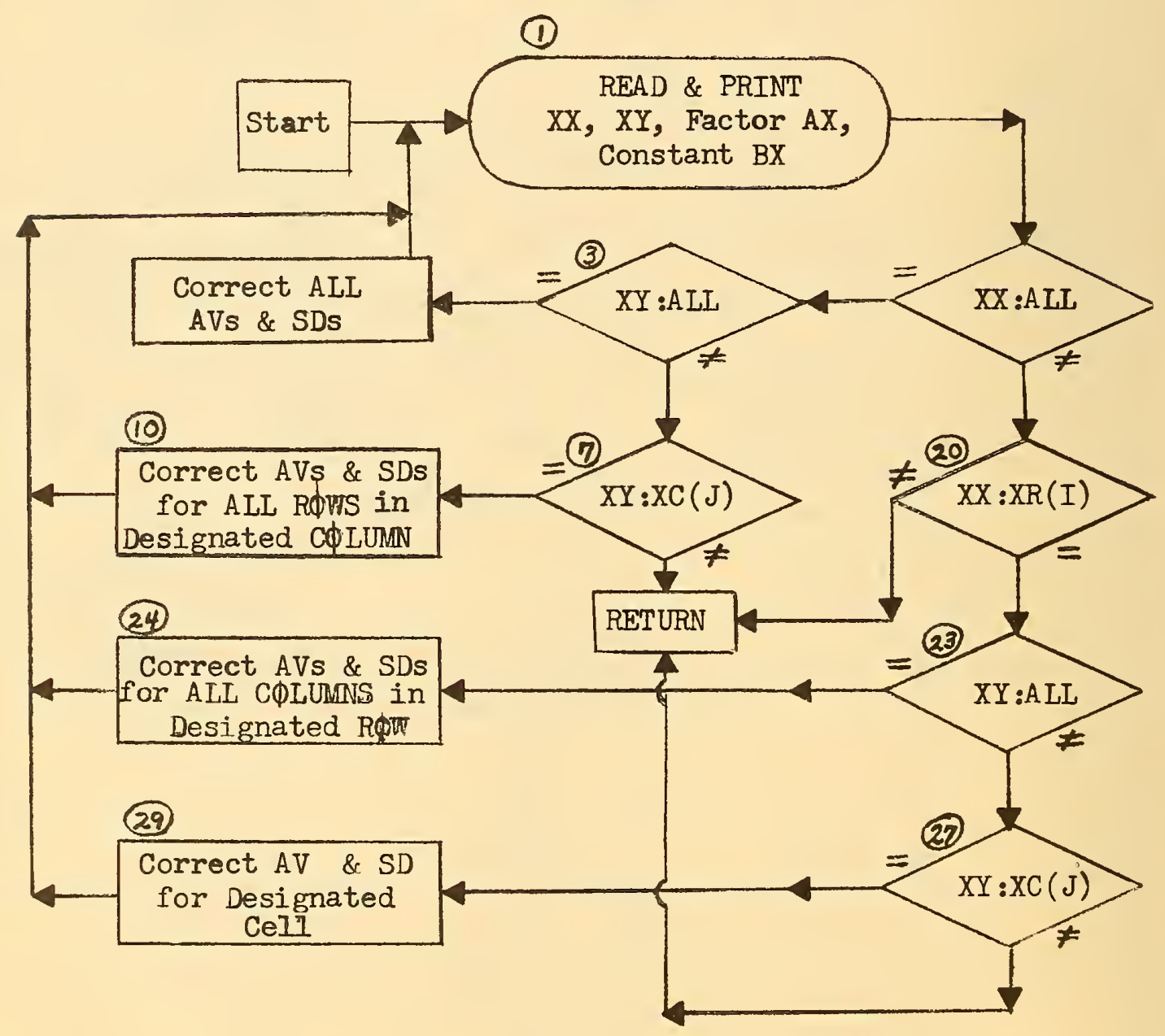

Figure 3. A. Flow Diagram for Subroutine TRAFOR B. Flow Diagram for Subroutine CORECT 


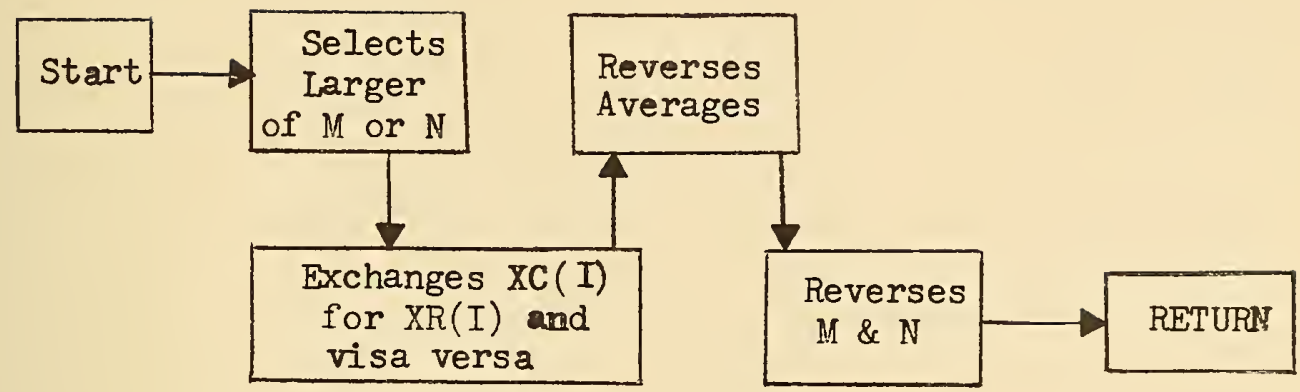

SUBR申申UTINE CQMBIN

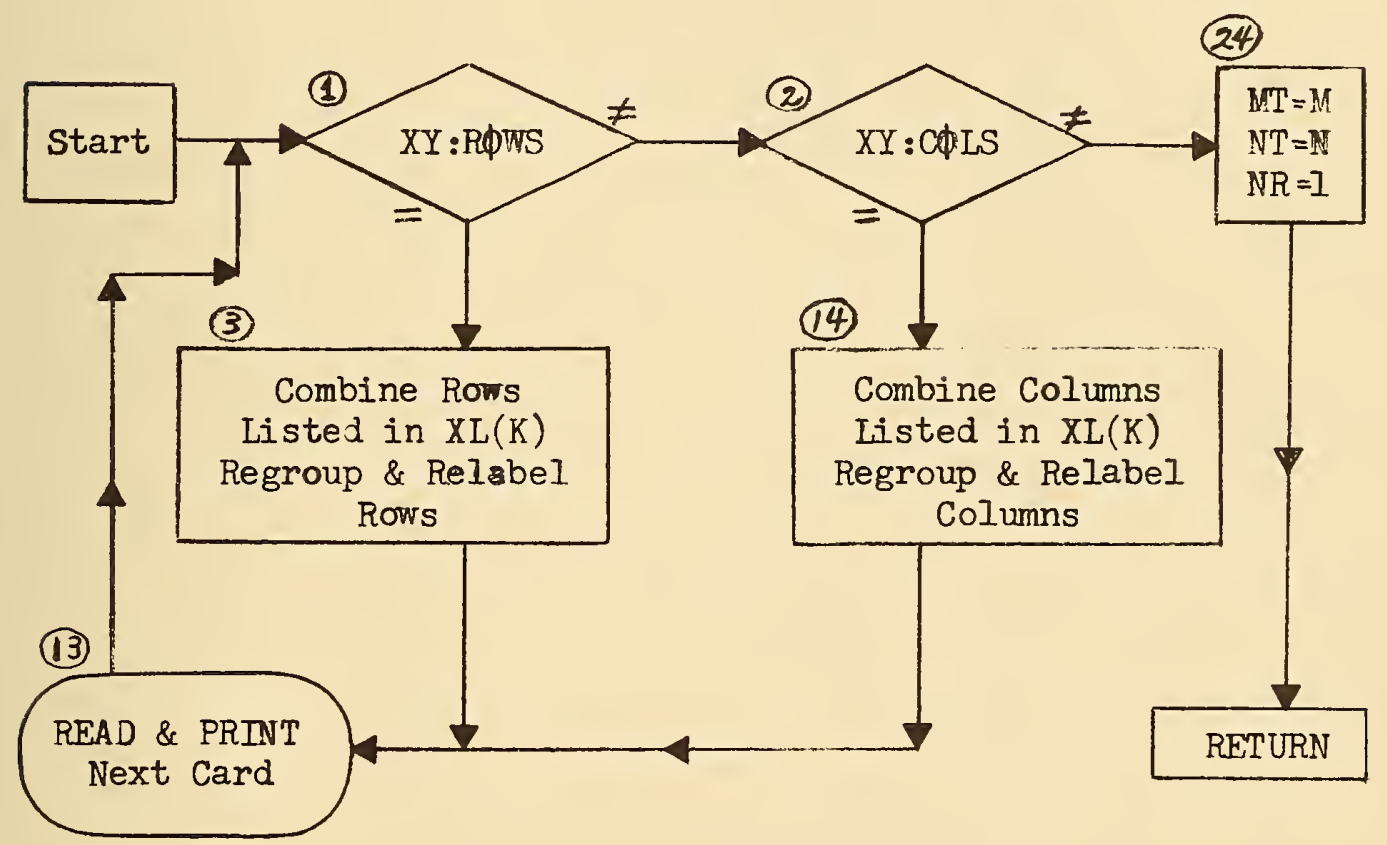

Figure 9. A. Flow Diagram for Subroutine REVERS B. Flow Diagram for Subroutine COMBIN 


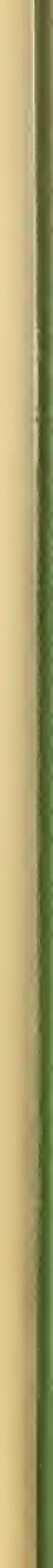





\section{U.S. DEPARTMENT OF COMMERCE}

WASHINGTON. D.C. 20230

OFFICIAL BUSINESS
POSTAGE AND FEES PAID

U.S. DEPARTMENT OF COMMERCE

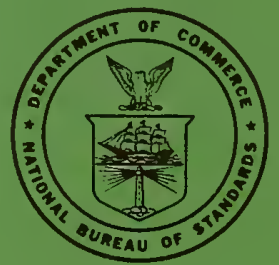






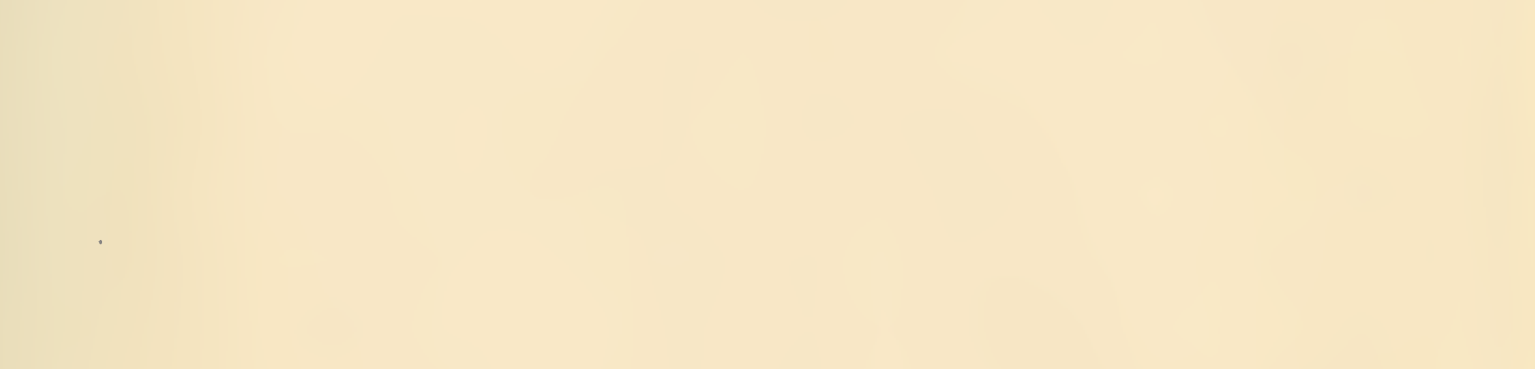




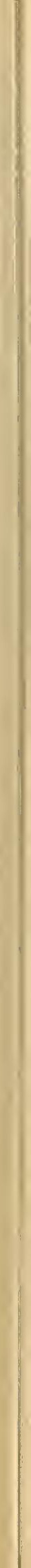





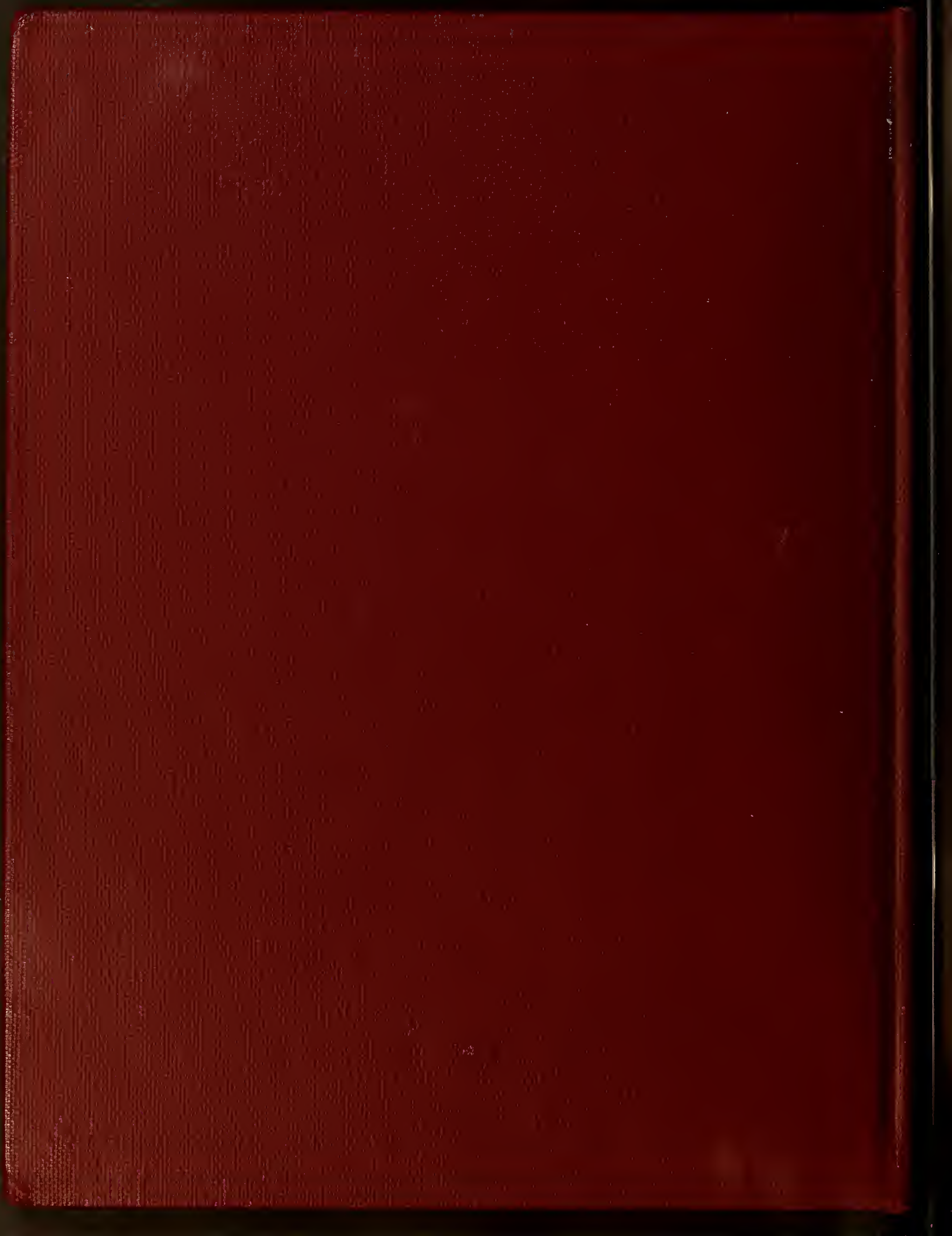

